\title{
Project Title: SMART FUEL CELL OPERATED RESIDENTIAL MICRO-GRID COMMUNITY
}

Project Period: September 20, 2003 to April 20, 2005

Date of Report: April 6, 2005

Recipient: University of South Alabama

Award Number: DE-FG36-03GO13060

Working Partner: Radiance Technologies

Cost-Sharing Partners: Radiance Technologies

Contact: Dr. Mohammad S. Alam (PI/PD)

University of South Alabama

College of Engineering

ECE Department, EEB 75

Mobile, AL 36688-0002

Phone: 251-460-6117

Fax: 251-460-6028

Email:malam@usouthal.edu

DoE Program Manager: Dr. Sigmund Gronich

Project Objectives: To build on the work of year one by expanding the smart control algorithm developed to a micro-grid of ten houses; to perform a cost analysis; to evaluate alternate energy sources; to study system reliability; to develop the energy management algorithm, and to perform micro-grid software and hardware simulations.

Background: Fuel cells for residential use have a specified power output, normally $5 \mathrm{~kW}$ that can only be exceeded for short periods of time. However, domestic loads in excess of $5 \mathrm{~kW}$ are not unusual and the purpose of the smart energy management and control system (SEMaC) is to regulate the demand to the specified output while minimizing occupants' discomfort.

DE-FG36-03GO13060 


\section{Task Schedule}

\begin{tabular}{|l|l|l|l|}
\hline $\begin{array}{l}\text { Task } \\
\text { Number }\end{array}$ & Project Milestones & $\begin{array}{l}\text { Percent } \\
\text { Complete }\end{array}$ & Progress Notes \\
\hline $\mathbf{1}$ & System Cost Analysis & $\mathbf{1 0 0 \%}$ & Complete \\
\hline $\mathbf{2}$ & Alternate Energy Evaluation & $\mathbf{1 0 0 \%}$ & Complete \\
\hline $\mathbf{3}$ & System Reliability Report & $\mathbf{1 0 0 \%}$ & Complete \\
\hline $\mathbf{4}$ & Energy Management Algorithm & $\mathbf{1 0 0 \%}$ & Complete \\
\hline $\mathbf{5}$ & Micro-grid Simulation & $\mathbf{1 0 0 \%}$ & Complete \\
\hline $\mathbf{6}$ & Final Technical Report & $\mathbf{1 0 0 \%}$ & Complete \\
\hline
\end{tabular}




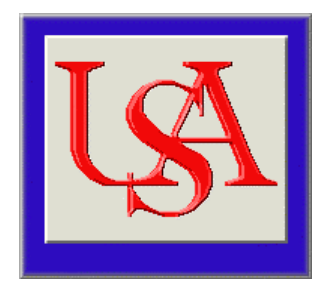

Final Report

\title{
SMART FUEL CELL OPERATED RESIDENTIAL MICRO-GRID COMMUNITY
}

\author{
Submitted by: \\ Dr. Mohammad S. Alam (PI/PD) \\ University of South Alabama \\ Department of Electrical and Computer Engineering, EEB 75 \\ Mobile, AL 36688-0002 \\ Phone: 251-460-6117 \\ Fax: 251-460-6028 \\ Email:malam@usouthal.edu
}

April 6, 2005 


\section{CONTENTS}

1. System Cost Analysis

1.1 Micro-Grid Configuration

1.2 Thermal Recovery Strategy

1.3 Excess Energy Strategy

1.4 Operational Strategy

2. Energy Management Algorithm

2.1 Load Smoothing

2.2 Micro-grid Migration

2.3 Data Collection

3. Alternative Energy Evaluation

3.1 Hydrogen Generation

3.2 Co-generation Sources

3.3 Supercapacitors

4. System Reliability

4.1 Reliability Modeling of Grid-connected PEM fuel cell Power Plants (FCPPs)

4.2 Reliability Modeling of PEM FCPPs

4.3 Development of Reliability Model for the PEM FC

4.4 Cooling System

4.5 Humidification System

4.6 Fueling System

4.7 Air Circulating System

4.8 Energy Storage System

4.9 Other Components

4.10 Estimation of Transition Probabilities and Aging Effects

4.11 Grid Reliability

4.12 Reliability Calculation

4.13 Considered Micro-grid System

4.14 Simulation Results

4.15 Conclusion

5. Micro-grid Simulation

5.1 Local and Micro-grid Energy Management Systems (LEMSYS and MEMSYS)

5.2 DAQ Simulation

5.3 Hardware Simulation: Steady-State and Transient

Publications

References

Appendices

Appendix A

Appendix B 


\section{System Cost Analysis}

\subsection{Micro-Grid Configuration}

The micro-grid comprises a cluster of 10 identical single storied homes fed from a single $50 \mathrm{KW}$ fuel cell power plant (FCPP). The exact layout of the homes around the FCPP is the challenge of the design. Since this is a micro-grid design, the factors that bear on the design are all electrical. These factors are:

1. The length of feeders from the FCPP to the homes.

2. Feeder ampacities.

3. Voltage drops in the feeders.

4. Power loss in the feeder system.

Further assumptions are enumerated below:

1) The designer has complete freedom with regard to the placement of the homes around the FCPP.

2) All ten homes are identical and have heated and cooled area of $1700 \mathrm{sft}$. Each home has 3 bedrooms, 2 bathrooms, a living room, a kitchen cum dining area and a laundry room.

3) The homes are all electric, and the power to each home is regulated and controlled electronically through the 'Local Energy Management System' (LEMSYS) and the 'Micro-grid Energy Management System' (MEMSYS). These controls will, in most instances, maintain a $5 \mathrm{~kW}$ power ceiling for each home. LEMSYS and MEMSYS are not part of the micro-grid design.

4) The design will adhere strictly to the National Electric Code (2002) [1], and reference will be made to the Articles and Sections of the code throughout the design. Other texts and publications are referenced in the design as well.

5) The heating and air-conditioning requirements of the home will be met by a $2 \frac{1}{2}$ ton heat pump (24A, 240V) as shown in Example D2(c) of [1]. Other appliances will be, a $12 \mathrm{~kW}$ range, a $4.5 \mathrm{~kW}$ water heater, a $1.2 \mathrm{~kW}$ dishwasher and a $5 \mathrm{~kW}$ clothes dryer.

\section{Layout of the micro-grid}

The layout design is based primarily on locating the FCPP in a centralized manner with respect to the homes. The centralized placement of the FCPP is critical because it determines the length of the feeder from the FCPP to the farthest home. The feeder length and the power carried by it determine the voltage drop in the feeder and the feeder loss. The sizing or ampacity of the feeder however, is determined in accordance with the NEC code. Fig. 1.1.1 shows the layout of the micro-grid. It is located on an 'island' surrounded by roads on all four sides. Roads 1, 2 and 3 provide access to nine homes while the tenth home can be accessed directly from the main road. The 'island' is divided into six $60 \mathrm{ft}$. wide home site strips, with the FCPP located on a $60 \mathrm{ft}$. strip of its own. Each home is located on a lot measuring $60 \mathrm{ft}$. x $110 \mathrm{ft}$. The FCPP is a $50 \mathrm{~kW}$ unit which is located at the center of the island. The nominal 240/120 V output of the FCPP transformer feeds power into two identical feeders. Each feeder, under ideal conditions, carries a maximum of $25 \mathrm{~kW}$ and feeds power to five homes $(5 \mathrm{~kW}$ each). The laterals that emerge from the feeders originate at isolator switches and terminate at the service entrance panels of the homes. The 
object of using the isolator switches is to ensure safety, and increase system reliability under fault conditions.

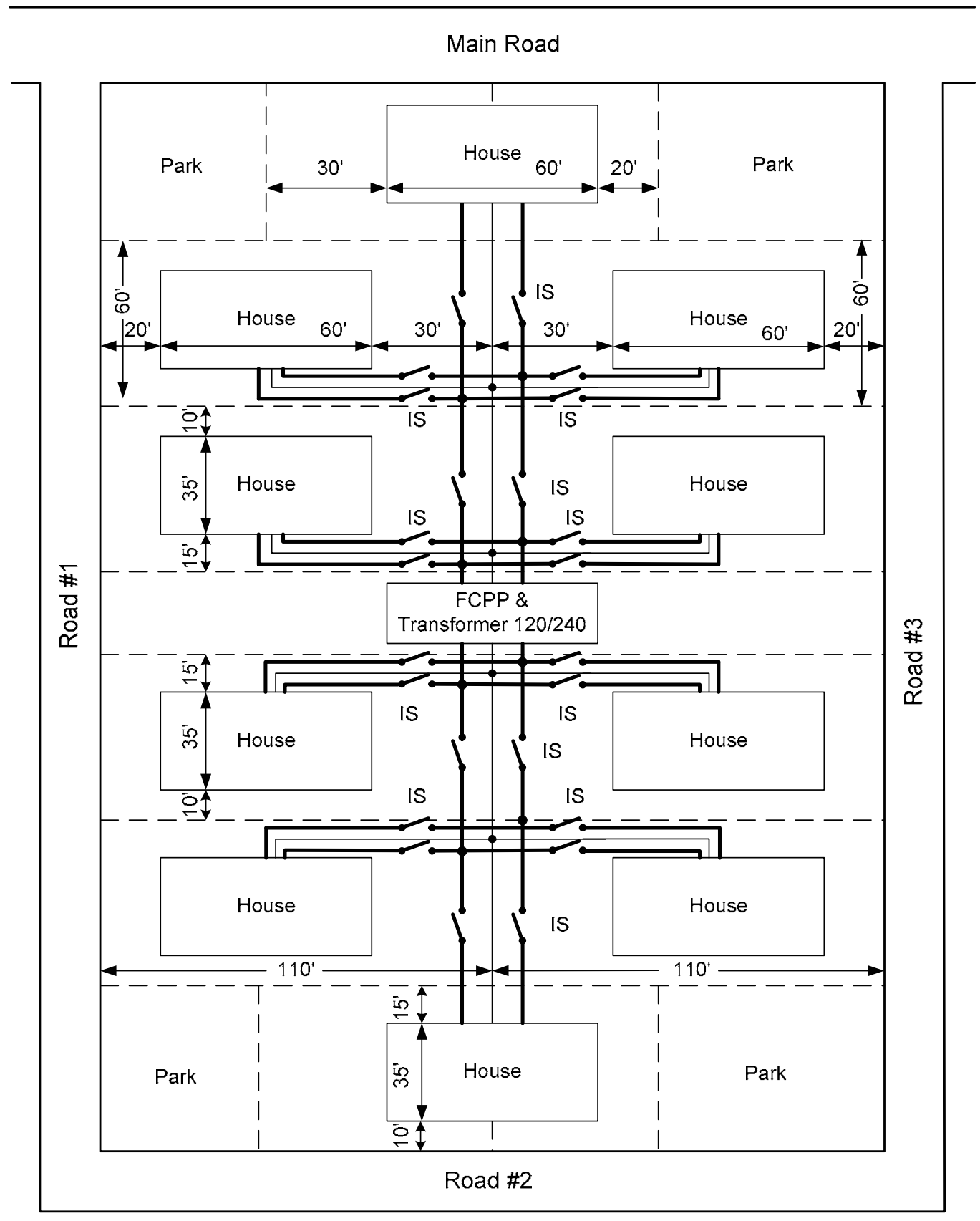

IS: Isolator Switch

Fig.1.1.1 Micro-grid community layout. 


\section{Feeder design}

The design of the feeder is

unconventional because the exact $\mathrm{kW}$

loading of the individual homes does

not come into the design process. A

review of Examples D1(a), D2(a),

D2(b) and D2(c) in Annex D of [1]

indicates that the design load of single

family homes ranging in floor area

from $1500 \mathrm{sft}$. to $2000 \mathrm{sft}$., varies from

about $15 \mathrm{~kW}$ to $40 \mathrm{~kW}$. This may

appear very high in view of the $50 \mathrm{~kW}$

rating of the FCPP. Load management

of individual homes is the function and

responsibility of LEMSYS and

MEMSYS. The management schemes

will individually maintain a ceiling of 5

$\mathrm{kW}$ for each home using algorithms

developed in Phase I of the project. On

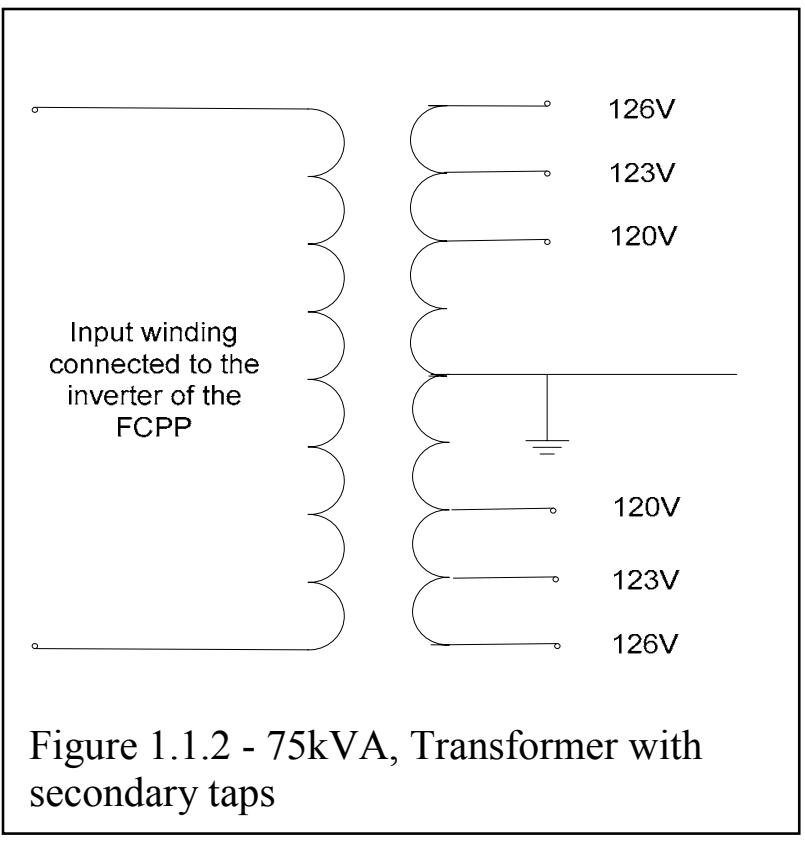

the other hand, the management scheme will raise the $\mathrm{kW}$ ceiling of individual homes if some homes reduce their demand below $5 \mathrm{~kW}$. Considering the micro-grid to be divided into two identical sectors, each of five homes, one might consider the extreme case of four out of the five homes shutting down completely, leaving the farthest home in the sector the freedom of drawing the allowable $25 \mathrm{~kW}$ of power. In such an event the feeder supplying the farthest home in each sector should be able to carry $25 \mathrm{~kW}$ and have a voltage drop within the limits specified by ANSI, and a loss that is acceptable from the FCPP operational strategy point of view. ANSI Standard C84 specifies that for low voltage systems $(<1000 \mathrm{~V})$, the actual service voltage must lie within $\pm 5 \%$ of nominal voltage for continuous operation. To minimize cost, no distribution transformers are specified for the homes in the micro-grid. This implies that power will be supplied to the homes from the FCPP at nominal 240/120V. The FCPP inverter will be connected to a $75 \mathrm{kVA}$ transformer with a $240 \mathrm{~V}$ (nominal) secondary winding having a center tap to allow for the grounded neutral and the two 'outer' lines for the $120 \mathrm{~V}$ (nominal) supplies. Taps will be provided on the secondary side as shown in Fig. 1.1.2, to allow for the adjustment of the supply voltage to the homes. Two identical feeders for the two sectors Fig.1.1.1, will be connected to the transformer. These feeders will be protected by breakers at the transformer end. The feeders will be carried by PVC Schedule 40 electrical conduits buried 18 inches below ground. The conduits will be placed along the 'right-of-way' area of the lots which is allocated for laying utility cables. Lateral cables, of the same size and type as the feeder cable, will originate at isolator switches located between the laterals and the feeder. The laterals will terminate at the service entrance panel of the homes. The purpose of using isolator switches is to ensure safety and reliability. 


\section{1) Feeder Length}

The longest length of the feeder plus lateral is taken conservatively as $200 \mathrm{ft}$. This includes $2 \times 60 \mathrm{ft}$ plus the length allowed for bends, risers and service entrance.

\section{2) Sizing of Feeders and Laterals}

Feeders and laterals will be buried 18 " below ground. The feeders will be laid along the right of way and extend from the FCPP to the remotest home in each sector. The laterals will extend from the feeder to the service entrance panel of each home. The layout is shown in Fig. 1.1.1 Since the power control strategy of LEMSYS and MEMSYS allows any one home in each sector to draw $25 \mathrm{~kW}$, the feeders and laterals must be sized alike. The next issue to be addressed is the type of cable appropriate for this application. Article 338 of [1] suggests that Type USE cables will meet the requirements of both feeder and service entrance (lateral) applications. This type of cable is identified for underground use and having a moisture-resistant covering.

To determine the size of the cables the current loading must be known. As indicated earlier, the worst case would be when a home will be allowed to draw the full $25 \mathrm{~kW}$ (balanced load) at $240 \mathrm{~V}$. Assuming a power factor of 0.95 lagging, the current is, $25000 / 240 \times 0.95=110 \mathrm{~A}$. This current will be considered continuous. Hence according to Article 215.2 of [1], the design load current will be 1.25 x $110=137.5 \mathrm{~A}$. The minimum overcurrent device (service entrance breaker) rating must be 150A. This is in accordance with Article 240.6 of [1]. Article $110.14(\mathrm{C})(1)(\mathrm{b})$ of [1] indicates that since the design load current is greater than $100 \mathrm{~A}$, the minimum cable size of Type USE cable must be taken from Table 310.16 of [1] from the column marked $75^{\circ} \mathrm{C}$. The size ascertained from the table is $\# 1 / 0$ AWG having a maximum allowable current rating of $150 \mathrm{~A}$. Now, the $N E C$ indicates that derating of cable ampacity must be allowed for conduit overfilling beyond $40 \%$ of the conduit cross-sectional area and an ambient temperature higher than $20^{\circ} \mathrm{C}$. Table $310.15(\mathrm{~B})(2)(\mathrm{a})$ of [1] indicates that the conduit fill derating factor is 1 provided the conduit is sized with the fill limited to $40 \%$ of its area. Since the southern United States is known for hot summers, an ambient temperature of $110^{\circ} \mathrm{F}\left(43.3^{\circ} \mathrm{C}\right)$ is assumed. Going back to Table 310.16 of [1] the derating factor is noted to be 0.82 . Using the two derating factors, the minimum table listed ampacity is $110 / 0.82 \times 1=134 \mathrm{~A}$. The $75^{\circ} \mathrm{C}$ column of Table 310.16 gives cable size \#1/0 AWG again. So the outcome of the design so far gives us the type and size of the feeder and laterals to be a 3conductor (2-ungrounded and 1-grounded), Type USE , \#1/0 AWG copper cable.

\section{3) Voltage drop in the feeders}

When calculating the voltage drop, the impedance of the $75 \mathrm{kVA}$ transformer as well as the feeder must be taken into account. Reference [2] indicates that a 75 $\mathrm{kVA}$ distribution transformer with a nominal $240 / 120 \mathrm{~V}$ secondary has a percent 
voltage drop in its resistance of about $1.3 \%$ and in its reactance of about $1.7 \%$. With a $\mathrm{kVA}$ base of $75 \mathrm{kVA}$ and voltage base of $240 \mathrm{~V}$ the actual resistance and reactance values can be determined as follows,

$$
\begin{aligned}
& \mathrm{R}_{\text {Trans }}=\frac{1}{100}\left[\frac{1.3 \% \times 240^{2}}{75000}\right]=0.01 \mathrm{ohm} \\
& \mathrm{X}_{\text {Trans }}=\frac{1}{100}\left[\frac{1.7 \% \times 240^{2}}{75000}\right]=0.01306 \mathrm{ohm}
\end{aligned}
$$

The cable resistance and reactance per $1000 \mathrm{ft}$. is obtained from Table 9, Chapter 9 of [1]. The resistance is obtained from the column entitled 'Alternating-Current Resistance for Uncoated Copper Wires' with the subheading 'PVC Conduit', and the reactance is obtained from the column entitled ' $\mathrm{X}_{\mathrm{L}}$ (Reactance) for All Wires.' The values for $\# 1 / 0$ AWG are, Resistance $=0.12 \mathrm{ohm} / 1000 \mathrm{ft}$. and Reactance $=$ $0.044 \mathrm{ohm} / 1000 \mathrm{ft}$. So, for a total length of $200 \mathrm{ft}$. we have,

$\mathrm{R}_{\text {Feeder }}=2 \times 0.12 \times \frac{200}{1000}=0.048 \mathrm{ohm}$ and $\mathrm{X}_{\text {Feeder }}=2 \times 0.044 \times \frac{200}{1000}=0.0176 \mathrm{ohm}$ Now the load current of the transformer when the FCPP is delivering its rated power at a power factor of 0.95 lagging is $50000 / 240 \times 0.95=219 \mathrm{~A}$. The phasor representation of the current is $219 /-18.2^{\circ} \mathrm{A}$. The drop in the transformer in phasor form is calculated as, $\mathbf{V}_{\text {Trans }}=\left(219 /-18.2^{\circ}\right)(0.01+j 0.01306)=3.6 / 34.4^{\circ} \mathrm{V}$. So the magnitude of the voltage drop in the transformer is $3.6 \mathrm{~V}$. To determine the drop in the feeder we first consider the feeder current on the basis of $25 \mathrm{~kW}$ of feeder loading. This current, in phasor form is $(219 / 2) /-18.2^{\circ} \mathrm{A}=109.5 /-18.2^{\circ} \mathrm{A}$. The feeder drop is therefore, $\mathbf{V}_{\text {Feeder }}=\left(109.5 /-18.2^{\circ}\right)(0.048+\mathrm{j} 0.0176)=5.6 / 2^{\circ} \mathrm{V}$. The total drop is therefore, $\mathbf{V}_{\text {Drop }}=3.6 / 34.36^{\circ} \mathrm{V}+5.6 / 2^{\circ} \mathrm{V}=8.85 / 14.53^{\circ} \mathrm{V}$. The magnitude of the drop is $8.85 \mathrm{~V}$ in a $240 \mathrm{~V}$ system. This drop is well within the allowable $\pm 5 \%$ drop as specified by ANSI Standard C 84 .

\section{4) Power loss in the feeder system and transformer}

The total power loss in the feeder system supplying all ten houses is, $P_{\text {Feeder }}=2 \mathrm{x}$ $0.048 \times 109.5^{2}$ watts $=1151$ watts. Assuming a transformer efficiency of $95 \%$ for a loading of $50 \mathrm{~kW}$, the loss in the transformer is determined as,

$50000 \cdot\left[\frac{1-0.95}{0.95}\right]=2632$ watts

\section{5) Conduit size}

To determine the trade-size PVC Schedule 40 conduit to accommodate three \#1/0 AWG Type USE cables and one \#1 equipment grounding conductor we look at Table 8-6, page 176 of [2]. The area of each USE cable is 0.2223 sq. inch and the area of the grounding \#1 AWG conductor is 0.0845 sq. inch. So the total area = $3 \times 0.2223+1 \times 0.0845=0.7514$ sq. inch. The minimum required conduit crosssectional area based on a $40 \%$ fill is $0.7514 \div 0.4=1.8785$ sq. inches. Table 8.5 , 
page 174 of [2] specifies that the minimum conduit size must be $1 \frac{1 / 2}{2}$ inch diameter trade-size PVC Schedule 40 conduit with an area of 1.986 sq. inches.

\section{Cost Analysis}

\section{Consumption Costs}

Natural gas consumption for the Plug Power unit was recorded at $1.10 \mathrm{ft}^{3} / \mathrm{min}$ at a power setting of $5.00 \mathrm{~kW}$. The cost per $\mathrm{kW}$ depends on whether industrial or residential prices for natural gas are used. The industrial price for natural gas is $\$ 7.21$ per thousand cubic feet leading to a cost of $[1.10 * 60 * 7.21 * 100 /(5 * 1000)] 9.52$ cents per $\mathrm{kWh}$. The residential price for natural gas is $\$ 15.16$ per MSCFM and hence the cost is $[1.10 * 60 * 15.16 * 100 /(5 * 1000)] 20.01$ cents per $\mathrm{kWh}$.

\section{Infrastructure Costs}

Using a cost per kW figure from Table 3.4.6 of the DOE Technical Plan - Fuel Cells (DOE Targets and Technical Barriers), we obtain $\$ 750 / \mathrm{kW}$ for large systems (50-250 $\mathrm{kW}$ ) projected for year 2010. This gives us a figure of $\$ 37,500.00$ for the $50 \mathrm{~kW}$ PEM Fuel Cell. To obtain a cost per house per hour this figure was divided by 10 and the amount was amortized over 20 years at $5 \%$ interest. This yields a monthly payment of $\$ 24.75$ per month or 3.3 cents per hour.

A cost estimate for the micro-grid layout was prepared using the 2004 National Electrical Estimator. This cost estimate does not include material-mark-up, contingency costs or profit margin. This estimate was $\$ 29,732.98$. To obtain a cost per house per hour this figure was divided by 10 and the amount was amortized over 20 years at $5 \%$ interest. This yields a monthly payment of $\$ 19.62$ per month or 2.7 cents per hour.

Not accounting for maintenance costs the costs for running a residential micro-grid are 26 cents per $\mathrm{kWh}$ and 15.5 cents per $\mathrm{kWh}$, using industrial and residential prices for gas, respectively.

\subsection{Thermal Recovery Strategy}

The University of South Alabama has an operational 5kW Proton Exchange Membrane (PEM) type fuel cell manufactured by Plug Power Corporation of Latham, NY. The fuel cell incorporates a natural gas reformer that operates as a methane-to-hydrogen converter. The flow rate of natural gas to the unit is approximately $1.5 \mathrm{ft} 3 / \mathrm{min}$ for the production of $5 \mathrm{~kW}$ of electrical power. The flow of hydrogen to the fuel cell stack is approximately $3.0 \mathrm{ft} 3 / \mathrm{min}$. The 88 -cell membrane electrode assembly provides power at $48 \mathrm{VDC}$ to an $\mathrm{AC}$ inverter at approximately $35 \%$ electrical efficiency. The output to the grid and to connected loads is $120 \mathrm{VAC}$. The unit is grid parallel, but is capable of stand-alone operation for short periods of time.

One of the main advantages of a PEM fuel cell is the relatively low operating temperature of the cell stack. The hydrogen stream from the fuel reformer is humidified at the stack anode at approximately $67^{\circ} \mathrm{C}$. The cell exhaust temperature is approximately $69^{\circ} \mathrm{C}$, so the heat directly available from the fuel cell stack is minimal. The partial oxidation 
reactor in the primary stage of the steam reformer, however, operates at about $700^{\circ} \mathrm{C}$. The final preferential oxidation reactor to remove carbon monoxide is operated at approximately $90^{\circ} \mathrm{C}$. The Plug Power system utilizes an ethylene glycol liquid cooling system to manage heat transfer in the system. There is a liquid-to-liquid heat exchanger that is available for customer use for heat reclamation. If the customer chooses not to utilize this system, the waste heat is rejected to the atmosphere by means of a large capacity automotive type radiator. At full rated power of $5 \mathrm{~kW}$, approximately $8 \mathrm{~kW}$ of thermal energy is produced. The combined electrical and thermal energy is approximately $13 \mathrm{~kW}$.

Using the heat of formation of water and carbon dioxide from the combustion of methane, the total amount of thermal energy available from the methane feed is approximately $15 \mathrm{~kW}$, indicating a reformer efficiency of $86 \%$. In practice, however, realistic operating efficiencies from the combination of electrical power and heat recovery are closer to $60 \%$. The difference is the thermal energy required to keep the reformer components at an elevated temperature for the steam reforming reactions to proceed.

Reported values for energy generation for larger fuel cell systems vary widely, but as a first approximation, the assumption can be made that a $50 \mathrm{~kW}$ fuel cell would be capable of operating at a minimum combined electrical and thermal efficiency of $60 \%$. This would indicate that a minimum of $40 \mathrm{~kW}$ of thermal energy would be available when the fuel cell is operating at maximum output.

The average hot water consumption in the US is $62.4 \mathrm{gal} /$ day/person. For an average family of four, the daily consumption of hot water is $250 \mathrm{gal} /$ day. Domestic hot water is typically supplied at a tank temperature of $60^{\circ} \mathrm{C}$. In the Southeast, a typical water supply temperature is $15^{\circ} \mathrm{C}$. Assuming 24-hour operation of the fuel cell at full rated power, 960 $\mathrm{kWh}$, or $3.28 \times 10^{6} \mathrm{BTU}$ would be available for water heating. This would be sufficient to raise the temperature of 3476 gallons of water from $15^{\circ} \mathrm{C}$ to $60^{\circ} \mathrm{C}$. For a 10 family microgrid community, 2500 gallons per day would be required. It is feasible to utilize the excess thermal energy from the fuel cell to heat domestic water, provided an economical means of delivery can be devised. 
For a micro-grid community of ten houses arranged as shown in Figure 1.2.1, it is proposed that two circulation loops be used to continuously circulate hot water from the fuel cell reformer cooling system to individual houses.

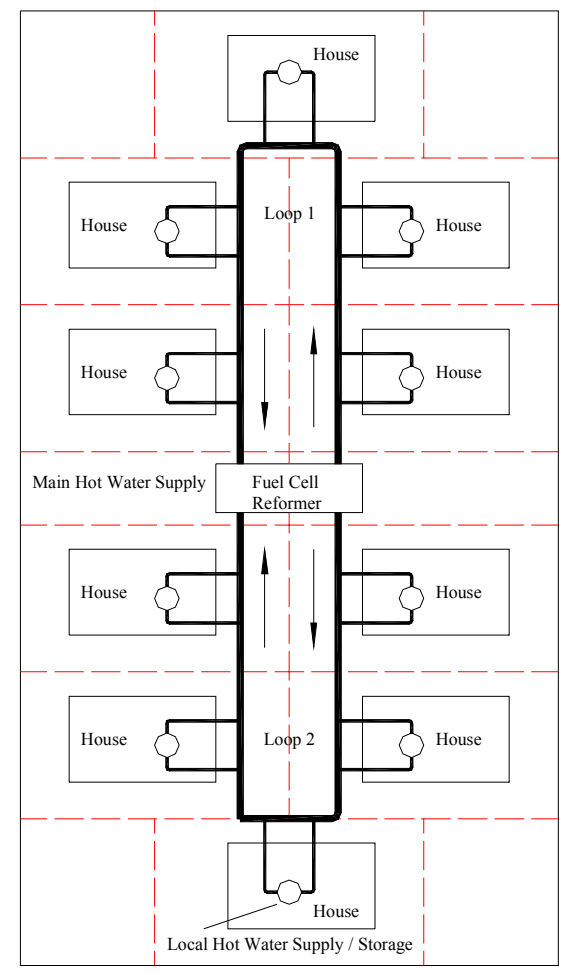

Figure 1.2.1. Proposed community hot water distribution.

The circulation piping and pumps must be sized such that the delivery pressure to individual houses is greater than that required by local building codes at the maximum total household consumption rate. It is recommended that two loops be employed to reduce the pressure and temperature drop incurred by the mechanics of continuous water circulation. The total piping length for each loop will be approximately 300 feet.

Figure 1.2.2 shows additional detail of each piping loop. Water is pumped through the reformer to remove excess heat via a heat exchanger. Hot water at a temperature of approximately $80^{\circ} \mathrm{C}$ at the reformer heat exchanger outlet is routed to a primary circulation tank. The hot water is pumped through each primary circulation loop by two pumps. When demand is low, a small circulating pump is used to maintain water circulation through the loop, preventing temperature decrease from stagnation. 
As the demand begins to increase, the delivery flow rate and pressure are maintained by a

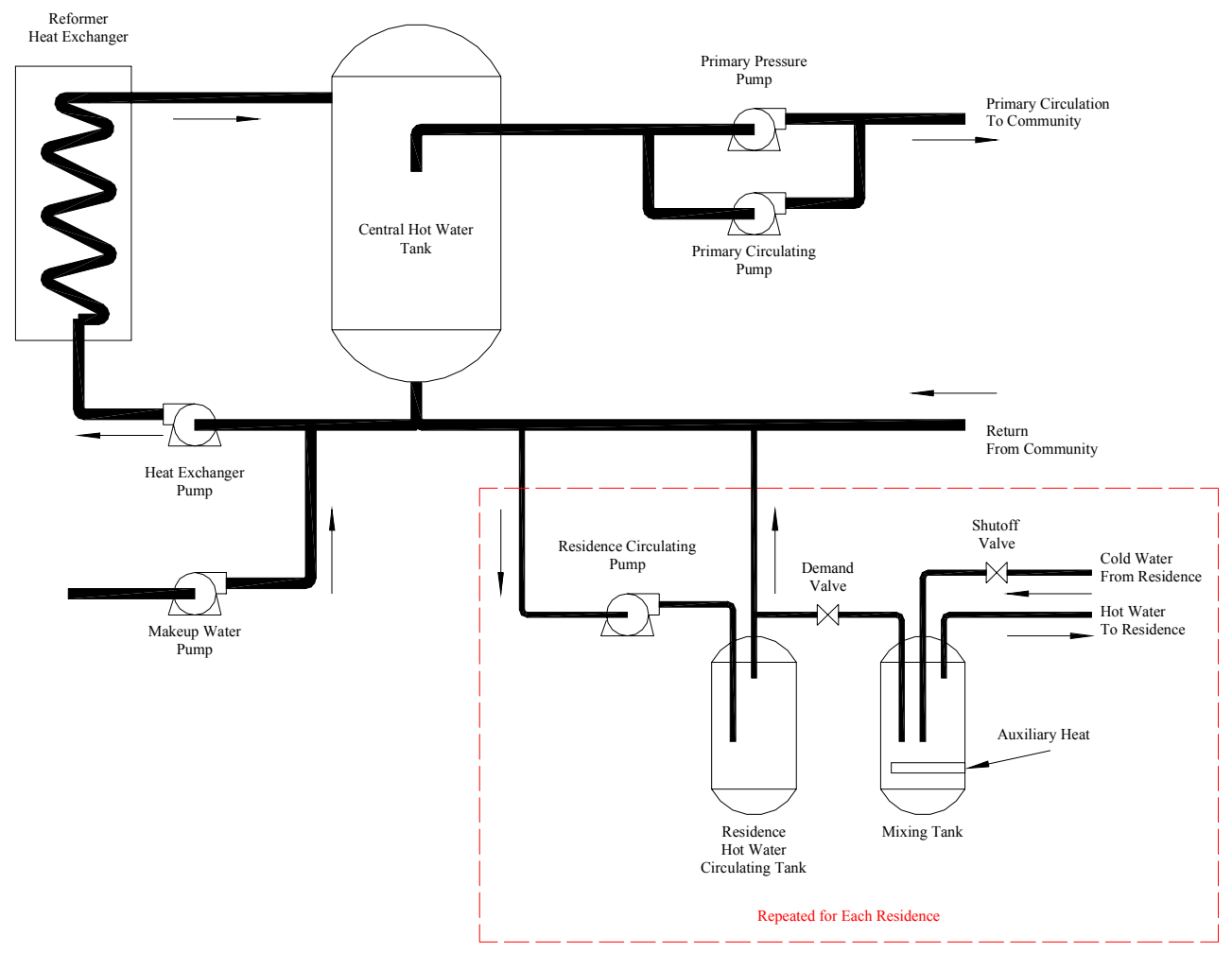

Figure 1.2.2. Plumbing detail.

second larger pump in series with the circulating pump. As hot water is removed from the primary system by the residences, makeup water is supplied at the heat exchanger inlet by a makeup water pump.

For each residence, there is a local circulation tank that is maintained at a water temperature of approximately $80^{\circ} \mathrm{C}$ by a local circulating pump. A mixing tank is used to supply hot water to the residence at approximately $60^{\circ} \mathrm{C}$. The water from the primary loop is mixed with cold water from the residence to reduce the temperature to that required for household use. If the mixing tank temperature cannot be maintained at the required delivery temperature, electrical heating elements are used for auxiliary heating.

Selection of the actual hardware components will be affected by a number of site-specific design considerations. These include the following:

- Delivery pressure required by local building codes

- Primary loop pipe sizing for minimum pressure drop at peak hot water demand

- Circulation flow rate for peak hot water demand

- Local circulation flow rate to maintain a minimum temperature

- Operating setpoint of the reformer system 
A valid economic assessment of the proposed cost of a thermal recovery system is difficult. It is relatively straightforward to determine the capital and installation costs associated with pumps, piping, and fittings, but a large fraction of the cost would be installation specific.

Capital Items would include:

Primary circulating loops (two loops required)

- Primary pressure pump

- Primary circulating pump

- Makeup water pump

- Primary heat exchanger pump

- Primary storage tank

- Reformer heat exchanger piping

- Primary piping

Residential loops (one loop required for each residence)

- Residence circulating pump

- Residence circulating tank

- Residence mixing tank

- Demand valve

- Residence piping

Capital costs and installation costs would be amortized over the lifetime of the equipment. A meaningful cost analysis should include the following:

- Cost of primary system operation (power required for pump operation, cost of makeup water, maintenance costs, fraction of heat energy actually utilized by residents, etc).

- Cost of residential system operation (power required for pump operation, power required for supplemental heat, maintenance costs, etc.).

\subsection{Excess Energy Strategy}

The likelihood of surplus energy being available from the micro-grid occurs only at time of low power demand. From actual load profiles of residences obtained during Phase I it has been determined that such occasions arise during the night when the loads are light. The option of using this excess energy can be divided into, (A) storing the energy in some form, or (B) using/selling the energy in real time.

$A$. Storing energy: The most viable means of storing energy that has been found in the literature are through the use of rechargeable batteries and supercapacitors. Since the batteries are an integral part of the FCPP, it is not too difficult to arrange for the charging 
of the batteries at times of low power demand. An extremely attractive option, which has recently become available, is the use of banks of super capacitors. These electrochemical capacitors are competitively priced when compared with the cost of equivalent batteries, and can therefore serve as energy storage devices. This particular energy storage device is analyzed in details and its operational aspects studied under Alternative Energy Evaluation Section.

$B$. Using/Selling/Buying energy: At night, when the residence power demand is low, the FCPP can be used to export power to the grid. If the FCPP is running at full power then the reformer temperature can be maintained at constant value while selling the excess power to the grid. This is operationally advantageous from the fuel cell point of view. If the electrical load power demand exceeds the generation capacity of the FCPP, the need arises to buy electrical energy from the grid.

Another option is the use of excess hydrogen during low power demand periods.

Hydrogen can be generated by the reformer and stored in tanks for later use as a fuel for cars or in pure hydrogen powered fuel cells.

The economic model incorporating energy management in optimized manner which addresses the issues of excess energy and short fall of energy production is dealt with in details in section 2 .

\subsection{Operational Strategies}

The objective of operational strategies is to minimize the operational cost of the FCPP in terms of \$/day. Fuel cell economics and economical aspects have been presented in the literature [3-7]. To study the economics of FCPP, the cost factors having a bearing on this problem must be put in a form of cost objective function. The objective function must be based on an economic model of a FCPP.

Refs. [6] and [7] introduce an economic model to estimate the optimal output power from the FCPP while minimizing the system cost and satisfying system operational constraints. The model considers the possibility of selling and buying energy from the local grid, and the optimal usage of thermal power output from the FCPP.

In references quoted in section 1.1, a mathematical formulation for the FCPP operational cost has been presented, where the FCPP provides electrical energy as well as thermal energy to a small micro-grid community. The model is summarized as follows:

$$
\begin{aligned}
\operatorname{Min} & C_{n 1} T \sum_{j} \frac{P_{j}-P_{a}}{\eta_{j}}+C_{e l, p} T \sum_{j} \max \left(L_{e l, j}-P_{j}, 0\right)+C_{e l, s} T \sum_{j} \max \left(P_{j}-L_{e l, j}, 0\right)+ \\
& C_{n 2} T \sum_{j} \max \left(L_{t h, j}-P_{t h, j}, 0\right)+\alpha+\beta\left(1-e^{-\frac{t_{o f f}}{\tau}}\right)+O M
\end{aligned}
$$

Subject to: 


$$
\begin{aligned}
& P^{\min } \leq P_{j} \leq P^{\max } \\
& P_{j}-P_{j-1} \leq \Delta P_{u} \\
& P_{j-1}-P_{j} \leq \Delta P_{D} \\
& \left(T_{j-1}^{o n}-M U T\right)\left(U_{j-1}-U_{j}\right) \geq 0.0 \\
& \left(T_{j-1}^{\text {off }}-M D T\right)\left(U_{j}-U_{j-1}\right) \geq 0.0 \\
& n_{\text {start-stop }} \leq N^{\max }
\end{aligned}
$$

where

$C_{n 1}$ : price of natural gas for FCPP $(\$ / \mathrm{kWh})$

$T \quad$ : length of time interval (h)

$P_{j} \quad$ : electrical power produced at interval $\mathrm{j}(\mathrm{kW})$

$P_{a} \quad$ : power for auxiliary devices $(\mathrm{kW})$

$\eta_{j} \quad:$ cell efficiency at interval $\mathrm{j}$

$C_{e l, p}$ : tariff for purchasing electricity $(\$ / \mathrm{kWh})$

$C_{e l, s}:$ tariff for selling electricity $(\$ / \mathrm{kWh})$

$L_{e l, j}:$ electrical load demand at interval $\mathrm{j}(\mathrm{kW})$

$C_{n 2} \quad$ : fuel price for residential loads $(\$ / \mathrm{kWh})$

$L_{t h, j} \quad$ : thermal load demand at interval $\mathrm{j}(\mathrm{kW})$

$P_{t h, j}:$ thermal load produced at interval $\mathrm{j}(\mathrm{kW})$

$\alpha, \beta \quad$ : hot and cold start up cost respectively

$t_{\text {off }} \quad:$ time the FCPP has been off (h)

$\tau$ : fuel cell cooling time constant (h)

$P^{\min }$ : minimum limit of generating power $(\mathrm{kW})$

$P^{\max }$ : maximum limit of generating power $(\mathrm{kW})$

$\Delta P_{u}$ : upper limit of the ramp rate

$\Delta P_{D}:$ lower limit of the ramp rate

$T^{o n}$ : FCPP on-time (number of intervals)

$T^{\text {off }} \quad$ : FCPP off-time (number of intervals)

$M U T:$ minimum up-time (number of intervals)

$M D T$ : minimum down-time (number of intervals)

$U$ : FCPP on-off status, $\mathrm{U}=1$ for running, $\mathrm{U}=0$ for stopping

$N^{\max }$ : maximum number of start-stop events

$N_{\text {start-stop: }}$ number of start-stop events

$O M$ : operation and maintenance cost

The first term of the objective function (equation 1.4.1) is the daily fuel cost for the fuel cell $(\$)$. The second term is the daily cost of electrical energy purchased if the demand exceeds the electrical energy produced (\$). The third term is the daily income from the electrical energy sold if the electrical energy produced exceeds the demand (\$). The 
fourth term is the daily cost of purchased gas for residential thermal loads if the thermal energy produced is not enough to meet the thermal energy demand (\$). The fifth term is the start up cost (\$). The last term is the operation and maintenance cost of the FCPP.

While most of the parameter values in the objective function are available, the efficiency $(\eta)$ and the thermal output power $\left(\mathrm{P}_{\mathrm{th}}\right)$ are obtained from experimental data [8]. The FCPP operates with a maximum efficiency of $41 \%$. The efficiency is slightly higher at low load compared to full load operation. At all load conditions, the FCPP produces thermal energy approximately equal to the electrical energy [8]. In Ref. [8], efficiency and thermal energy to electrical energy ratio curves have been developed, Fig. 1.4.1. These curves approximate the efficiency and the thermal output of the FCPP. The efficiency and the thermal energy to electrical energy ratio are functions of the part load ratio (equal to electrical generated power/maximum power). Mathematical expressions to approximate the curves have been developed in Ref. [8] as follows:

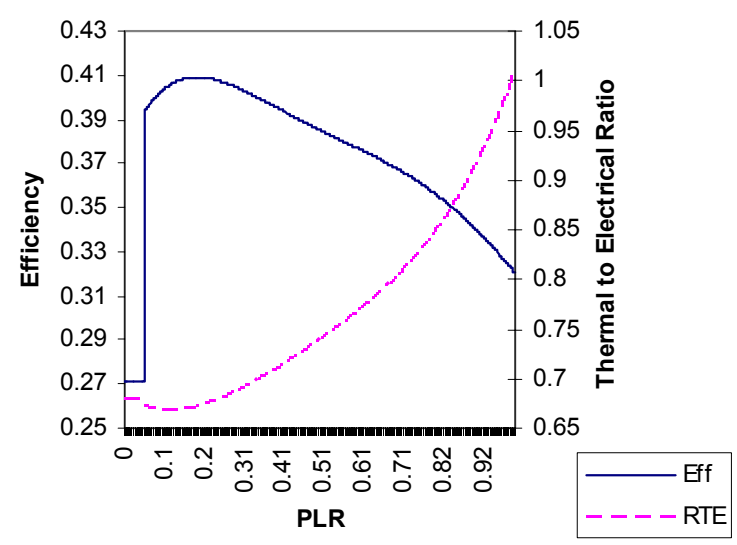

Fig. 1.4.1. Performance curves of FCPP.

$$
\begin{aligned}
\eta= & 0.2716 \text { for } P L R<0.05 \\
\eta= & 0.9033 P L R^{5}-2.9996 P L R^{4}+3.6503 P L R^{3}- \\
& 2.0704 P L R^{2}+0.4623 P L R+0.3747 \\
& \quad \text { for } P L R>0.05 \\
r_{T E}= & 0.6801 \text { for } P L R<0.05 \\
r_{T E}= & 1.0785 P L R^{4}-1.9739 P L R^{3}+1.5005 P L R^{2}- \\
& 0.2817 P L R+0.6838 \text { for } P L R>0.05
\end{aligned}
$$

where $\eta$ is the FCPP efficiency, PLR the part load ratio, $r_{T E}$ the thermal energy to electrical energy ratio.

To obtain the optimal operating cost of the FCPP, the objective function of the economic model must be optimized to find the optimal output power from the FCPP in each time interval (for time interval length, T) for a horizon of $24 \mathrm{~h}$. Due to the high nonlinearity of the suggested model, solving for the optimal output power from the FCPP using classical 
optimization techniques may not guarantee an optimal solution. In this report a technique based on Evolutionary Programming (EP) [9] is used to find the optimal output power from the FCPP and also the Hill-Climbing technique is used to help move the infeasible solution to a feasible region.

Evolutionary programming is a search optimization method. It moves from one solution to another using a probabilistic search technique. Evolutionary programming starts with random individuals. Each individual represents a complete solution for the problem under study. The individuals are moved from one generation (or iteration) to the other after passing through two main steps, mutation and competition. During a mutation step a new individual is produced when a Gaussian random variable with uniform probability is added to the current individual. The competition step is a probabilistic selection scheme used to assign a weight to each individual according to a comparison between current individual and a randomly chosen one. It may happen that the new solution is infeasible. Therefore, using EP alone may require a long time to reach the optimal solution or it may get trapped in a local optimum. This limitation was overcome by the use of the HillClimbing technique (HCT) [10].

The proposed technique has been tested to find the optimal output power from an FCPP for the following cases:

Case 1: In this test case, a small FCPP of $4 \mathrm{~kW}$ capacity has been used. The purpose of this test is to validate the performance of the proposed technique by comparing the results against genetic algorithms (GA) results [6]. The FCPP system and evolutionary program parameters are shown in Table 1.4.1.

Comparison of the different cost components of the EP and the GA solutions Table 1.4.2 showed that the proposed EP algorithm arrived at a better production cost. The other cost components are slightly lower in the EP solution except the residential natural gas cost. The overall cost of the EP solution is lower than the GA solution. The EP solution saves $\$ 0.46$ per day amounting to a saving of \$167.9 yearly. For a larger unit as in Case 2 (discussed later), the cost saving is expected to be more in the case of EP solution. The electrical and thermal power output from the FCPP and the electrical and thermal loads are shown in Figs. 1.4.2 and 1.4.3. The power trade between the FCPP system and the local network is shown in Fig. 1.4.4.

Case 2: In this test case the model is tested using an actual residential load profile. The load profile for a micro-grid of ten identical houses is used. The micro-grid houses have all electrical appliances. In the micro-grid system each house is permitted to consume a maximum of $5 \mathrm{KW}$ power through the LEMSYS and MEMSYS system control.

According to the above assumption, a soft limit for the maximum power for each house is set equal to $5 \mathrm{~kW}$. The load profile for a $24 \mathrm{~h}$ period with a 15 -minute sampling interval is used. Due to the lack of information of the thermal load for the micro-grid community, the thermal load of Case 1 is multiplied by a factor of 50/4=12.5. Table 1.4.1, parameters for the FCPP and the EP are used except for the following: maximum power is set to 50 
Table 1.4.1. FCPP and evolutionary program parameters.

\begin{tabular}{|l|l|}
\hline Maximum limit of generating power, $P^{\max }(\mathrm{kW})$ & 4.0 \\
\hline Minimum limit of generating power, $P^{\min }(\mathrm{kW})$ & 0.0 \\
\hline Length of time interval, $T(\mathrm{~h})$ & 0.25 \\
\hline Upper limit of the ramp rate, $\Delta P_{u}(\mathrm{~kW})$ & 2.5 \\
\hline Lower limit of the ramp rate, $\Delta P_{D}(\mathrm{~kW})$ & 3.0 \\
\hline Price of natural gas for FCPP, $C_{n l}(\$ / \mathrm{kWh})$ & 0.04 \\
\hline Tariff for purchasing electricity, $C_{e l, p}(\$ / \mathrm{kWh})$ & 0.13 \\
\hline Tariff for selling electricity, $C_{e l, s}(\$ / \mathrm{kWh})$ & 0.07 \\
\hline Fuel price for residential loads, $C_{n 2}(\$ / \mathrm{kWh})$ & 0.05 \\
\hline Hot start up cost, $\alpha(\$)$ & 0.05 \\
\hline Cold start up cost, $\beta(\$)$ & 0.15 \\
\hline The fuel cell cooling time constant, $\tau(\mathrm{h})$ & 0.75 \\
\hline Minimum up-time, $M U T($ number of intervals) & 2 \\
\hline Minimum down-time, $M D T$ & 2 \\
\hline Maximum number of intervals $)$ & 5 \\
\hline Maximum number of evolutionary generation & 20000 \\
\hline Number of individuals & 200 \\
\hline
\end{tabular}

Table 1.4.2. Cost comparison between EP and GA.

\begin{tabular}{|l|l|l|}
\hline & GA & EP \\
\hline Daily fuel cost & $\$ 4.82$ & $\$ 4.28$ \\
\hline Daily profit from electricity sold & $\$ 1.54$ & $\$ 1.52$ \\
\hline Daily cost of purchased electricity & $\$ 0.14$ & $\$ 0.13$ \\
\hline Daily cost of residential natural gas & $\$ 0.06$ & $\$ 0.10$ \\
\hline Operation and maintenance cost & $\$ 0.20$ & $\$ 0.21$ \\
\hline Start up cost & $\$ 0.00$ & $\$ 0.00$ \\
\hline Total cost & $\$ 3.67$ & $\$ 3.20$ \\
\hline
\end{tabular}

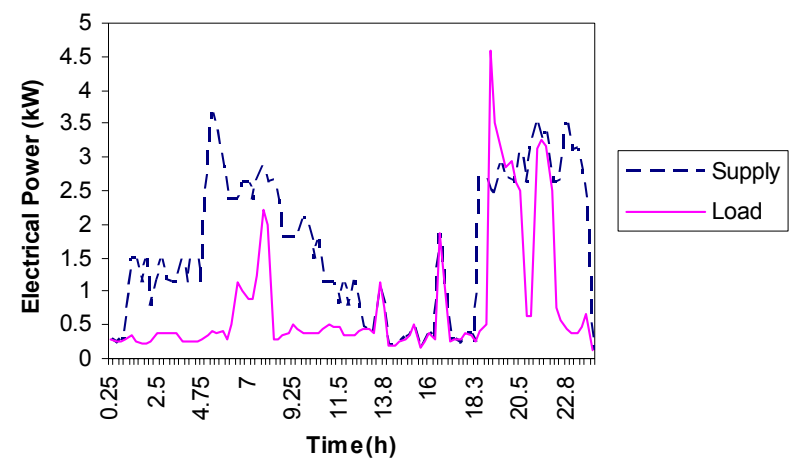

Fig. 1.4.2. Electrical power output from FCPP.

$\mathrm{kW}$, the upper and lower limit of the ramp rate are 25 and $30 \mathrm{~kW}$ respectively, and the number of individuals is 150 . The different cost components for using the proposed EP to 
find the optimal output power from the FCPP are shown in Table 1.4.3. The electrical and thermal power outputs from the FCPP are shown in Figs. 1.4.5 and 1.4.6. Fig. 1.4.7 shows the power trade with the local network. The daily cost for the FCPP working at full capacity is $\$ 97.78$. Comparing the full capacity cost with the cost obtained through scheduling the power output from the FCPP using EP shows that the proposed technique saved $\$ 14,377.35$ annually.

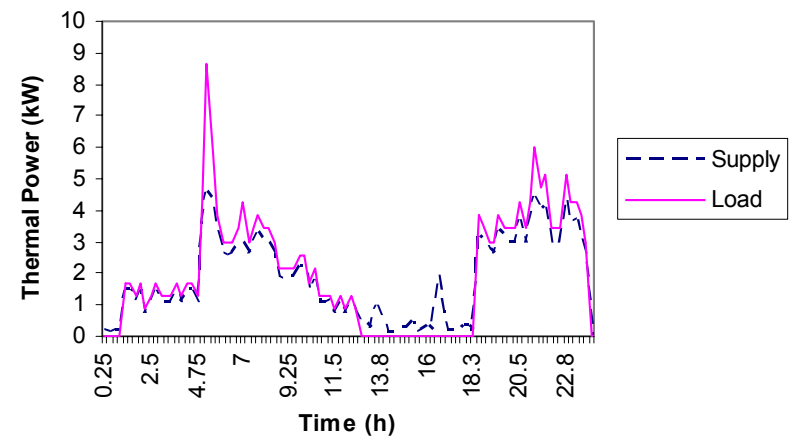

Fig. 1.4.3. Thermal power output from FCPP.

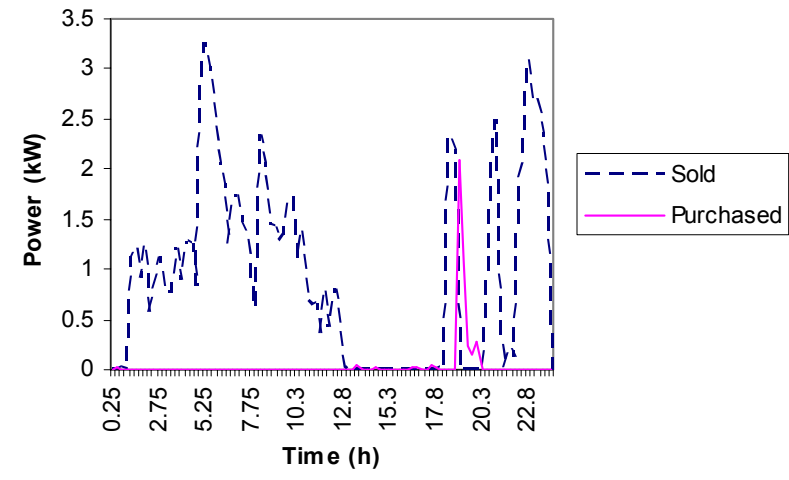

Fig. 1.4.4. Power trade with the local network.

Table 1.4.3. Cost components for $50 \mathrm{~kW} \mathrm{FCPP.}$

\begin{tabular}{|l|l|}
\hline Daily fuel cost & $\$ 54.92$ \\
\hline Daily profit of sold electricity & $\$ 13.66$ \\
\hline Daily cost of purchased electricity & $\$ 2.95$ \\
\hline Daily cost of residential natural gas & $\$ 12.21$ \\
\hline Operation and maintenance cost & $\$ 1.97$ \\
\hline Start up cost & $\$ 0.00$ \\
\hline Total cost & $\$ 58.39$ \\
\hline
\end{tabular}




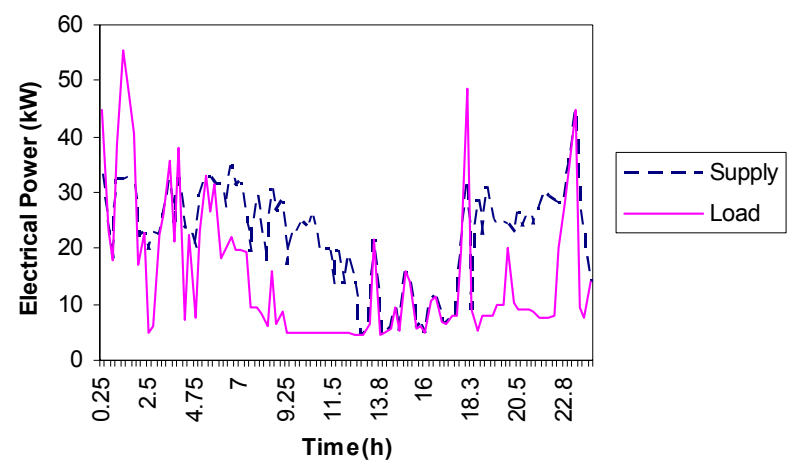

Fig. 1.4.5. Electrical power output form $50 \mathrm{~kW} \mathrm{FCPP.}$

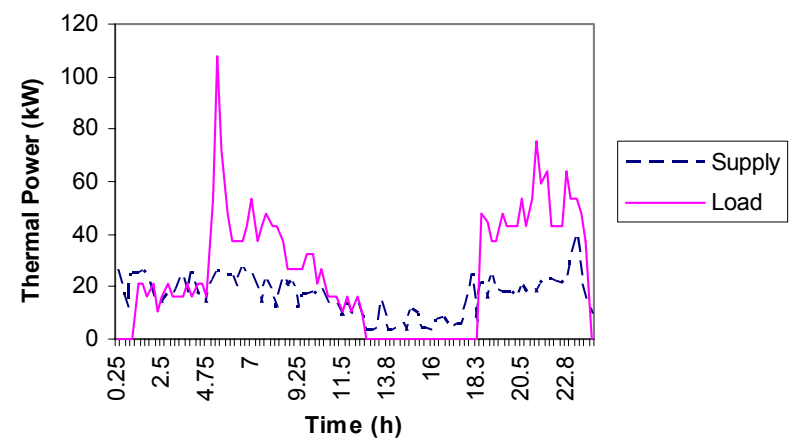

Fig. 1.4.6. Thermal power output from FCPP.

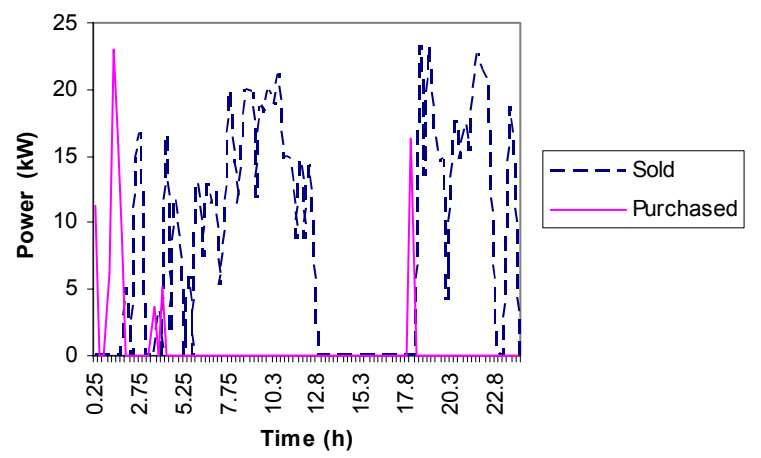

Fig. 1.4.7. Power trade with the local network.

In conclusion, it can be said, given a certain electrical and thermal load profile the EP approach will arrive at the lowest operational cost of the FCPP in \$/day. Furthermore, the EP solution will provide the interval by interval electrical and thermal power generation profile of the FCPP in addition to the interval by interval power trade with the load grid. The hydrogen production can be added to the operational strategy during the time intervals where the produced power is lower than the maximum capacity of the FCPP. During these intervals the FCPP reformer can run at maximum capacity and the excess of hydrogen can be stored or used in other revenue generation purposes. 


\section{Energy Management Algorithm}

\subsection{Load Smoothing}

There are two objectives of the Load Smoothing study. The first objective is to find the amount of inherent load smoothing that occurs in a micro-grid environment. The second is to analyze home load profiles to determine the loads/appliances that should be available for load management.

\subsubsection{Inherent load smoothing in micro-grid environment}

It is hypothesized that the power graph of homes in a micro-grid community is smoother than the power graph of an individual home with no computer management in either situation. The reason is that occupants in different households will have differing daily routines and will use high powered loads at different times. If scale is taken into account, then it follows that the micro-grid community will have a smoother power graph.

\subsubsection{Comparing a micro-grid to a single house}

The comparison uses load profiles based upon load profiles of real homes, but the profiles are artificial because it was not feasible to actually move different types of families into the lab house for a week. The team measured power usage in real homes and conducted appliance surveys to ascertain certain load values and running times to help create the profiles. The profiles consist of different occupants using loads in a house that contains the same loads as the lab house for one week's time.

There are ten house profiles in all consisting of a combination of one or more of the following: a man, woman, girl, boy, teenage boy, teenage girl, retired man and/or retired woman. A small amount of randomness is present because any of the profiles can be designated as a "Traveler." A traveler has a random chance of being out of the house for a few days of the week and was introduced so that profiles generated would not all appear exactly the same.

The metric used for comparison is the standard deviation and load factor of power usage per day in a single home versus that of a hypothetical micro-grid. The lower the standard deviation is, the "smoother" the load curve is. The load factor consists of the average load divided by the peak load. The higher the number, the closer the peak is to the average. According to the hypothesis, the standard deviation of a micro-grid should be lower than the average standard deviation of the individual houses and the load factor should be higher. Results to-date show that the micro-grid's standard deviation is 14800 while the average standard deviation of the individual houses is 1530 . If you multiply by the scaling factor of 10, then the standard deviation of the individual houses is $3.3 \%$ higher than the micro-grid. The micro-grid load factor calculates to $23.1 \%$ while the average load factor of the individual homes is $20.4 \%$. The load factor increases by 2.7 percentage points when in the micro-grid configuration. Both calculations show that the load curve is smoother if the houses operate within a micro-grid. It is likely that with more randomized occupant profiles the curve would be even smoother. 


\subsubsection{Analyzing home load profiles for manageable appliances}

In the process of gathering data for analysis, the project team ran scenarios in the lab house located on the USA campus. The team ran unmanaged scenarios first in order to create a baseline. They then ran scenarios where MEMSYS was enabled, so management occurred whenever energy usage surpassed $5 \mathrm{~kW}$. The unmanaged scenarios are four hours long and typically consume around $8 \mathrm{kWh}$ of energy. The managed scenarios run longer because appliances that are turned off must wait to run when enough power is available. The managed scenarios run typically an hour longer and have used less power because loads like the stove are not automatically restored. Future runs will include overriding the MEMSYS and keeping the stove on. During the runs, the team noted the management decisions that seemed to unnecessarily inconvenience occupants.

\section{Problems Noted}

Inconveniences occurred whenever the power hovered around the $5 \mathrm{~kW}$ limit. Because the limit is a hard limit, even a small load over $5 \mathrm{~kW}$ will cause appliances to shut off. The MEMSYS would often manage large loads first instead of small ones that could easily bring the total under $5 \mathrm{~kW}$. Also, the MEMSYS would sometimes cycle large loads like the dryer on and off within the space of a few minutes repeatedly because the water heater or refrigerator would run intermittently. Analyzing the data revealed measurement error that would cause the power measured to fluctuate enough to place the management software in a cycle. Sometimes a load that was completely turned off would register $6 \mathrm{~W}$ of power usage. For larger loads using a different current sensor, the error was around $36 \mathrm{~W}$. The measurement errors increase as the loads increase so it is thought that crosstalk contributes to the error. Other possible sources of error include the multiplexer which is built with components that are already $5 \%$ error tolerant. The smaller current sensors, which output $1 \mathrm{~V}$ at the full scale of $20 \mathrm{~A}$, have a $4 \%$ error. Many house loads typically run at $1 \mathrm{~A}$ or less. The reading is then sent to an $\mathrm{A} / \mathrm{D}$ card which has a range of $\pm 5 \mathrm{~V}$ and a sensitivity of 12 bits. Since the reading is always positive and $1 \mathrm{~V}$ max, the slightest interference can lead to a visible error. To keep an error of $6 \mathrm{~W}$ within the $5 \%$ tolerance range, a load must be at least $72 \mathrm{~W}$. However, the lights and many other appliances draw more than $72 \mathrm{~W}$ or draw a small enough wattage as to fade into the noise. The larger $50 \mathrm{~A}$ sensors output $.45 \mathrm{~V}$ and are constructed with a $3 \%$ error. The errors in this sensor are potentially greater since it outputs on a smaller voltage range. Again, if an output error of $5 \%$ is required, then the error of $36 \mathrm{~W}$ would dictate the loads they measure be at least $720 \mathrm{~W}$. Most loads outfitted with the larger sensors draw around $600-3000 \mathrm{~W}$. So some of the error will be larger than $5 \%$, but much of it will not.

\section{Potential Solutions}

In the third year, the team will investigate the source of these errors and attempt to ensure they remain within the $5 \%$ error tolerance. One potential source of the interference is cross talk between the wires, and the solution to this may be to place the current sensors at the wall outlet and send the readings wirelessly or by powerline carrier. Another potential source is the wires between the multiplexer and the A/D card which is located in the computer several feet away. The error could be reduced by placing an A/D converter next to the multiplexer on the next version of the MEMSYS hardware. Finally, the hard limit of $5 \mathrm{~kW}$ will be removed with the inclusion of either fuzzy logic or error 
compensation algorithms or both. With fuzzy logic, the MEMSYS can operate in a given power band acceptable to the fuel cell and so reduce cycling. Error compensation may be investigated by creating an error curve and programming it into the MEMSYS to achieve a similar result to the fuzzy logic. Since the third year consists of algorithm improvement, all these proposed solutions fit with the overall direction of the project. Some specific nuisance load cycling can also be improved by keeping a larger water heater. Team members observed the water heater interrupting other loads that are more noticeable. In addition to lowering its place in the priority list, it is suggested that a larger water heater would reduce the need to reheat water. The fuel cell's co-generation features will help with this aspect also. The team also proposes that in a commercial product, the number of loads that are actually controlled directly by the MEMSYS be reduced. The installation of the current system is very costly and the utility of some of its functions is questionable. If the primary purpose of MEMSYS is power management, the commercial product could simply manage the larger loads in the house like the washer, dryer, water heater and stove. If electric companies can manage the usage of these specific items during their peak usage periods, they will be managing the majority of a home's load. The system could pay for itself in a smaller time period and will be less intrusive.

\subsection{Micro-grid Migration}

The micro-grid migration from the single home project in year one consisted of moving the single home SEMaC software into a client/server environment, made up of MEMSYS (Master Energy Management SYStem) and LEMSYS (Local Energy Management SYStem). MEMSYS is the management application for the entire micro-grid, receiving the loads from all homes connected to the micro-grid.

The LEMSYS is the SEMaC software from year one, with code added to allow networking with the MEMSYS server. SEMaC also has code added to allow reporting total load to MEMSYS, and also receive commands from MEMSYS indicating that management needs to take place.

In year one of the GIFCO project, the SEMaC is connected to a home constructed in the Energy Laboratory in the Engineering Lab at USA. In year two, the other 9 homes in the micro-grid system are simulated using software written to generate load profiles based on data collected in year from the lab home. The LEMSYS connects to the simulation software in the same way it would connect to the Data AcQuisition (DAQ) hardware and the System Hardware Controller (SHC).

\subsection{Data Collection}

Fig. 2.3.1 covers a 24 hour period of 10 homes running different profile simulations, with no management by MEMSYS/LEMSYS. The graph is of a 15 minute running average of the average home load of the micro-grid.

The simulation uses artificial load profiles which are partly based upon data gathered from real homes. There are ten house profiles in all consisting of a combination of one or more of the following occupants: a man, woman, girl, boy, teenage boy, teenage girl, retired man and/or retired woman. Each occupant has different daily routines, so as long 
as houses include different occupants the resulting profiles will also be different. The power that appliances consume and their usage time are randomized to a certain degree. Different occupants and randomness are introduced in order to differentiate one profile from another.

The results of running 10 different profiles through the simulation simultaneously shows that the inherent load smoothing of multiple homes allows for a much smaller fuel cell than previously thought. With management, it is suggested that 10 homes could be easily run off of a $30 \mathrm{~kW}$ fuel cell.

15 Min Unmanaged Average Profile

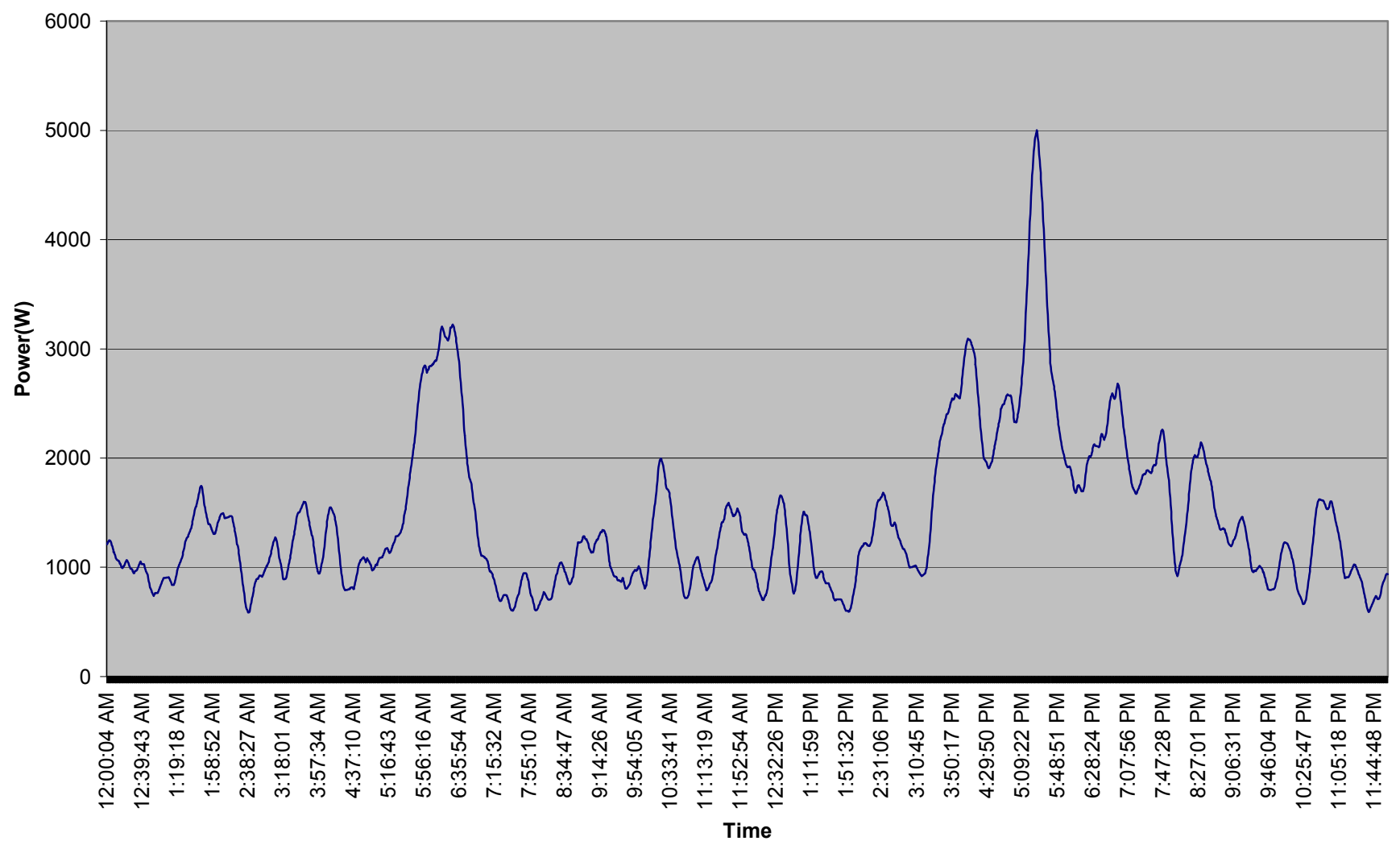

Fig. 2.3.1 Unmanaged Load Profile

Fig. 2.3.2 shows the results of a management set point of $35 \mathrm{kw}$ being applied to the micro-grid. Once the power usage of the micro-grid reaches $35 \mathrm{kw}$, MEMSYS instructs LEMSYS to reschedule loads until power usage decreases below 35kw. MEMSYS does this by arranging the homes in a list from highest to lowest power consumption, and requesting that the home consuming the most power to manage first. 


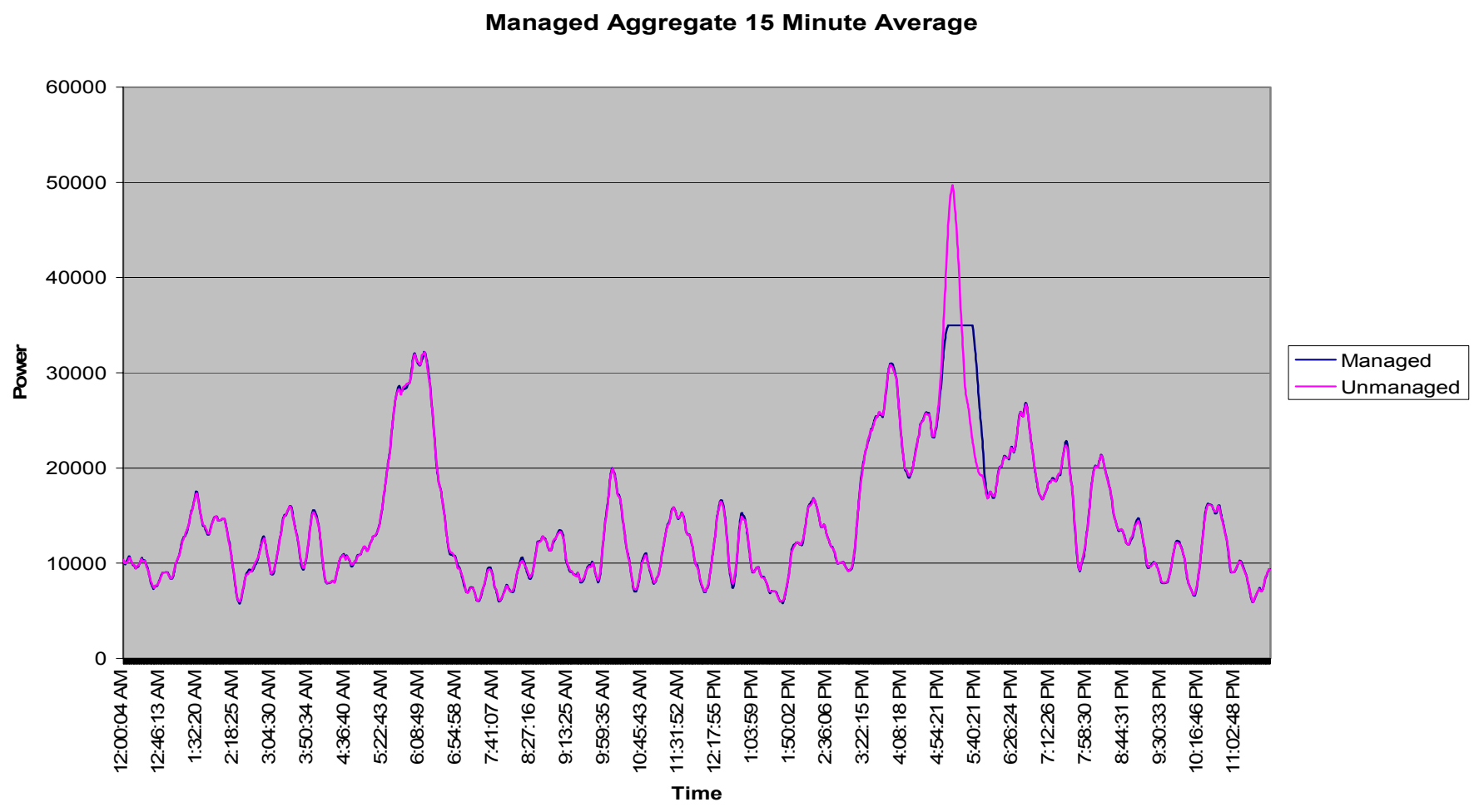

Fig. 2.3.2 Managed Load Profile

\section{Alternative Energy Evaluation}

\subsection{Hydrogen Generation}

The University of South Alabama's 5kW PEM fuel cell operates on natural gas and has an integrated steam reforming system. The reformer consumes approximately $1.5 \mathrm{ft}^{3} / \mathrm{min}$ of natural gas and produces approximately $3 \mathrm{ft}^{3} / \mathrm{min}$ of hydrogen when operating at the rated capacity of $5 \mathrm{~kW}$. In a micro-grid community of ten homes, the power capacity would be about $50 \mathrm{~kW}$. Assuming a linear scale factor, the hydrogen production capacity of a $50 \mathrm{~kW}$ reformer system would be $150 \mathrm{ft}^{3} / \mathrm{min}$.

Based on the actual residential data collected during Phase I of the project, it has been determined that the average daily power consumption of a typical residence is usually less than $5 \mathrm{~kW}$. There are periods during which loads reach or exceed $5 \mathrm{~kW}$, but they are typically confined to relatively brief periods of the day and are subject to considerable seasonal variations. The possibility of utilizing the excess capacity of the fuel cell, both electrical and thermal, to generate hydrogen is being investigated.

Assuming that the average load would be $2.5 \mathrm{~kW}$ per household, a 10-home micro-grid community would consume an average of $75 \mathrm{ft}^{3} / \mathrm{min}$ of hydrogen to produce $50 \mathrm{~kW}$ of electrical power. A surplus of $75 \mathrm{ft}^{3} / \mathrm{min}$ of hydrogen would be available for storage, provided that the reformer could be operated at full capacity. 
There are several technical challenges that will have to be overcome to make excess hydrogen production and storage feasible:

\section{$A$. The reformer must be able to operate independently of the fuel cell}

Operational experience with the $5 \mathrm{~kW}$ fuel cell indicates that the reformer operates most efficiently when in a steady state. The response of a reformer to step changes in electrical load is sluggish, due to the reaction kinetics of the multi-stage steam reforming reaction and the thermal load of the vessels in the reforming system. If the PEM cell stack and reformer were separate systems, the reformer could continue to produce the maximum amount of hydrogen during times when the fuel cell is not operating at full load. The cell stack would use hydrogen on electrical demand, while the reformer would continue to independently produce hydrogen at a constant rate.

\section{$B$. A cost effective means of hydrogen storage must be identified}

The hydrogen produced by a typical reformer is at or near atmospheric pressure. Hydrogen is a light fuel and must be stored at very high pressures $(3000-5000 \mathrm{psig})$ to provide a useful capacity for power generation. Hydrogen at $4600 \mathrm{psig}$ in a modern composite tank has about a 3\% mass fraction. For example, a tank weighing $100 \mathrm{~kg}$ would contain $3 \mathrm{~kg}$ of hydrogen at $4600 \mathrm{psig}$. The volume of $3 \mathrm{~kg}$ of high-pressure hydrogen at atmospheric pressure would be approximately $1270 \mathrm{ft}^{3}$, or a sufficient quantity of hydrogen to operate a $50 \mathrm{~kW}$ fuel cell at full capacity for about 8 minutes. The volume of $1270 \mathrm{ft}^{3}$ of hydrogen at 4600 psig would be approximately $4 \mathrm{ft}^{3}$.

Fortunately, in fixed installations, tank size and weight will not be a problem. The major challenge is to efficiently achieve high storage densities. Mechanical compression has an electrical efficiency of approximately $20 \%$. Liquification of hydrogen is technically challenging and requires about $79 \mathrm{~kJ} / \mathrm{mol}$. This amounts to about $1 / 3$ of the LHV (242 $\mathrm{kJ} / \mathrm{mol}$ ) of hydrogen, which means that $33 \%$ of the available energy is consumed by the liquification process. Metal hydride storage can achieve higher efficiencies and higher storage densities, but there are some material problems. Thermal compression by adsorbing hydrogen in a metal hydride bed at a low temperature and desorbing the bed at a higher temperature has a relatively low efficiency, but may be an attractive use for the waste heat from the reformer. There is currently some research in hydrogen storage with carbon nanotube materials that are capable of very dense concentrations at relatively low pressures.

\section{$C$. The hydrogen must be purified before storage}

The hydrogen stream from a reformer typically consists of about $40 \mathrm{~mol} \%$ hydrogen and about 50 PPM of carbon monoxide, with nitrogen, carbon dioxide, water vapor, and methane making up the balance. The carbon monoxide acts as a poison to the fuel cell catalytic membrane. The nitrogen and carbon dioxide are inert diluents that must be removed prior to compression and storage. The energy cost to compress gases that cannot be used to power the fuel cell will be prohibitive. In addition, it is known that PEM fuel cell stacks operate for longer periods of time with fewer maintenance problems when supplied with pure hydrogen. 
There are a number of methods for hydrogen purification including permeable membranes, liquid stripping, and selective adsorption. Each method has advantages and disadvantages in terms of energy cost.

Figure 3.1.1 illustrates some of the issues that must be addressed for hydrogen purification. Assuming that the fuel cell reformer can be separated from the fuel cell assembly and can be operated at full capacity at all times, a continuous stream of reformate would be available. The reformate composition would be approximately 40 mol\% hydrogen, $20 \mathrm{~mol} \%$ carbon dioxide, and $40 \mathrm{~mol} \%$ nitrogen. Using existing technology, such as zeolite-based molecular sieves, the water vapor, carbon dioxide, and nitrogen could be removed. The resulting pure hydrogen stream would be compressed for use at a later time.

As mentioned above, compression is the most technically challenging and energy expensive step in the process. Storage of hydrogen for short-term use in a community fuel cell would not require high pressures. It is possible that a pressure of a few hundred psi would be sufficient for this application. Storage for automotive use would be more challenging, however. In automotive storage tanks, pressures in excess of 5000 psi are not uncommon. To achieve a pressure increase from atmospheric pressure at the reformer outlet to $5000 \mathrm{psi}$ in the hydrogen storage vessel would require an appreciable fraction of the energy available from the hydrogen, either as heat or as electrical power. As with the thermal recovery strategy, selection of the actual hardware components will be affected by a number of site-specific design considerations. These include the following:

- Hydrogen delivery pressure required

- Electrical demand profile (affects amount of reformate available for purification)

- Maximum mass flow rates of inlet and outlet feeds

- Purification bed technology and sizing

- Metalurgical considerations for high purity and high pressure 


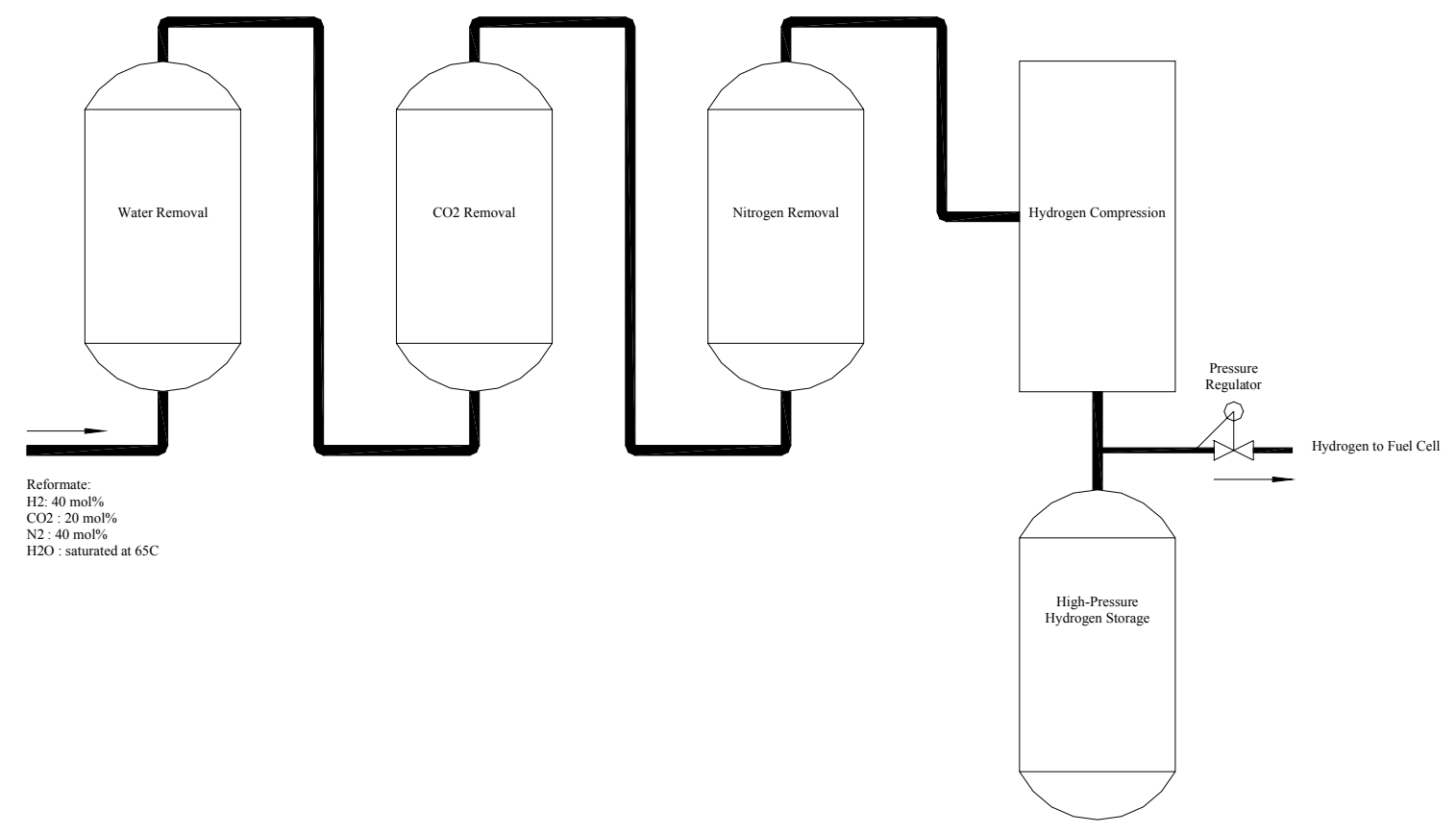

Figure 3.1.1. Schematic of a hydrogen purifier.

Capital Items would include:

- Purification vessels

- Hydrogen storage tank

- Piping

- Instrumentation

- Compressor(s)

Capital costs and installation costs would be amortized over the lifetime of the equipment. A meaningful cost analysis should include the following:

- Cost of system operation

- Power required for compressor operation

- Cost of molecular sieve beds

- Maintenance costs

- Fraction of hydrogen production from the reformer available for purification

The design, construction, and operation of the system would be similar to a chemical processing facility. The technologies to perform hydrogen production and purification exist, but it is difficult to say conclusively if the proposed system is cost effective in the proposed context. 


\subsection{Renewable Sources}

\section{Solar Power}

The basic unit of a solar power system is the photovoltaic cell. The cell is usually rectangular or circular and made of doped silicon. The cells are connected in series to form a module of about $1 \mathrm{~m}^{2}$ and the modules are connected in series to form an array. Cells absorb energy from the sunlight, and convert it to dc electricity. Common properties of available systems are:

- The modules are hail-resistant and produce 100 watts DC power in full sunlight.

- Array sizes are available consisting of 2 to 96 modules.

- Arrays generate 1,200 to 9,600 watts of solar power in full sunlight.

- Pre-engineered rooftop mounting systems can withstand up to $125 \mathrm{mph}$ wind (50 lbs $\left./ \mathrm{ft}^{2}\right)$.

- A high reliability DC-AC inverter continuously converts solar DC current into common household AC current.

- They easily mount above curved or flat tiles and also asphalt shingles.

Solar arrays find application in satellites, remote communications and road signs.

2. Wind Power

Wind power has been in use for decades. These devices consist of a rotor, turbine blades, gear box, generator drive and a generator. The turbine blades vary in length from 10 to $40 \mathrm{~m}$ and can generate from $25 \mathrm{~kW}$ to $1.5 \mathrm{MW}$ of output power.

- Wind power costs as little as three to five cents per kilowatt hour.

- The land used for wind turbines can also be used for other purposes such as grazing and farmland.

-Wind plants can be built quickly to respond to electricity shortages.

- The United States uses about 90 quadrillion BTUs of energy in a year. Most of this electricity is created from fossil fuels like coal, oil and natural gas.

- Wind power provides less than half of one percent of the electricity for the U.S., but could provide much more.

- There is enough wind and windy areas in the U.S. to produce three times as much electricity as the U.S. uses today.

- U.S. winds could generate more electricity in 15 years than all of Saudi Arabia's oil, without being depleted.

- A 1.5 MW wind turbine can produce enough clean electricity for about 400 homes each year.

- A $1.5 \mathrm{MW}$ wind turbine is more than 328 feet tall at its tallest point

- A $1.5 \mathrm{MW}$ wind turbine weighs about 92 tons.

- One blade from the $1.5 \mathrm{MW}$ wind turbine is 112 feet long.

\subsection{Supercapacitors}

\section{The supercapacitor as a supplementary source of energy}

The recent development and advances in electrochemical capacitor (ultracapacitors or supercapacitors) production makes it the most promising device to replace the batteries in fuel cells application. The distinctive features of this type of capacitor are high 
capacitance density $\left(\mathrm{F} / \mathrm{cm}^{3}\right)$ and low voltage as compared to traditional capacitors. The commercially available FCPPs come equipped with storage batteries connected in parallel with the DC bus. These batteries serve as a short period auxiliary power source to meet load demand that cannot be met by the FCPP, particularly during transient periods.

Supercapacitors are a double layer capacitor, with two electrodes immersed in electrolyte. The electrodes are made of a large surface area of porous material with nano-diameter pores. Supercapacitors store energy through charges separation in the pores near the interface between the electrodes and the electrolyte. In [11] and [12], the authors demonstrated the advantages and disadvantage of supercapacitors and batteries. Unlike batteries, which store the energy in form of chemical energy, the supercapacitors directly store energy in electrostatic way. Batteries charge and discharge involves chemical reaction and phase changes, which has a negative effect on the cycle life of batteries. Avoiding chemical reactions and phase changes gives the supercapacitors high degree of recyclability in the order of $10^{5}-10^{6}$ times [12]. One major difference between batteries and supercapacitors is the electrons transfer during charging and discharging process. In batteries, electrons transfer occurs between the electrodes through the electrolyte. On the other hand, in supercapacitors energy stored electrostatically and no electron transfer occur between electrodes, which results in a short recharging time for supercapacitors compared to batteries. While supercapacitors have a high power density, the main disadvantage is the low energy density compared to batteries. In fuel cell residential application where the weight and size of capacitors are not restricted, the low energy problem can be solved using a stack of capacitors to provide the required energy density. Another disadvantage of supercapacitors is the rapid voltage change during charging and discharging periods compared to batteries [12].

\section{Integration of the Supercapacitor with the fuel cell}

In [13] and [14], the supercapacitor is integrated with fuel cell via a dc-dc converter. The block diagram of the fuel cell and the supercapacitor and associated controls are shown in Fig. 3.3.1.

1. The dc-dc converter converts the voltage of the supercapacitor to the dc bus voltage of 48 volts.

2. The converter compensates for the decrease in supercapacitor voltage during the discharge period to guarantee a fixed DC bus voltage of 48 volts.

3. The control circuit decides when to connect the supercapacitor (S3) to provide power to the load.

4. The operation of the switches S1, S2 and S3 follow certain protocols which is described in the next section.

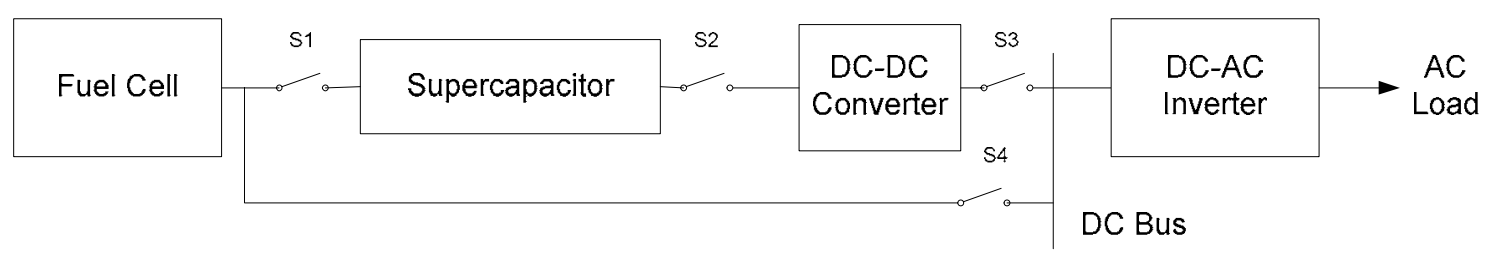

Fig. 3.3.1 Integration of supercapacitor with the fuel cell 


\section{Operation protocol of the supercapacitor and the control circuitry}

Fig. 3.3.1 shows the interconnection between the FCPP, the supercapacitor, the converter and the dc bus through a number of controlling switches. The FCPP feeds dc to the $48 \mathrm{~V}$ $\mathrm{dc}$ bus through $\mathrm{S} 4$. It also feeds dc power to the supercapacitor through $\mathrm{S} 1$. The supercapacitor is connected to the dc converter through S2 and the converter feeds power at $48 \mathrm{~V} \mathrm{dc}$ to the dc bus. Not shown in the block diagram are sensing, limiting and controlling circuits.

The protocol governing switch operation can be explained as follows. S4 is normally closed except for maintenance and intentional interruption of power. Under normal operation, the FCPP will supply power to the load up to its load limit. If the limit is exceeded (extra demand), the supercapacitor is turned on as a supplementary source of power to supply the short fall of load demand. Switch S1 governs the charging of the supercapacitor from the FCPP. S1 is controlled by a variety of sensing and limiting circuits. The voltage limiting circuit opens S1 if the supercapacitor voltage reaches $48 \mathrm{~V}$ or the FCPP voltage deviates from $48 \pm 0.8 \mathrm{~V}$. Switches S2 and S3 are normally open. These switches close when the supercapacitor is called upon to supply supplementary power. The controlling circuit for S2 and S3 is actually a current sensor in the S4 line that causes $\mathrm{S} 2$ and $\mathrm{S} 3$ to close when a certain limiting value of the dc bus current demand is exceeded. S1, S2 and S3 cannot all be closed at the same time to avoid drawing charging power from the FCPP when the FCPP is operating at its maximum power output.

\section{Design of Supercapacitor Stack}

Survey of the literature indicates that for the set-up detailed in Fig. 3.3.1, the supercapacitor can deliver up to $80 \%$ of the energy stored in the capacitor to the load. The commercially available $5 \mathrm{~kW}$, PEM FCPPs are capable of delivering $2.5 \mathrm{~kW}$ for 15 minutes $(1 / 4 \mathrm{hr})$ from the stand-by battery source provided with the FCPP. This amounts to $625 \mathrm{~W}$-hrs of energy. If the batteries in such a unit were to be replaced by a supercapacitor stack the energy capacity of such a stack must have a minimum rating of $625 / 0.8=781.25 \mathrm{~W}$-hrs.

The actual residential load profile, Fig. 3.3.2, of a 2500 sq. ft. house with all electric appliances occupied by 2 adults and 4 children, indicates that the demand exceeds the 5 $\mathrm{kW}$ maximum of the available fuel cell for a maximum period of 15 minutes. The maximum load spikes are between 7 and $7.5 \mathrm{~kW}$. The supercapacitor stack should therefore be able to provide a maximum of $3 \mathrm{~kW}$ for 15 minutes. In [12], the author provides typical performance characteristics of large supercapacitors. To design the required supercapacitor stack, supercapacitors rated 3.0 V, $4000 \mathrm{~F}$ are chosen. Other parameters are: $1.25 \mathrm{~m} \Omega$ resistance, $5.0 \mathrm{~s} \mathrm{RC}$ time, $5.0 \mathrm{Wh} / \mathrm{kg}, 203 \mathrm{~W} / \mathrm{kg}$ at $95 \%$ efficiency, and $1.0 \mathrm{~kg}$ weight. Assuming a $48 \mathrm{~V}$ dc output of the FCPP, the stack will have multiple legs of 16 series connected supercapacitors per leg. The capacitance per leg will be $4000 / 16=250 \mathrm{~F}$. The energy stored in a $48 \mathrm{~V}, 250 \mathrm{~F}$ capacitor is $80 \mathrm{~W}$-hrs. The required energy for the residential load is $3000 \times 0.25=750 \mathrm{~W}$-hrs. To provide the required amount of energy, 10 legs of 16 supercapacitors per leg, should be connected in 
parallel, which provides a total capacitance of $2500 \mathrm{~F}$, and energy of $800 \mathrm{~W}$-hrs. The supercapacitor stack is shown in Fig. 3.3.3.

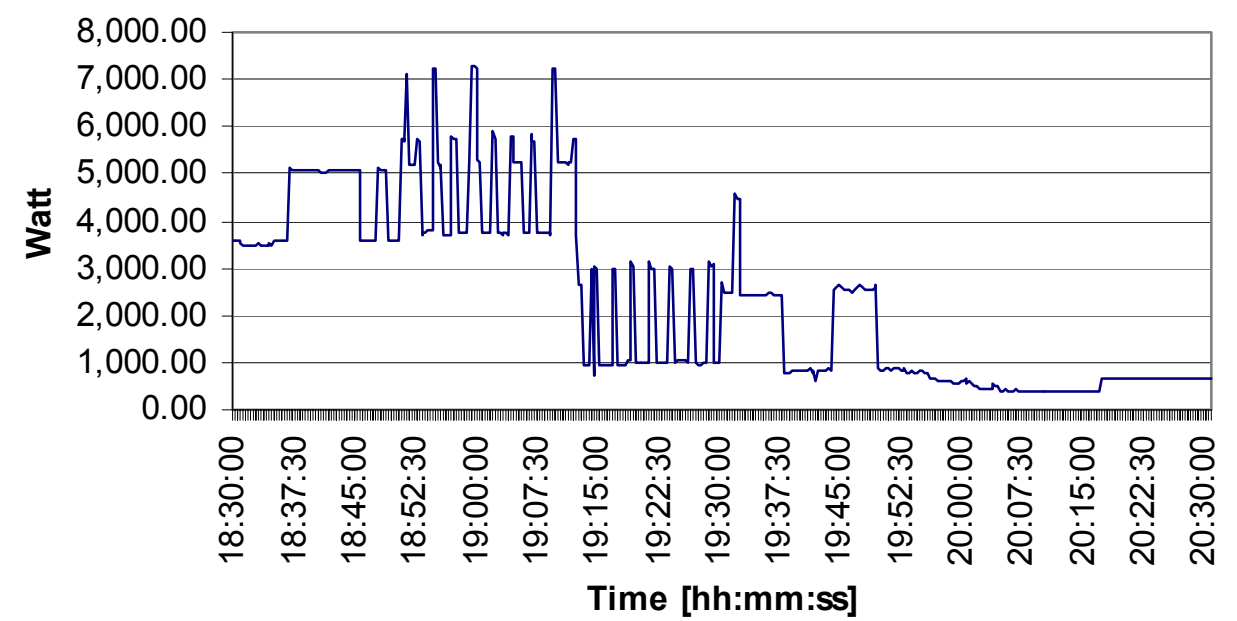

Fig. 3.3.2. Real power of residential load

In the case of the micro-grid with 10 identical homes and a $50 \mathrm{~kW}$ FCPP, the question that arises is this: "Is it justified to extrapolate the $2.5 \mathrm{~kW}$ extra demand for 15 minutes of the $5 \mathrm{~kW}$ FCPP to the $50 \mathrm{~kW}$ FCPP?" Linear extrapolation means an extra demand of 25 $\mathrm{kW}$ for 15 minutes. This appears to be particularly excessive. In the absence of specific load profile and load factor information of the micro-grid, an assumption of $12.5 \mathrm{~kW}$ for a period of 15 minutes (3125 W-hrs.) seems appropriate. Under this assumption and using the stack design for $800 \mathrm{~W}$-hrs., as indicated above, there will be 4 stacks of 800 $\mathrm{W}$-hrs each connected in parallel to meet the extra load demand.

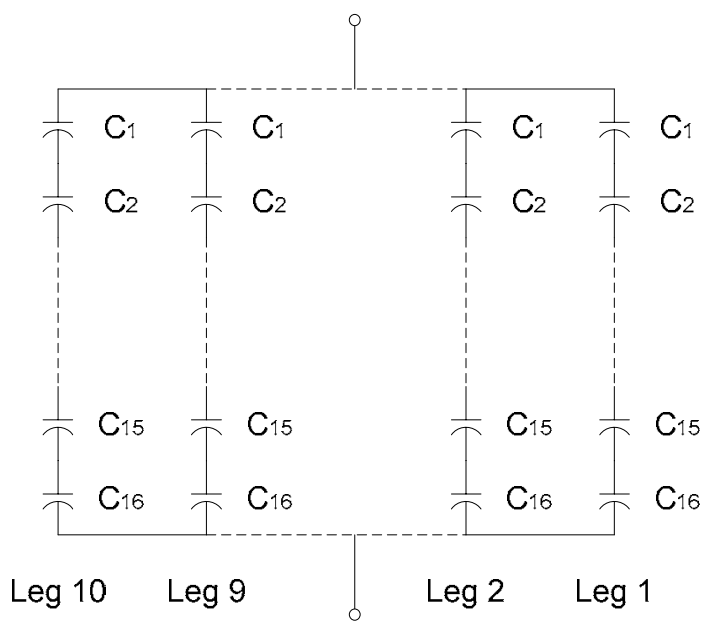

Fig. 3.3.3. Supercapacitor stack arrangement 


\section{System Reliability}

The basic function of any power system is to supply customers with electrical energy as economically as possible and with an acceptable degree of reliability and quality. While satisfying this function, power system should also remain within a set of operational constraints. Some of these constraints relate directly to the quality of supply such as bus voltage variations (voltage sag, voltage swell, voltage transient, etc.), frequency variations and the amount of harmonic component in the system. Power system reliability assessment is, in general, made for two reasons; 1.) Short-term reliability evaluation for daily operation decisions, and 2.) Long-term reliability evaluation for long-range system planning. For this reason, power system reliability assessment can be divided into two main phases, as shown in Fig. 4.1.

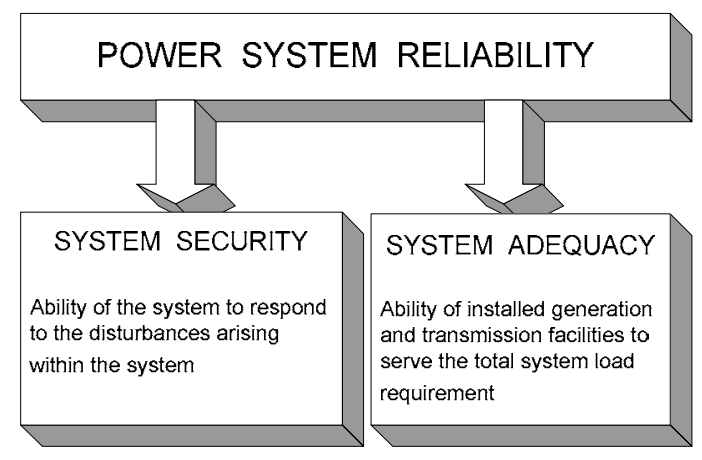

Fig. 4.1. Basic aspects of power system reliability assessment.

According to these definitions, as one would expect, the system adequacy assessment has a direct relationship with power quality, which can be illustrated as in Fig. 4.2.

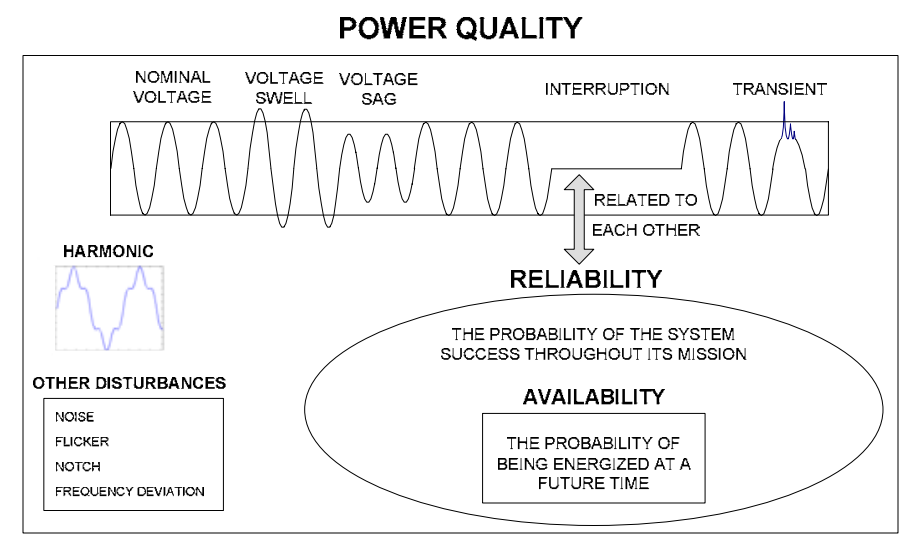

Fig. 4.2. The hierarchical levels of power quality, reliability and availability.

Among the aforementioned disturbances, voltage sag, swell, harmonic distortion and interruptions are the most influential power quality problems, which should be worked out. Computer Business Equipment Manufacturers Association (CBMEA) developed a power acceptability curve to set the limits to the withstanding capabilities of computers. The curve quantifies the acceptability of supply power as a function of duration versus 
the disturbances of bus voltage magnitude. However, the CBMEA curve has become a common standard for all types of equipment and power systems performance measurement. This CBMEA curve has recently been updated by Information Technology Industry Council and renamed as ITIC curve, shown in Fig. 4.3.

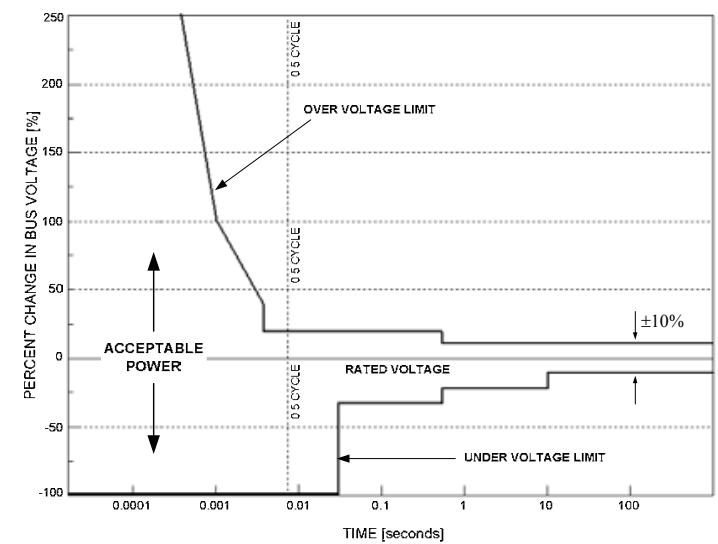

Fig. 4.3. ITIC voltage tolerance curve.

Line to voltage rms magnitude versus duration scatter plot will be evaluated based on the ITIC curve for the monitoring period at grid-connected fuel cell (FC) house built in University of South Alabama. Another important power quality problem is harmonics distortions in supply waveform, which caused by non-linear elements in the system. Furthermore, the Total Harmonic Distortion (THD) at the FC house will be tested according to the 5\% IEEE-519 limits.

\subsection{Reliability Modeling of Grid-Connected PEM Fuel Cell (PEMFC) Power Plants}

Since the considered power supply system consists of both PEMFC and Grid that supply residential loads (10 houses) through a transformer, the simple system reliability model can be depicted as in Fig. 4.1.1.

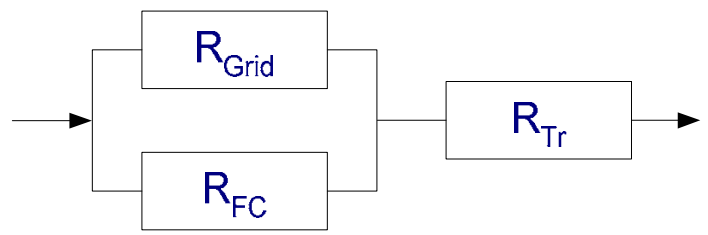

Fig. 4.1.1. Reliability model of grid-connected FC system.

The solution process of the proposed algorithm is as follows:

i. Modeling of individual reliabilities of PEMFC and grid.

ii. Determination of PEMFC and grid reliabilities, individually.

iii. Calculation of entire system reliability by combining the step-ii reliabilities based on the Fig. 4.1.1 as follows : 


$$
R_{s y s}=\left[1-\left(1-R_{\text {Grid }}\right) \cdot\left(1-R_{F C}\right)\right] \cdot R_{T r}
$$

Although the aforementioned solution process seems simple, the whole process in calculating the entire system reliability is quite complex. This is because of the fact that both FC and grid are subject to a number of different factors that affect system reliability. The reliability indices for grids such as failure rate, outage duration etc. vary for different time period due to weather conditions, power demands variety and random faults. Besides, FC power plants are subject to a number of possible outage and derated states due to partial or full failure of auxiliaries. Hence, it is essential to obtain the estimation of reliability under all environmental, operational and loading conditions.

\subsection{Reliability Modeling of PEMFC Power Plants}

FC power plants are subject to a number of possible outage and derated states due to partial or full failure of auxiliaries [15-18]. Derated state here means that the unit may not be able to develop full rated capacity for some reasons. Some FC failure modes are fuel quality deterioration, membranes drying out (insufficient humidification), overheating, passages clogging up with water, and freezing of water in humidification channels etc. In addition, after a certain operation time period, the mechanical parts could experience deformations like cracks, breakdowns and holes in radiator, pump and fan blades due to fatigue, wear-out and stresses, which may result in insufficient parameter control.

Furthermore, electrical motor and/or electrical drives to control system parameters such as pump and fan speeds may malfunction as well due to failures in control circuits. For these reason a number of components and auxiliaries in FC system may cause to partial or total system outage. In this case, general state-space model of the FC generating unit can be depicted as in Fig. 4.2.1, where $\lambda$ is failure rate and $\mu$ is repair rate. In Fig. 4.2.1, while the indices $i=1,2, \cdots, k$ represent the number of components that cause unit failure, the indices $j=1,2, \cdots, m$ represent the number of components that affect derating level of the unit.

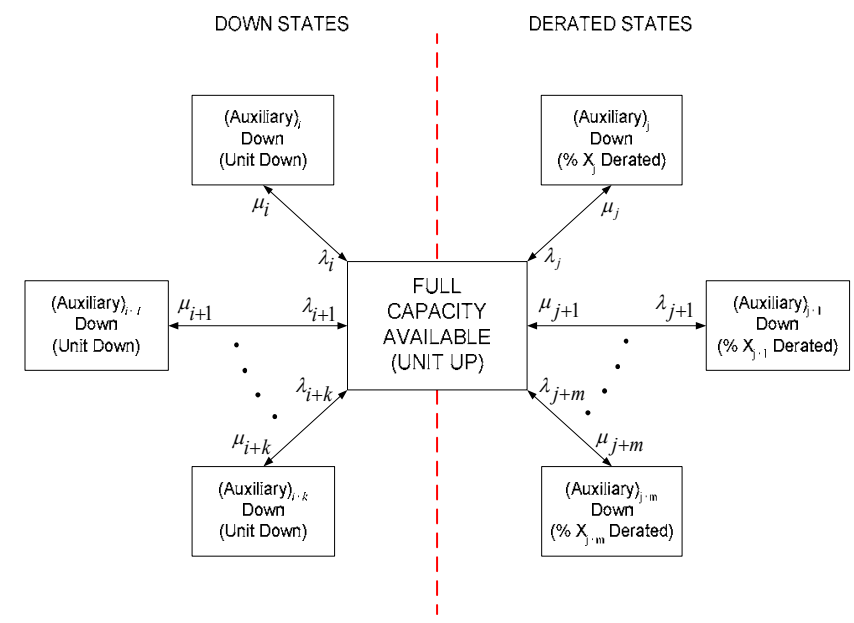

Fig. 4.2.1. The state-space model of the generating unit. 
In this section, some of the important auxiliaries and their effects on overall FC system performance are discussed. It should be useful to give here a PEMFC system block diagram as shown in Fig. 4.2.2.

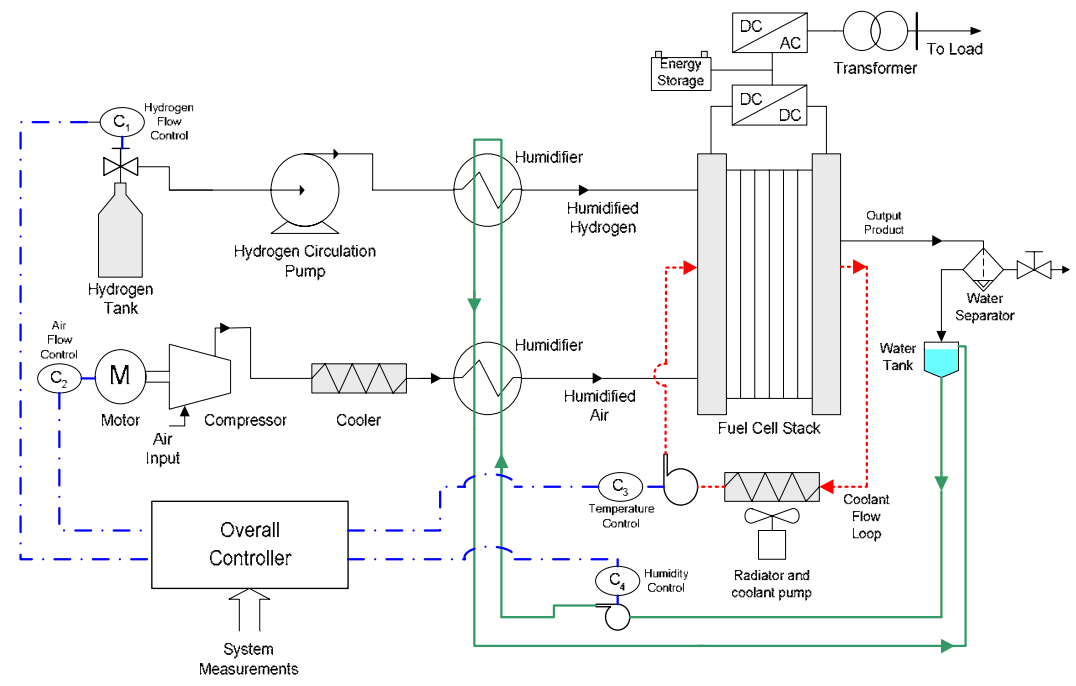

Fig. 4.2.2. PEMFC system block diagram.

As shown in Fig.4.2.2, the FC system includes the FC stack, plus all the auxiliary equipment such as air compressors, pumps, humidification equipment, coolers and control electronics. During normal operation, the FC system components such as compressor, fans, pumps, motors, temperature and humidity sensors, relays, and other control electronics could contribute to a system failure or derated mode by different reasons such as ignition of any leaking hydrogen, material fatigues, wear outs, break downs, membrane drying out, overheating, and freezing of water in channels [18] etc. If any of the components go beyond its operating limits for some reasons, the output of them will be reduced by a factor. For instance, insufficient circulating coolant flow due to the failure of coolant water pump may cause the nominal output to be reduced. Certain other failures may cause either a reduction in nominal output power or total system outage.

As a result, reliability modeling of PEMFC system is formed based on the failure modes of system auxiliary components. The failure and repair rates in the state-space generation model of a PEMFC are estimated based on the assumption that failure and repair rates of the components change with operation age of FC. The functional relationship between operational age of FC and state of health of auxiliary devices (failure modes) is estimated based on the fuzzy set theory and expert knowledge. It is assumed that possible wear out period (component failure or loss of performance period) starts after 5000 hours operation and continues to maintenance time, typically one year and this process is repeated at regular maintenance intervals with a difference that the repair times and the duration of maintenance increase at each cycle while state of health of the auxiliary components decreases. 


\subsection{Development of Reliability Model for PEMFC}

Possible results of aforementioned auxiliary failures are considered here rather than failure modes itself to calculate the effects of performance reduction in FC sub-systems on overall FC performances. Let us assume that there are insufficiencies associated with FC sub-systems due to any reduction in their performance. Following sections discusses how overall FC system performance is affected, and then how they can be demonstrated as a FC generation model in terms of state-space representation in these cases.

It should be useful to give here the PEMFC DC stack voltage with all irreversibilities, which is expressed as [19]

$$
V_{\text {stack }}=V_{\text {open }}-V_{\text {ohmic }}-V_{\text {activation }}-V_{\text {concentration }}
$$

where

$$
\begin{aligned}
& V_{\text {open }}=N_{0} \cdot\left(E^{0}+E^{1}\right)=N_{0} \cdot\left[-\frac{\Delta \bar{g}_{f}^{0}}{2 F}+\frac{R T}{2 F} \ln \left(\frac{p_{H_{2}} \cdot \sqrt{p_{O_{2}}}}{p_{H_{2} O}}\right)\right] \\
& V_{\text {ohmic }}=\left(i+i_{n}\right) \cdot R_{F C}=I_{\mathrm{dc}} \cdot R_{F C} \\
& V_{\text {activation }}=N_{0} \cdot \frac{R T}{2 \alpha F} \cdot \ln \left(\frac{I_{\mathrm{dc}}}{I_{0}}\right) \\
& V_{\text {concentration }}=-c \cdot \ln \left(1-\frac{I_{\mathrm{dc}}}{I_{\mathrm{Lim}}}\right)
\end{aligned}
$$

$N_{0} \quad$ : Cell number

$V_{0} \quad$ : Open cell voltage [V]

$E^{0} \quad:$ Cell emf at STP $\left(25^{\circ} \mathrm{C}\right.$ and $\left.1 \mathrm{~atm}\right)[\mathrm{V}]$

$\Delta \bar{g}_{f}^{0} \quad$ : Change in Gibbs free energy at STP

$R \quad: \quad$ Universal gas constant $[8.1345 \mathrm{~J} / \mathrm{mol} / \mathrm{K}]$

$T \quad$ : Temperature of the FC stack [K]

F : Faraday's constant [96485 C/mol]

$p_{H_{2}}$ : Hydrogen partial pressure [atm]

$p_{\mathrm{H}_{2} \mathrm{O}}$ : Water partial pressure [atm]

$p_{\mathrm{O}_{2}} \quad$ : Oxygen partial pressure [atm]

$\alpha \quad$ : Charge transfer coefficient of the electrodes

$I_{\mathrm{dc}} \quad$ : Current of the FC stack [A]

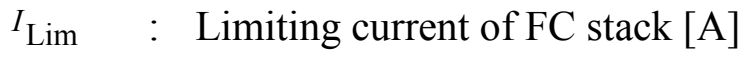

$I_{0} \quad:$ Exchange current density $\left[\mathrm{A} / \mathrm{cm}^{2}\right]$

c : Empirical coefficient for concentration voltage

The total stack power is defined as $P=V_{\text {stack }} \cdot I_{d c}$ 


\subsection{Cooling System}

Operating temperature of the $\mathrm{FC}$ will change by $\Delta T$ as shown in Eq. (4.4), if there is an insufficient cooling due to loss of performance in coolant system.

$$
\dot{T}=T+\Delta T
$$

where $\dot{T}$ denotes the new operating temperature. Augmentation in temperature leads to reduction in FC output voltage due to the fact that Gibbs free energy, which is a chemical energy and converted into electrical energy, changes inversely with temperature. This effect can simply be given by Eq. (4.5).

$$
\dot{V}_{\text {stack }}=V_{\text {stack }}-\Delta V
$$

The other effects of $\Delta T$ temperature change are as follow: $i$.) Resistive voltage loss, $V_{\text {ohmic }}$ tends to increase at higher temperature due to dry out mode of the FC stack. ii.) Activation voltage loss, $V_{\text {activation }}$, will be increased as well due to the constant of $\frac{R T}{2 \alpha F}$ in the equation. ii.) The only decrease takes place at concentration voltage loss due to minus coefficient of $\frac{R T}{2 F}$ in $V_{\text {consentration }}$ expression. However, \% voltage loss reduction in $V_{\text {consentration }}$ will be smaller than a percent voltage loss increase in $V_{\text {activation }}$ due to coefficient $\alpha$ that takes value between zero and one, generally $\alpha=0.5$. Hence, a decrease of maximum power level will be observed for higher temperature as shown in Eq. (4.6).

$$
\dot{P}=P-\Delta P
$$

where $\Delta P=\Delta V \cdot I_{\mathrm{dc}}$. As a consequence, due to temperature increase because of insufficient cooling, there is a certain reduction in power supplying capacity of FC, proved both theoretically and experimentally, is calculated as follow:

$$
R P_{C}[\%]=\frac{P-\Delta P}{P} \times 100=\frac{\dot{P}}{P} \times 100
$$

where $R P_{C}$ is the percent reduction in power supplying capacity of FC due to in sufficient cooling. If $\mathrm{FC}$ coolant system is completely fails rather than partial failure or if its failure leads instability in FC operation with a following emergency stop function to shut of the system, then the system will be passed to off state. This phenomenon can be represented by a state-space model as shown in Fig. 4.4.1.

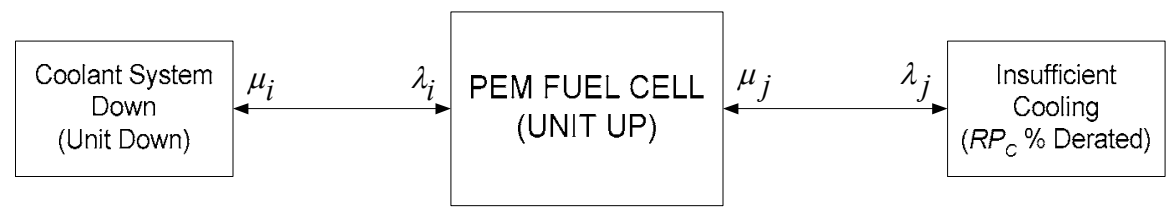

Fig. 4.4.1. The effect of cooling system failure on FC generation in terms of state-space representation. 


\subsection{Humidification System}

PEMFCs are quite sensitive to the humidity of the reactant gases, and any excess liquid water from the humidification process that flows into the FC can reduce the output power capacity and possibly cause stack damage. The loss of performance is mainly caused by internal ohmic resistance increase resulted from drying-out of the membrane (insufficient humidification). In various studies, it is proved experimentally that after membrane dryout mode, the magnitude of the FC stack impedance is increased. This change can be expressed as

$$
\dot{R}_{F C}=R_{F C}+\Delta R
$$

However, the reduction level in FC output power is dependent upon the severity of insufficient humidification. The resistive voltage loss, $V_{\text {ohmic }}$ increases in proportion to FC stack resistance, which leads output voltage reduction and accordingly power reduction. Another effect of insufficient humidification is on the partial pressure of the reactants. Since humid reactants are a mixture of dry gasses and vapor, dry partial pressure is the difference between total pressure and the vapor pressure, which is given as

$$
\dot{p}_{T}=p_{T}-p_{v}
$$

Since humidity ratio, $\phi$ is expressed as the ratio of partial pressure of water vapor, $p_{v}$ to saturation pressure, $p_{s}$ then the vapor pressure, $p_{v}$ can be written as

$$
p_{v}=\phi \cdot p_{s}
$$

If Nernst voltage, $V_{\text {open }}$ re-written in terms of total system pressure, $p_{T}$

$$
V_{\mathrm{open}}=E^{0}+\frac{R T}{2 F} \cdot \ln \left(\frac{w \cdot \sqrt{x}}{y}\right)+\frac{R T}{4 F} \ln \left(p_{T}\right)
$$

where $w, x$ and $y$ are the constants related to molar masses and concentrations of $\mathrm{H}_{2}$, $\mathrm{O}_{2}$ and partial pressures are $p_{\mathrm{H}_{2}}=w \cdot p_{T}, p_{\mathrm{O}_{2}}=x \cdot p_{T}, p_{\mathrm{H}_{2} \mathrm{O}}=y \cdot p_{T}$.

As it can be seen from Eq. (4.11) that if the total system pressure, $p_{T}$ is reduced to $\dot{p}_{T}$ as in Eq. (4.9), then the open circuit voltage and correspondingly output voltage will be reduced by $\frac{R T}{4 F} \ln \left(p_{T}-\dot{p}_{T}\right)$.

Let us assume that $R P_{H}$ is the percent reduction in power supplying capacity of FC due to insufficient humidification, then, the state-space model of this event can be represented as in Fig. 4.5.1. Possible stack failure due to lack of humidification is not considered in the model. 


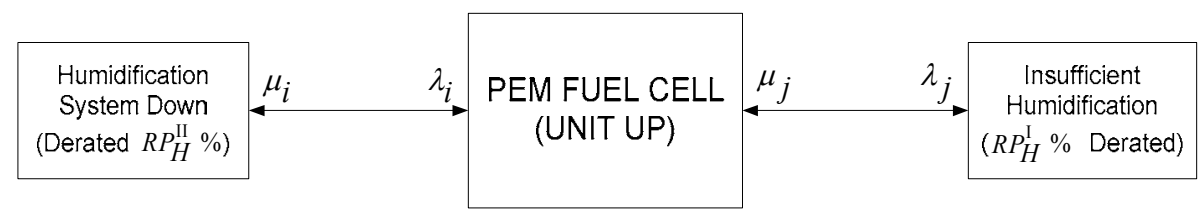

Fig. 4.5.1. The effect of humidification system failure on FC generation in terms of statespace representation.

\subsection{The Hydrogen Circulating System}

For the PEMFC, the cell must be supplied by continuous fuel of hydrogen as pure as possible to provide energy output. As well as some mechanical wear outs and control malfunction, degeneration of pure hydrogen may be the cause of any possible reduction in state of health of hydrogen supply that leads to derated states of FC unit.

Since hydrogen has a direct effect on the system output power, It is good to start from basic operation of the FC. We know that $Q=2 F \times w_{H_{2}}$, where $Q$ is the charge and $w_{H_{2}}$ is the amount of hydrogen in mol. Since $Q=I_{\mathrm{dc}} \times t$, then $I_{d c}=2 F \times \frac{w_{\mathrm{H}_{2}}}{t}$. If we re-write this expression by equating the $q_{\mathrm{H}_{2}}=\frac{w_{\mathrm{H}_{2}}}{t}$, then we get

$$
I_{\mathrm{dc}}=2 F \times q_{\mathrm{H}_{2}}
$$

where $I_{\mathrm{dc}}$ is the total stack current and $q_{\mathrm{H}_{2}}$ is the molar hydrogen usage per second. If stack current is written in terms of total stack power, then we get $I_{\mathrm{dc}}=\frac{P}{V_{\text {stack }}}$. Substituting this expression into Eq. (4.12)

$$
P=2 F \cdot q_{H_{2}} \cdot V_{\text {stack }}
$$

It is evident from Eq. (4.13) that $\mathrm{FC}$ output power will decrease as much power as $\Delta P$ as in Eq. (4.14) if there is a $\Delta q_{H_{2}}$ reduction in maximum designed level of pure hydrogen.

$$
\Delta P=2 F \cdot \Delta q_{H_{2}} \cdot V_{\text {stack }}
$$

As a result, percent reduction in power supplying capacity of FC due to insufficient hydrogen usage can be calculated as follow:

$$
R P_{q}[\%]=\frac{q_{H_{2}}-\Delta q_{H_{2}}}{q_{H_{2}}} \times 100=\frac{\dot{q}_{H_{2}}}{q_{H_{2}}} \times 100
$$

The state-space model in Fig. 4.6.1 illustrates this event. 


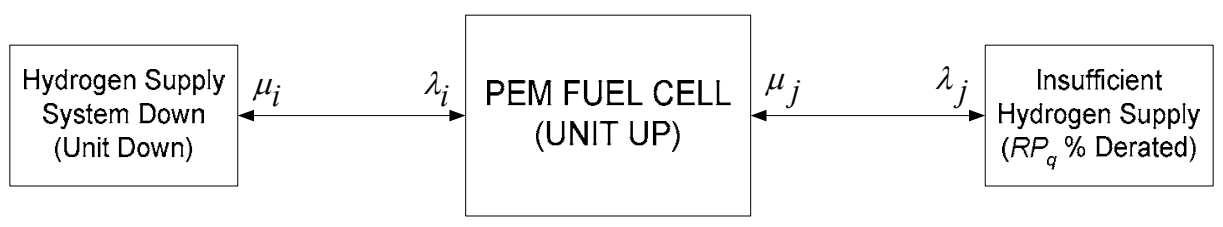

Fig. 4.6.1. The effect of hydrogen supply system failure on FC generation in terms of state-space representation.

\subsection{Air Circulating System}

The FC is supplied with air to complete the reaction. Indeed, the oxygen derived from air is used for reaction completion. The molar oxygen usage of the FC per second, $q_{\mathrm{O}_{2}}$ for a given power can then be computed as below by following the way, of which hydrogen usage is calculated.

$$
q_{O_{2}}=\frac{P}{4 F V_{\text {stack }}}
$$

This equation can easily be adopted to air usage by multiplying the $q_{\mathrm{O}_{2}}$ with 0.21 since oxygen is available in the air mixture with the ratio of $21 \%$. However, it is not practical to consume all oxygen amounts entering the FC stack. Hence, in real applications, the FCs are supplied with air more than enough, typically as much as twice [20]. For this reason, the blower and the compressor are sized so that the excess oxygen ratio $\gamma$ is equal to 2 , where

$$
\gamma=\frac{\text { supplied rate of } \mathrm{O}_{2}}{\text { reacted rate of } \mathrm{O}_{2}}
$$

Since oxygen is supplied more than reaction needs, system output will not be affected unless partial pressure of oxygen drops below a certain threshold value. If oxygen partial pressure falls below the critical level, FC will experience oxygen starvation event, which may cause to catastrophic membrane failure. Before the system reaches this jeopardous stage, an emergency stop function will either isolate the system from load or shut down the system. Hence, none of the failure mode in airflow circulation leads to any derated state but results in FC system failure or system will not be affected. The state-space model in Fig. 4.7.1 demonstrates this event.

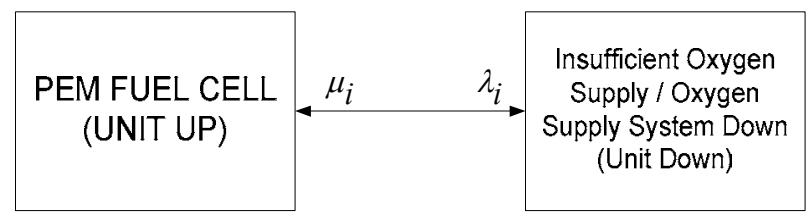

Fig. 4.7.1. The effect of oxygen supply system failure on FC generation in terms of statespace representation. 


\subsection{Energy Storage System}

The flow rate of hydrogen is controlled continuously in order to follow the electrical load variations. However depending upon FC system type, this flow rate adjustment can be achieved with a time delay, ranging from some microseconds to 30 -seconds. For that reason, some type of energy storage is needed for fast transient response and meeting the peak load requirement.

In this application, we considered super-capacitor as energy storage and contrary to batteries they can cycle hundreds of thousands of charges and discharges without performance degradation [11], [12], [21]. Therefore, we did not consider performance degradation of energy storage in the report.

\subsection{Other Components}

Other system components such as reformer stack, power conditioner and transformer can be considered to be essential components for the system power supply and it can be assumed that any of these component failures bring the system down state. However, stack performance has gradual performance deterioration rather than catastrophic failures. As the electrodes and electrolyte become older, FC output voltage, accordingly its power drops steadily with the time. This situation can be given as decline of voltage in units of $\mathrm{mV} /$ hour or percent power deterioration per hour. This is more important generally for stand-alone FC systems.

\subsection{Estimation of Transition Probabilities and Aging Effects}

It is assumed that system auxiliary components failure or performance loss take place after some time operation of FC, typically after 5000 hours. In other word, it is based on the assumption that the failure rate of the auxiliary component changes with age of the component. In this report, failure rates of the components increase with time until maintenance, and the failure rate dropped to its original value after maintenance. It is also assumed that maintenance is performed at regular intervals, and the repair times and the duration of maintenance increase when the components grow older.

Another aspect we considered is that the state of health of the auxiliary components becomes worse in proportion to component aging. The principle plot of failure rate as a function of time is shown in Fig. 4.10.1. 


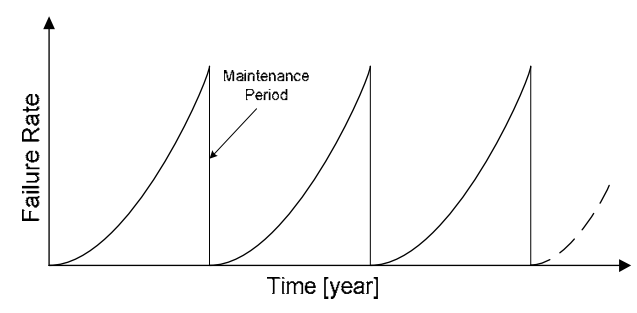

Fig. 4.10.1. Component failure rate versus time for regular maintenance periods.

The relationship described above is estimated by Weibull model. The Weibull model is proving to be a practical tool for the modeling of aforementioned component aging [22]. The Weibull distribution and its failure rate are:

$$
\begin{aligned}
& f(\mathrm{~T})=\frac{\beta \mathrm{T}^{\beta-1}}{\alpha^{\beta}} \cdot e^{-(\mathrm{T} / \alpha)^{\beta}} \\
& \lambda(\mathrm{T})=\frac{\beta \mathrm{T}^{\beta-1}}{\alpha^{\beta}}
\end{aligned}
$$

where $\mathrm{T}$ is the component age (or time from last overhaul), $\beta$ is the shape factor which determines how the failure rate changes with equipment age (if $\beta<1$ the failure rates decreases with age, if $\beta=1$ the failure rate is independent of age, and if $\beta>1$ the failure rate increases with age), and $\alpha$ is characteristic time interval. Since FC technology is so young and there is no publicly available data associated with the failures of FC system, a fuzzy logic rule base system is formed based on the expert knowledge to determine the performance loss of system auxiliary. In this perspective, the rule format for non-healthy state level and associated membership functions are given as in Table 4.10.1 and Fig. 4.10.2, respectively.

Table 4.10.1 The general format of the rule for component state of health determination

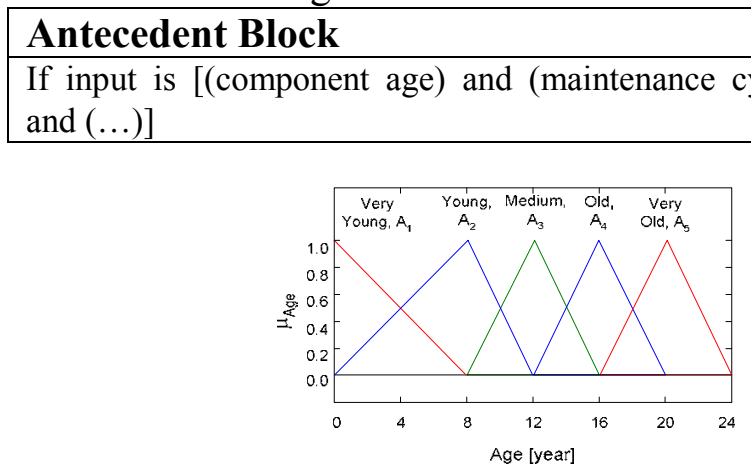

(a)

\section{Consequent Block}

Output is (State of health of component/Degree of failure severity)

Fig. 4.10.2. FC system component aging model.

\subsection{Grid Reliability}

The failure and repair rates vary from time to time according to weather conditions since the power system faults and their repair time are related to environmental conditions. The 
data in ref [23] is used for grid reliability, which are derived by considering past data and expert knowledge. In the reference, the reliability variation is given versus weather temperature. These reliability data are obtained from past behavior of failure and repair rates.

\subsection{Reliability Calculation}

Normally the reliability of the system in Markov models is the summation of operating states probabilities as shown below:

$$
R=\sum_{i=1}^{n} P_{i}
$$

where $P_{i}$ is a row vector and shows operating state probabilities. However, our concern is related to both up and derated states. If these states probabilities are grouped in the vector, then $P_{i}$ is

$$
P_{i}=\left[\begin{array}{llll|llll}
P_{1}^{u} & P_{2}^{u} & \cdots & P_{m}^{u} & P_{m+1}^{d} & P_{m+2}^{d} & \cdots & P_{n}^{d}
\end{array}\right]_{1 \times n}
$$

where " $u$ " represent the up states and " $\mathrm{d}$ " represent the derated states. Derated state means that the unit may not be able to develop full rated capacity. That's why derated states probabilities must be reduced by a reduction factor appropriate to the deratings. Let us define a correction vector, $C_{i}$ in order to take this effect into calculation.

$$
C_{i}=\left[\begin{array}{llll|llll}
1 & 1 & \cdots & 1 & c_{1} & c_{2} & \cdots & c_{n}
\end{array}\right]_{1 \times n}^{T}
$$

where $c_{i}=1-R P_{i}^{\%}$ and $R P_{i}^{\%}$ is percent power reduction corresponding to each derated state.

Hence, individual reliability of the system elements can be calculated by

$$
R=\left[P_{i}\right]_{1 \times n} \cdot\left[C_{i}\right]_{n \times 1}
$$

Afterward, individual FC and grid reliabilities are combined to get whole system reliability using Eq. (4.1). 


\subsection{Proposed Micro-Grid System}

Grid-Connected 50kW PEMFC power supply system that provides 10 houses with electric energy is considered. There are two basic distribution network configurations for the considered micro-grid, which are radial and ring network structures as shown in Fig. 4.13.1.

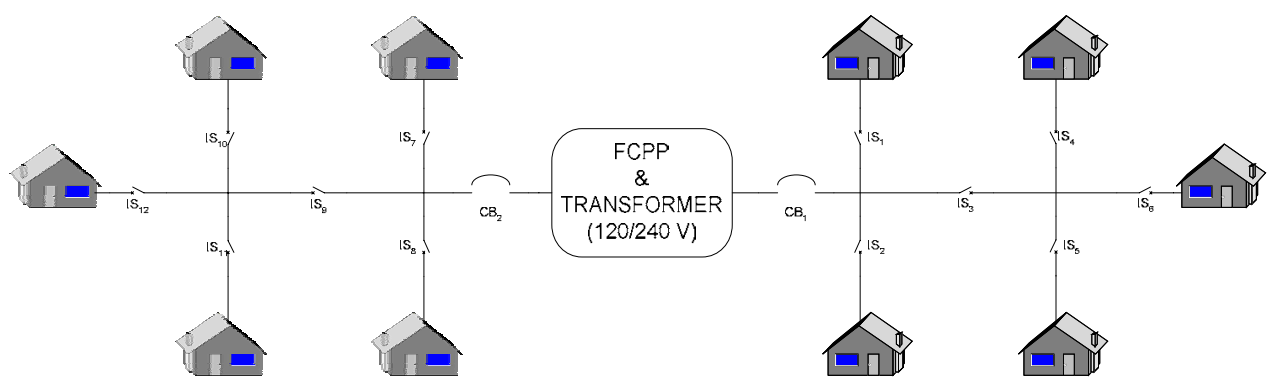

(a)

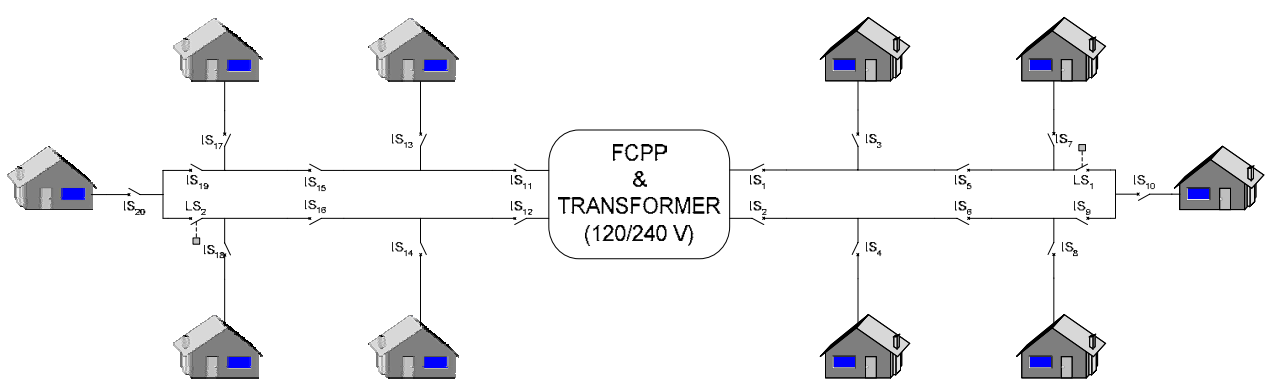

(b)

Fig. 4.13.1 Possible micro-grid configurations (a) radial feeding design (b) ring network

Operational security is relatively low in distribution networks with radial feeding design. However, distribution network security can significantly be enhanced with ring network structure whose usage is growing mostly in city centers. While the configuration in Fig. 4.13.1(a) is the most economical one, Fig. 4.13.1(b) is the most reliable one.

Consequently, complete reliability model of the micro-grid system for radial and ring feeding design can be depicted as in Fig. 4.13.2 (a) and (b) respectively. In the model, the overlapping possibility of two or more failure is neglected. 


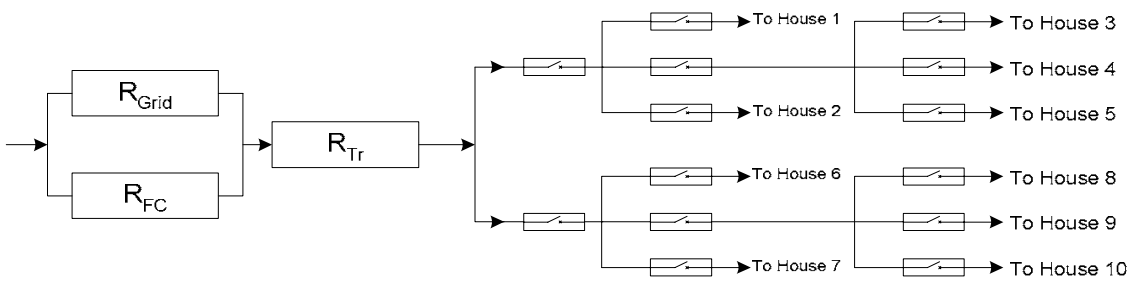

(a)

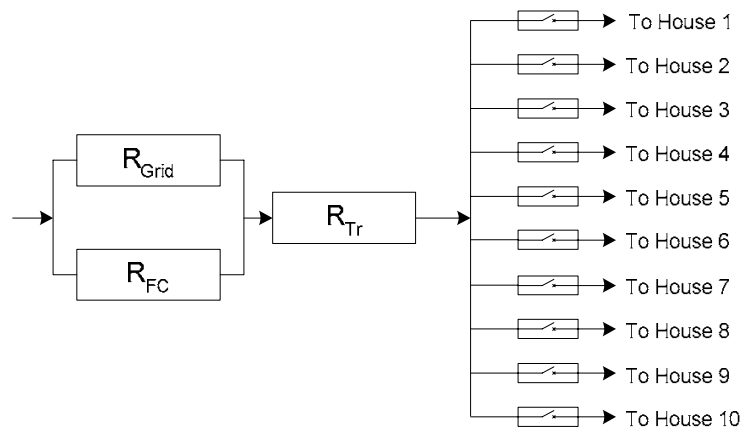

(b)

Fig. 4.13.2. Reliability model of micro-grid system design (a) radial feeding design (b) ring feeding design.

\subsection{Simulation Results}

The simulation studies have been conducted to cover different aspects of the system operation. The simulation of grid reliability variations for multiple weather conditions based on temperature is calculated in Ref [18]. Reliability variation of the grid versus weather temperature is given in Fig. 4.14.1 by an increased number of temperature levels.

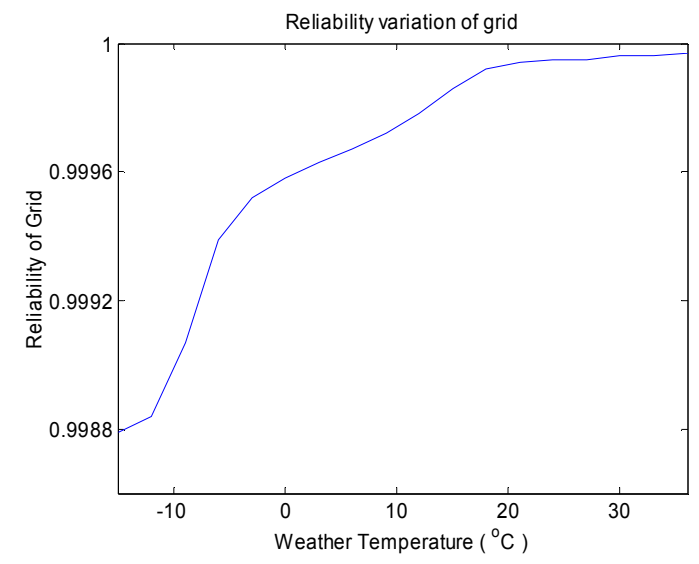

Fig. 4.14.1. Reliability variation of grid versus weather temperature. 
The simulation of FC reliability variations using proposed approach is carried out for different operation of lifetime, as shown in Fig. 4.14.2. In Fig. 4.14.2, FC degradation and energy storage capacity is not considered. While instantaneous FC reliability for ten years operation period is given respectively from bottom to top in Fig. 4.14.2(a), steadystate reliability variation of FC versus year is given in Fig. 4.14.2(b).

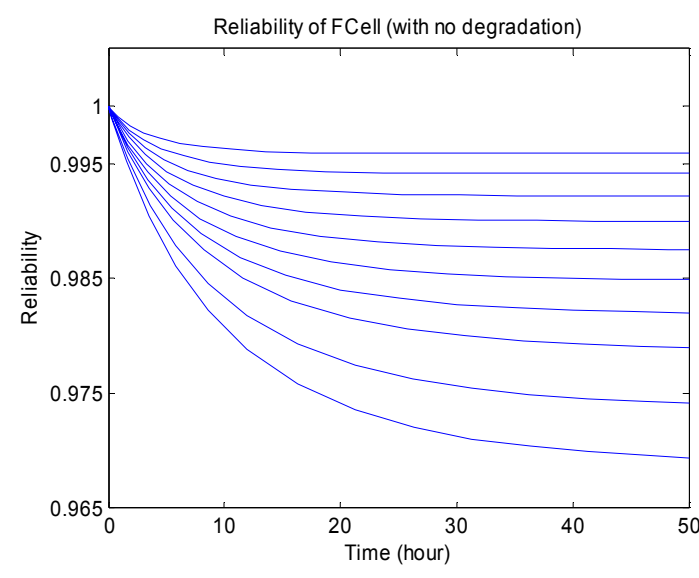

(a)

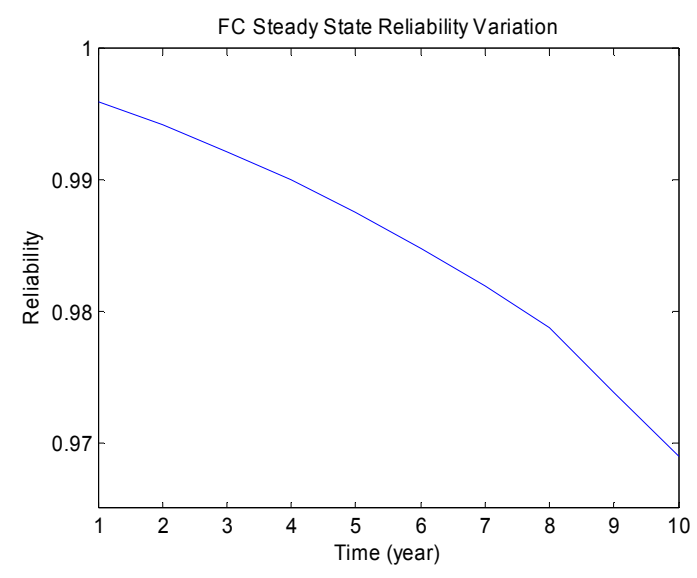

(b)

Fig. 4.14.2. Reliability variation of FC, (a) instantaneous FC reliability for $1,2, \ldots, 10$ years (from upper to lower lines respectively) (b) reliability variation of the FC versus year.

Stand-alone FC system reliability with the consideration of $\% 0.5 \mathrm{~kW}$ degradation per 1000 -hour and $16 \mathrm{kWh}$ super-capacitor bank is given for the peak loads of $55 \mathrm{~kW}$ and below as shown in Fig. 4.14.3.

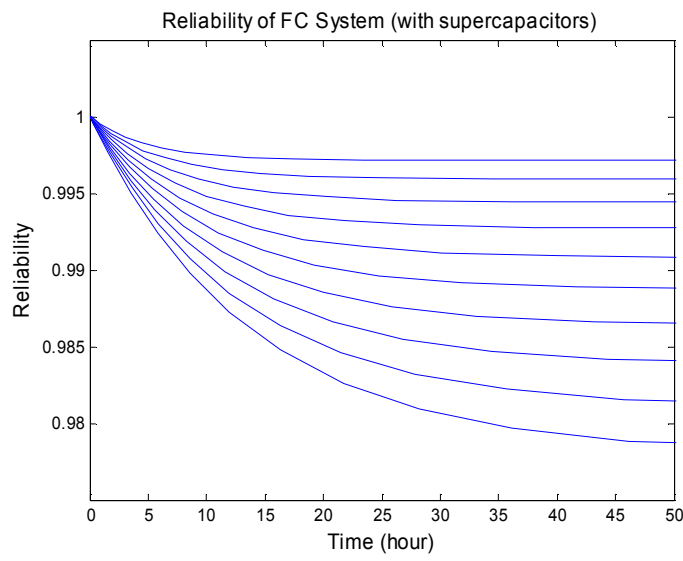

(a)

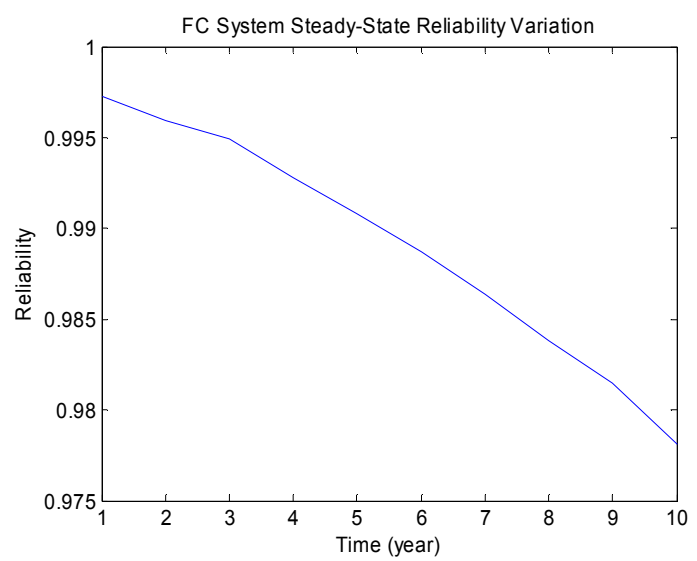

(b)

Fig. 4.14.3. Reliability variation of FC, (a) instantaneous FC reliability for $1,2, \ldots, 10$ years (from upper to lower lines respectively) (b) reliability variation of the FC versus year. 
Stand-alone FC system reliability with the consideration of $\% 0.5 \mathrm{~kW}$ degradation per 1000 -hour and $16 \mathrm{kWh}$ super-capacitor bank is given for the peak loads of $60 \mathrm{~kW}$ as shown in Fig. 4.14.4.

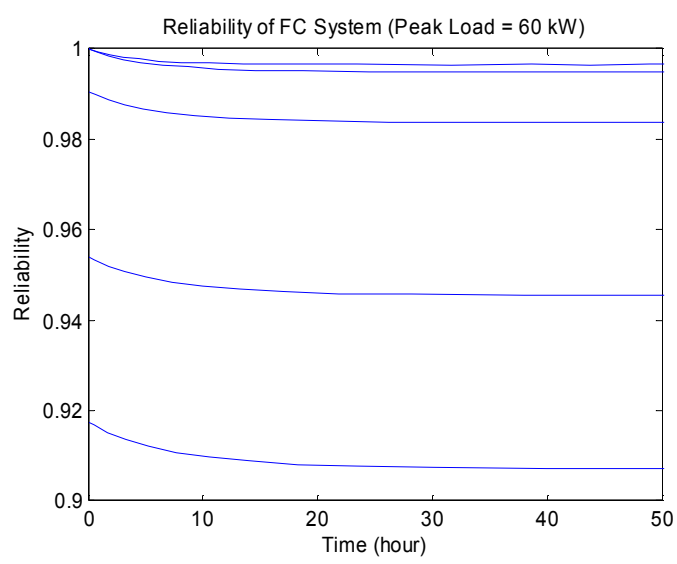

(a)

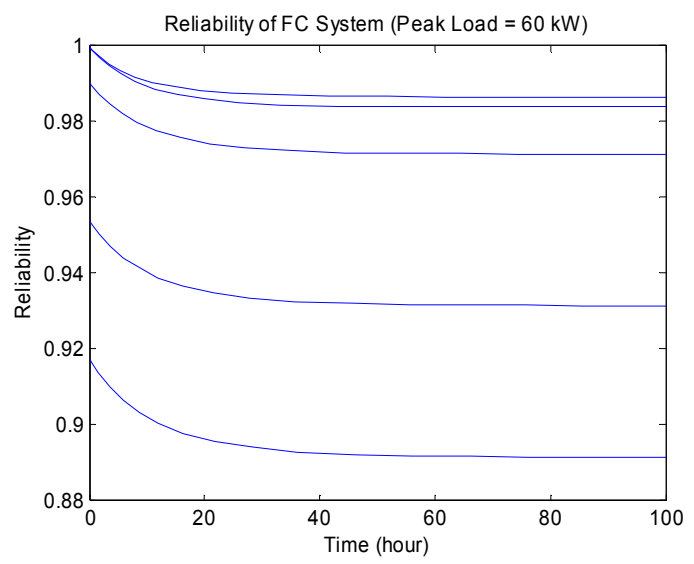

(b)

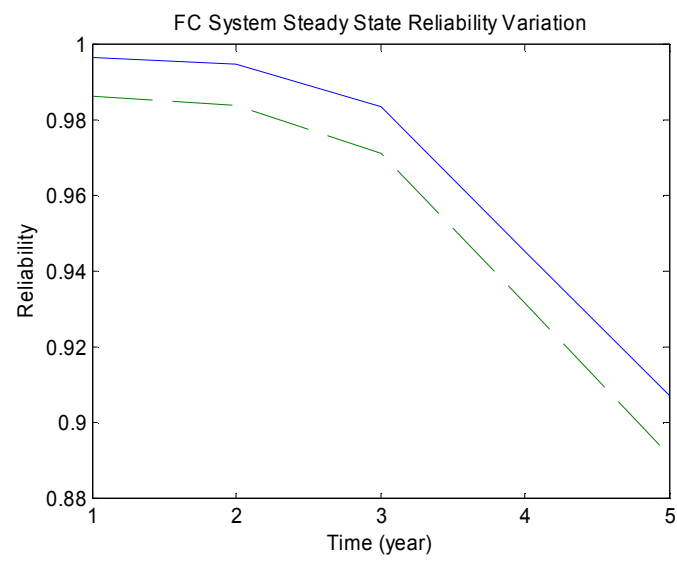

(c)

Fig. 4.14.4. Reliability variation of FC, (a) instantaneous FC reliability for 1 to 5 years, (b) 6 to 10 years (from upper to lower lines respectively) (c) reliability variation of the FC versus year (solid line: first 5 year period, dashed line second: 5 year period).

Similarly, Fig. 4.14 .5 (a) \& (b) shows the FC steady-state reliability variations for the peak load of 65 and $70 \mathrm{~kW}$ over ten year period, respectively. 


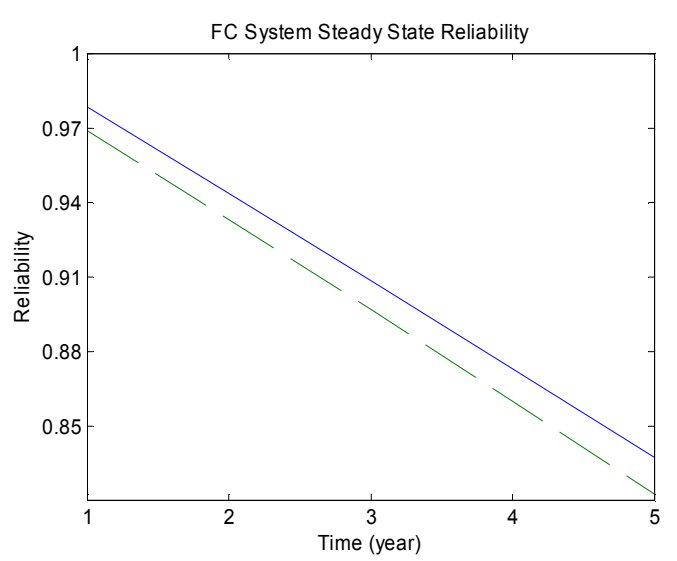

(a)

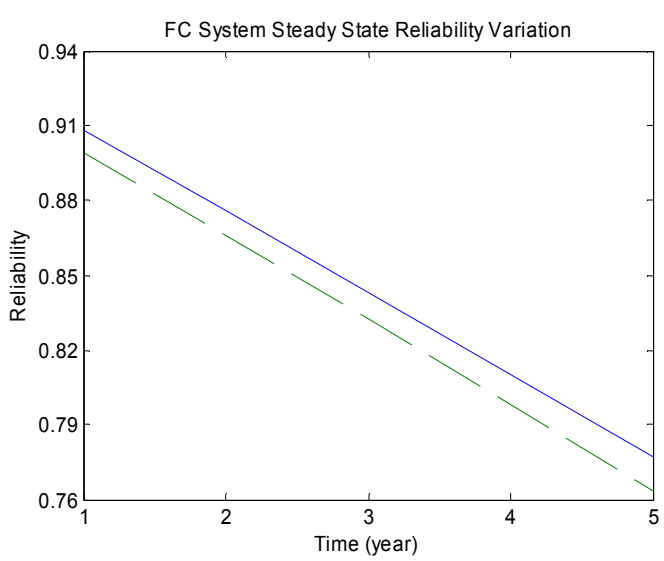

(b)

Fig. 4.14.5. Steady-State reliability variation of FC, (a) for the peak load of $65 \mathrm{~kW}$ (b) for the peak load of $70 \mathrm{~kW}$ (solid line: first 5 year period, dashed line: second 5 year period).

Entire system reliability variation versus weather temperature is shown in Fig. 4.14.6 for different default value of transformer reliability and operation age, which is obtained by combining the FC, grid and transformer reliabilities.

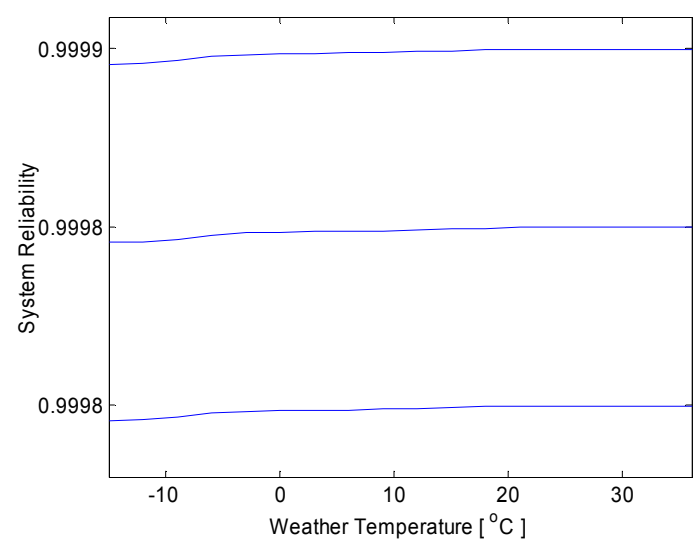

(a)

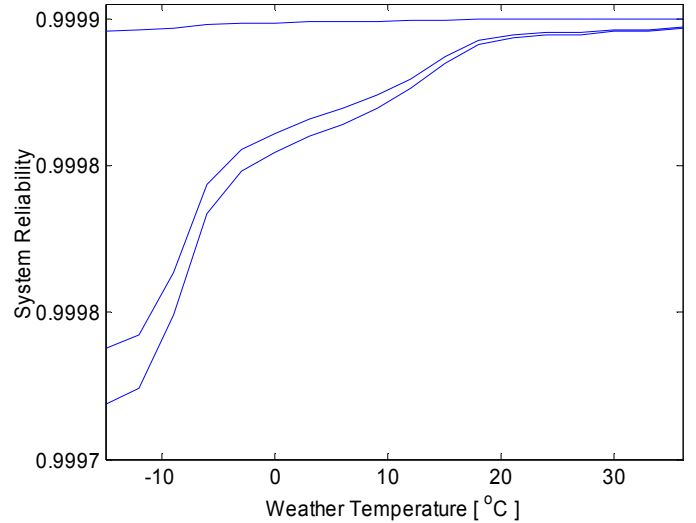

(b)

Fig. 4.14.6. Reliability variation of System versus weather temperature for (a) transformer reliabilities of $0.9998,0.99985,0.9999$ (respectively from bottom to top) (b) 1,5 and 10 years of operation (respectively from top to bottom) in case transformer reliability is 0.9999 .

It is evident from Fig. 4.14.6 that while the negative impact of weather temperature on grid reliability is almost vanished due to parallel connection of FC, negative impact of FC aging is almost disappeared due to grid connection. At first glance, it is seemed that there is still considerable weather temperature and aging effect on system reliability. This is due to very small range of $y$ (reliability) axes, i.e. (0.9998 to 0.9999) for Fig. 4.13.6(a), and (0.99975 to 0.9999) for Fig. 4.14.6(b). Indeed, the aforementioned effects on system reliability variation are very near to zero, around $10^{-5}$ rank. 
If we considered the load bus reliability instead of entire system, the availability of the bus would be 0.999868715 for the worst case, and 0.999999895 for the best case. This means that unavailability of load bus will be within the annual interruption time of 1.15 hour to 3.31 seconds, which is an excellent service availability level.

\subsection{Conclusion}

In this report, reliability analysis of Grid-Connected PEM Fuel Cell Power Plants is developed based on the Markov-Chains. The result of multiple weather reliability calculation given by Fig. 4.14.6 reveals the effects of weather conditions on grid reliability. It confirms that the major impact takes place during low temperature level. As for the aging effects on PEMFC, reliability of FC drops steadily with time as the components age. However, in grid-connected system, the negative impacts of mentioned factors are almost vanished.

Significant amount of unavailability of fuel cell system is due to lacking of generation capacity, which is resulted mostly from stack and battery degradation. However, this negative impact can be minimized by establishing smart energy management control system (SEMCS) in stand-alone FCPPs, which delays the load, starting from the least important load until energy demand is equal to generation capacity. So, FC reliability can considerably be improved by utilizing the SEMCS in FCPPs, which increases the competitiveness and market value of the stand-alone FCPP. In addition, super-capacitor banks can be used as an energy storage device in order to compensate the degradation of FC.

With the methods presented here, it is possible to schedule a maintenance plan like energy storage replacement schedule (if battery is used instead of super-capacitors). Furthermore, bipolar plates and membrane electrode assemblies can be renewed in order to lengthen the lifetime of FC. The schedule for this replacement can be decided yet again with the aid of presented approach. In this report, it is assumed that bipolar plates and membrane electrode assemblies are renewed after five years operation.

\section{Micro-Grid Simulation}

\subsection{Local and Micro-grid Energy Management Systems (LEMSYS and MEMSYS)}

The algorithm for management of a micro-grid based community uses a novel approach. The algorithm is very simple, and its simplicity is what makes it such an elegant solution. The approach used is called the "Greedy Home Management Algorithm" and the algorithm is as follows:

a) All LEMSYS report power usage to MEMSYS

b) MEMSYS sorts power usage in homes from high to low based on the percentage each home is over their current management setpoint 
c) If total power usage approaches maximum power level, MEMSYS sends a command to manage to LEMSYS at top of list

d) GOTO a.

\section{Example:}

Five homes are connected to a common grid. It's 9:00 am. At 9:00 am, MEMSYS

decides that the following set points are to be used by the LEMSYSs:

Home $1=8000$ watts

Home $2=5000$ watts

Home $3=4500$ watts

Home $4=3500$ watts

Home $5=6000$ watts

At 9:10am, the power usage approaches a crisis level, so MEMSYS evaluates the current usage of all homes, sorting them by the amount (if any) that the homes are over their budget, as a percentage of their budget:

Home $4=5000$ watts $=43 \%$ over budget

Home $2=5500$ watts $=10 \%$ over budget

Home $5=6300$ watts $=5 \%$ over budget

Home $3=4600$ watts $=2.2 \%$ over budget

Home $1=6000$ watts $=25 \%$ under budget

So a command is sent to Home 4 to manage loads. MEMSYS returns to point 1 to reevaluate the current load state. This eliminates too many homes managing loads, reducing convenience level in homes that may be over budget, but aren't causing a crisis in the power grid. Home 4 may eliminate a significant load, restoring the grid to a nominal state. If Home 4 eliminates a load that puts it below the home that is second in the "over budget home list", then the list is reordered and now Home 2 is at the top of the list. If the power level is still at a critical level, then Home 2 is now asked to manage its list of loads. This process continues indefinitely. In year two, all homes are given a 5000 watt setpoint by MEMSYS, but this could be a dynamic setpoint. Year three will further refine this algorithm into a dynamic variable.

\subsection{DAQ Simulation}

The DAQ simulation is implemented as a $\mathrm{C}++$ console application. The program is implemented to accommodate various home configurations as well as many different power consumption scenarios. The program first reads a configuration file which lists all of the power consuming devices in the home. The file contains the name of the appliance, the DAQ channel to which that appliance is assigned, whether or not run time must be maintained, and the power conversion factor. The latter being a specification of the multiplier to be applied to the simulated load to convert it to a voltage level which can be understood by LEMSYS. This conversion factor will depend on the range of the current reading device. After the home configuration is established, a second, user-specified file is read which contains the performance profile for the home being simulated. This file contains a list of 
devices that are to be turned on/off. The information contained in this file includes the device ID, the time the device is to be turned on, and the length of time the device will remain on. The program will cycle through this file until execution is terminated. A measure of randomness is introduced in the course of execution of the program. Before each pass through the file, the data contained therein is adjusted using a random function seeded off the clock. The original data is maintained and the randomizing factors are always applied to the original values to prevent excessive drift. Properties adjusted include the starting time, the total running time, and the average load drawn by the device. Any of these parameters may be adjusted by $+/-15 \%$. In addition, a small fluctuation in power usage is built in, about $5 \%$, which is applied during the course of each pass to simulation minor power fluctuations which would normally be expected.

The process is designed to send power consumption information to LEMSYS at approximately 3 to 4 second intervals. This is roughly the same amount of time required to read the actual data in the laboratory home. This is passed as a message to LEMSYS for further processing. LEMSYS will send instructions to the simulator indicating any appliances that are to be turned on/off as a result of user interaction with the GUI or actions resulting from power management decisions made by LEMSYS. In cases where appliances are being managed, the simulation will stop the timer associated with each appliance so that the full runtime for that appliance will ultimately be realized. Not all appliances should be extended. For example, the dishwasher requires a fixed amount of time to wash dishes. If the dishwasher is turned off due to a management decision, the full run time must occur when power is restored. On the other hand, a management decision causing a light to be turned off would not require that the system keep track of the time the light is off. Any appliance turned on by LEMSYS that is not specified in the file will be permitted to run until turned off by LEMSYS.

\subsection{Hardware Simulation}

The hardware simulation is divided into two different simulation tasks; steady-state simulation, and transient simulation. Accordingly, two models have been developed to study operational performance under steady-state and transient conditions.

\subsubsection{Steady-State Simulation}

In Year I, a steady-state model of a Proton Exchange Membrane (PEM) fuel cell stack was developed using MATLAB. A theoretical 5-kW FCPP was designed using characteristic curves obtained from model simulations. The same design is adjusted to provide a 50-kW FCPP. It consists of 100 individual stacks, connected in series, each with a membrane area of $1000 \mathrm{~cm}^{2}$. Each stack supplies $100 \mathrm{~A}$ at $0.55 \mathrm{~V}$. Hence, 100 stacks in series will nominally supply $1000 \mathrm{~A}$ at $55 \mathrm{~V}$ or $55 \mathrm{~kW}$ of power. Losses up to 5 $\mathrm{kW}$ in the DC/DC converter and the inverter are assumed. The steady-state model of the 50-kW FCPP is simulated, and the results are shown in Appendix A. The efficiency and consumption of hydrogen and natural gas versus power were obtained from the model, using the design parameters chosen. A consumption rate of $13 \mathrm{ft}^{3} / \mathrm{min}$ of natural gas was obtained from the theoretical design, operating at a nominal $50-\mathrm{kW}$ load output. 


\subsubsection{Transient Simulation}

Also in Year I, a transient model of a 5-kW PEM FCC was developed. The model included the methanol reformer, the PEM stack and the power conditioning unit. The same model is adjusted to provide a 50-kW FCPP. The transient model is then used to predict the output voltage and study the transient response of a PEM FCC when subjected to step changes in a residential load connected to it. The results, shown in Appendix B, show the fast response capabilities of the PEM power plant in following changes in the load.

\section{Publications:}

1. M. Y. El-Sharkh, A. Rahman, M. Alam, P. C. Byrne, A. A. Sakla, T. Thomas, "A dynamic model for a stand-alone PEM fuel cell power plant for residential applications," Journal of Power Sources, 138, 199-204, 2004.

2. M. Y. El-Sharkh. A. Rahman, M. S. Alam, A. A. Sakla, P. C. Byrne and T. Thomas, "Analysis of Active and Reactive Power Control of a Stand-Alone PEM Fuel Cell Power Plant," IEEE Transactions on Power Systems, vol. 19, no. 4, pp. 2022-2028, 2004.

3. P. Byrne, T. Thomas, M. Alam, A. Rahman, M. El-Shark, A. Sakla, "Proton Exchange Membrane Fuel Cell Steady-State Model for Residential Use," (under review)

\section{References:}

[1] NFPA 70 The National Electric Code (C) 2002, National Fire Protection Association, Quincy, MA 02269.

[2] Theodore R. Bosela, "Electrical Systems Design," Prentice Hall, 2003.

[3] F. Barbir and T. Gomez, "Efficiency and Economics of Proton Exchange Membrane (PEM) Fuel Cell”, Int. J. Hydrogen Energy, Vol. 21,No 10, pp 891-901,1996.

[4] Y. Zoka, H. Sasaki, J. Kubokawa, R. Yokoyama, and Tanaka, "An optimal deployment of fuel cells in distribution systems by using genetic algorithms", IEEE International Conference on, Volume: 1, Page(s): 479, 29 Nov-1 Dec 1996.

[5] Georg Erdmann, "Future economics of the fuel cell housing market," International Journal of Hydrogen Energy 28, 685- 694, 2003.

[6] Ahmed M. Azmy, Björn P. Wachholz, and István Erlich, "Management of PEM Fuel Cells For Residential Applications Using Genetic Algorithms," The Ninth International Middle-East Power Systems conference (MEPCON), Egypt, December, 2003.

[7] Ahmed M. Azmy, and István Erlich, "Online Optimal Management of PEM Fuel Cells Using Neural Networks," Accepted for publication in IEEE Transactions on Power delivery.

[8] Mehmet Burak Gunes, "Investigation of a Fuel Cell Based Total Energy System for Residential Applications," Master of Science Thesis, Dept. Mechanical Engineering, Virginia Polytechnic Institute and State University, 2001.

[9] D. B. Fogel "Evolutionary Computation toward a New Philosophy of Machine Intelligence" IEEE Press. 
[10] P. H. Winston, "Artificial Intelligence" $3^{\text {rd }}$ ed, Addison-Wesley Publishing Company. 1993.

[11] B.E. Conway, Electrochemical Capacitors: Scientific Fundamentals and Technological Applications, Kluwer Academic Publishers/Plenum Publishers, New York, 1999.

[12] A. Burke, J., "Ultracapacitors: why, how, and where is the technology," Journal of Power Sources 91, pp. 37-50, 2000.

[13] K. Hauer, "Analysis tool for fuel cell vehicle hardware and software (controls) with an application to fuel economy comparisons of alternative system designs," Ph.D. dissertation, Dept. Transportation Technology and Policy, Univ. California, Davis, 2001.

[14] A. Burke, "Ultracapacitors for Electric and Hybrid Vehicles- Performance Requirements, Status of the Technology, and R\&D Needs," University of California, Davis UCD-ITS-RR-95-23, 1995.

[15] Levent U. Gökdere, Khalid Benlyazid, Roger A. Dougal, Enrico Santi and Charles W. Brice, "A virtual prototype for a hybrid electric vehicle," Mechatronics, Vol 12, Issue 4, pp. 575-593, May 2002

[16] Cunningham, Joshua M., Myron A. Hoffman, David J. Friedman, "A Comparison of High-Pressure and Low-Pressure Operation of PEM Fuel Cell Systems," SAE Paper 2001-01-0538, SAE International, Warrendale, PA, 2001.

[17] Pischinger, S., C. Schönfelder, W. Bornscheuer, H. Kindl, A. Wiartalla, "Integrated Air Supply and Humidification Concepts for Fuel Cell Systems," SAE Paper 200101-0233, SAE International, Warrendale, PA, 2001.

[18] C. E. Thomas, "Direct-Hydrogen-Fueled Proton-Exchange-Membrane Fuel Cell System for Transportation Applications", Ford Motor Company \& U.S. Department Of Energy Office of Transportation Technologies, May 1997.

[19] Thirumalai D. and White R.E., "Mathematical Modeling of Proton-ExchangeMembrane Fuel-Cell Stacks" Journal of the Electrochemical Society, Vol. 144, pp.1717-1723, 1997.

[20] Sylvain Gelfi, Anna G. Stefanopoulou, Jay T. Pukrushpan, Huei Peng, "Dynamics of Low-Pressure and High-Pressure Fuel Cell Air Supply System," Proceedings of the 2003 American Control Conference, Denver, CO, June, 2003.

[21] Maxwell Technologies "Ultracapacitor Product Information", http://www.maxwell.com/ultracapacitors.

[22] H. Paul Barringer, Michael Kotlyar, "Reliability Of Critical Turbo/Compressor Equipment", Fifth International Conference on Process Plant Reliability, Houston, TX, October 2-4, 1996.

[23] M. Tanrioven and M. S. Alam "Reliability Modeling and Evaluation of GridConnected PEM Fuel Cell Power Plants Based on Fuzzy Markov-Chains," IEEE Transaction on Energy Conversion (Under review). 


\section{APPENDIX A}

\section{STEADY-STATE MODEL AND SIMULATION}


The following is a listing of a MATLAB steady-state model of the 50-kW PEM fuel cell.

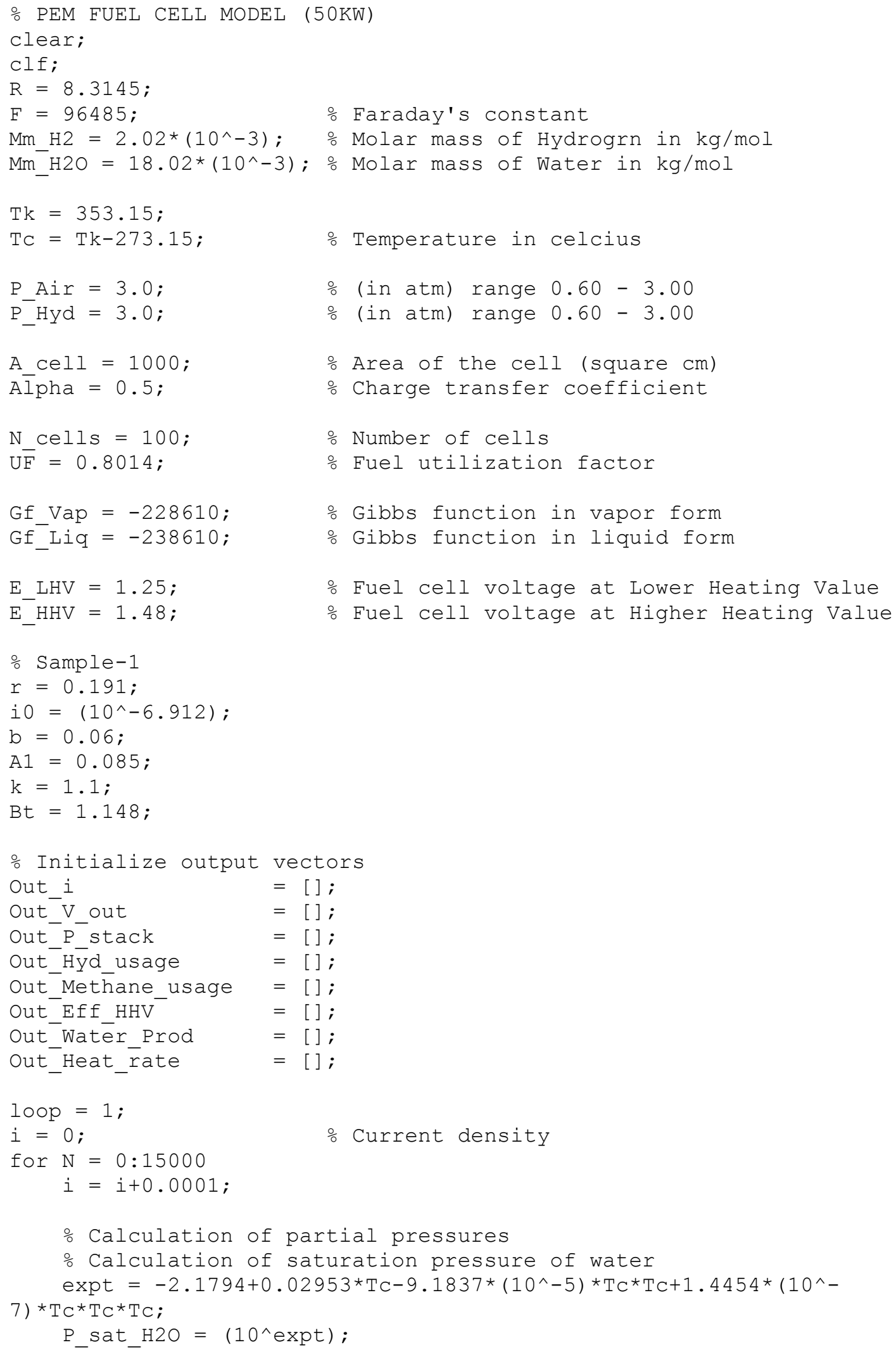




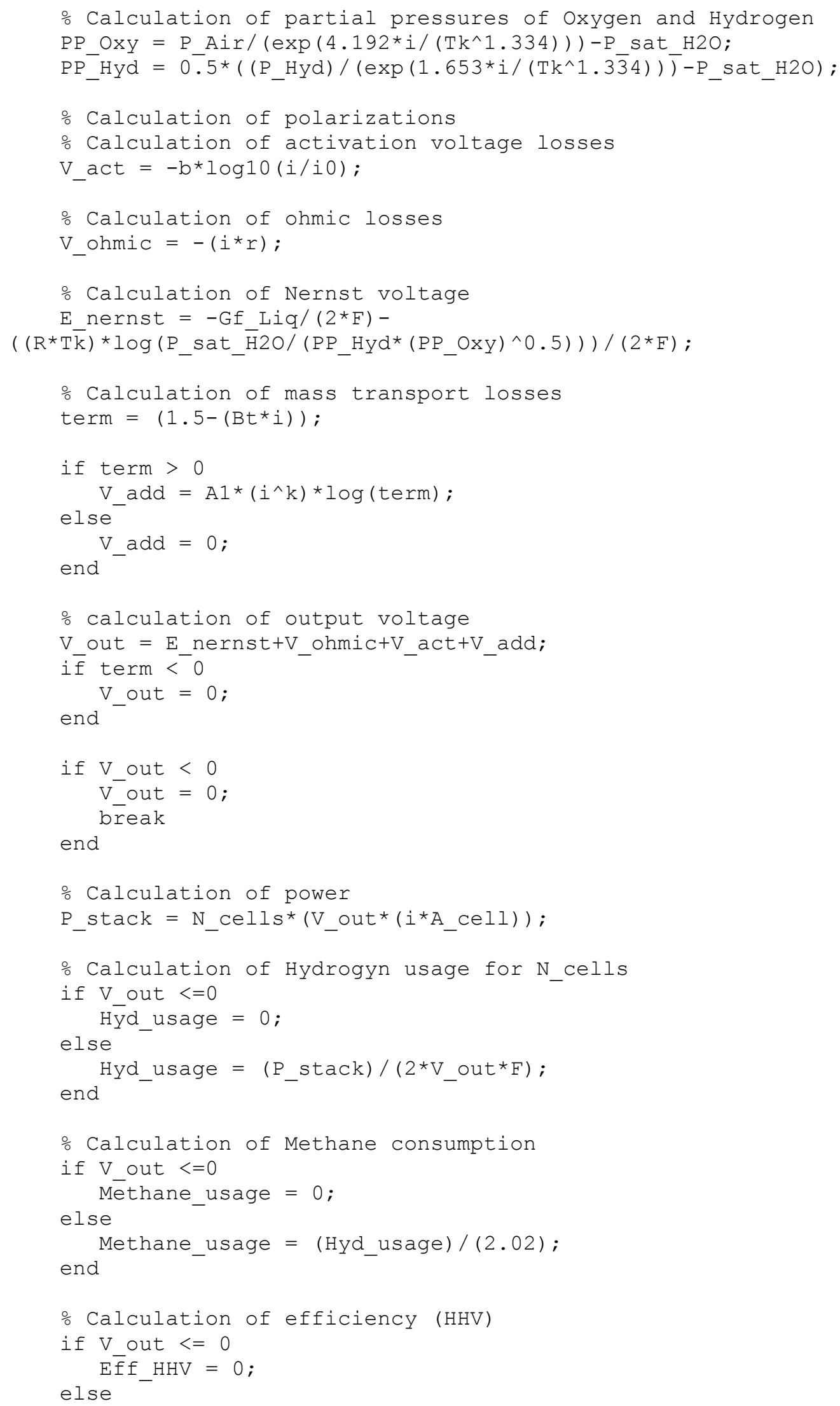




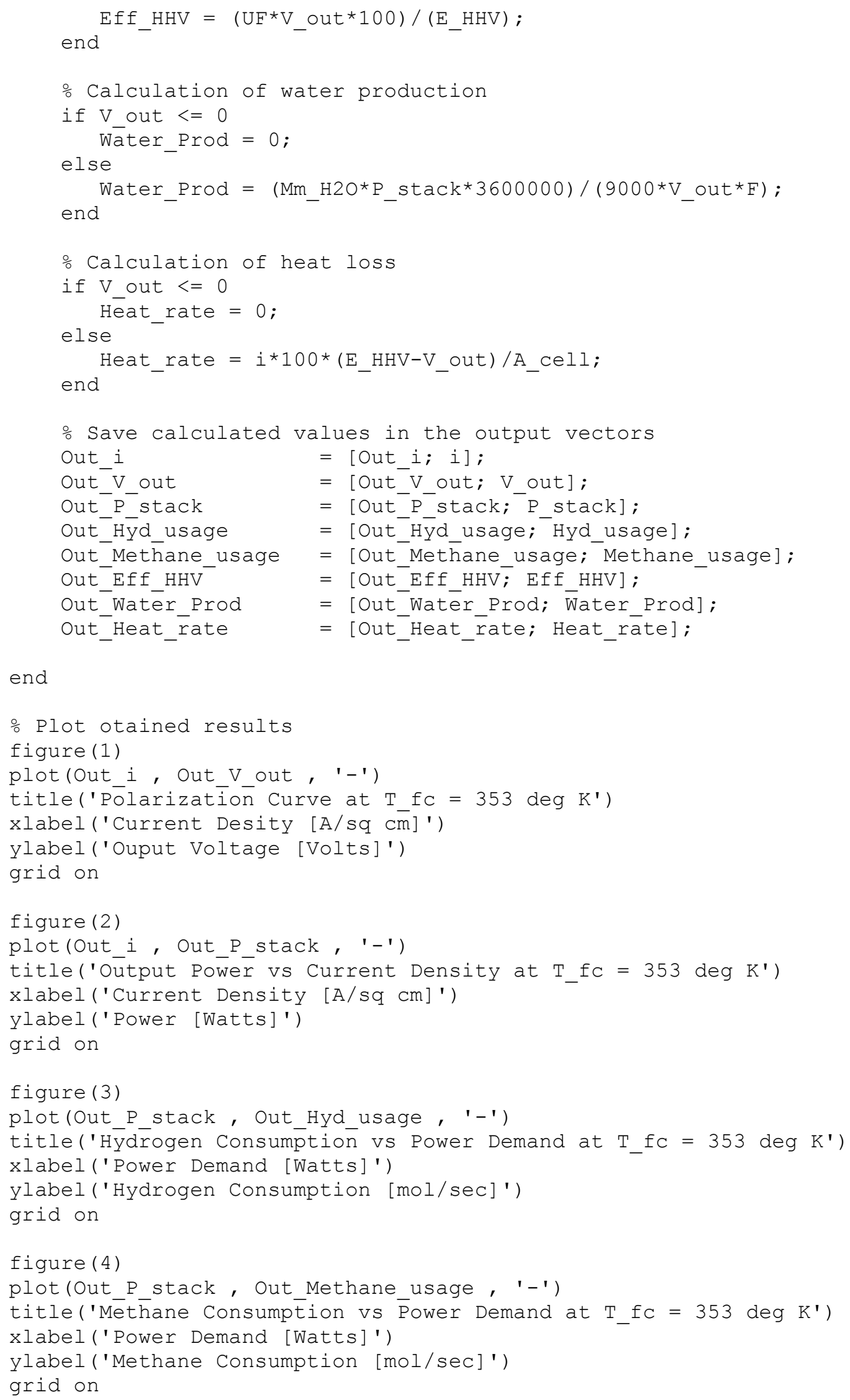




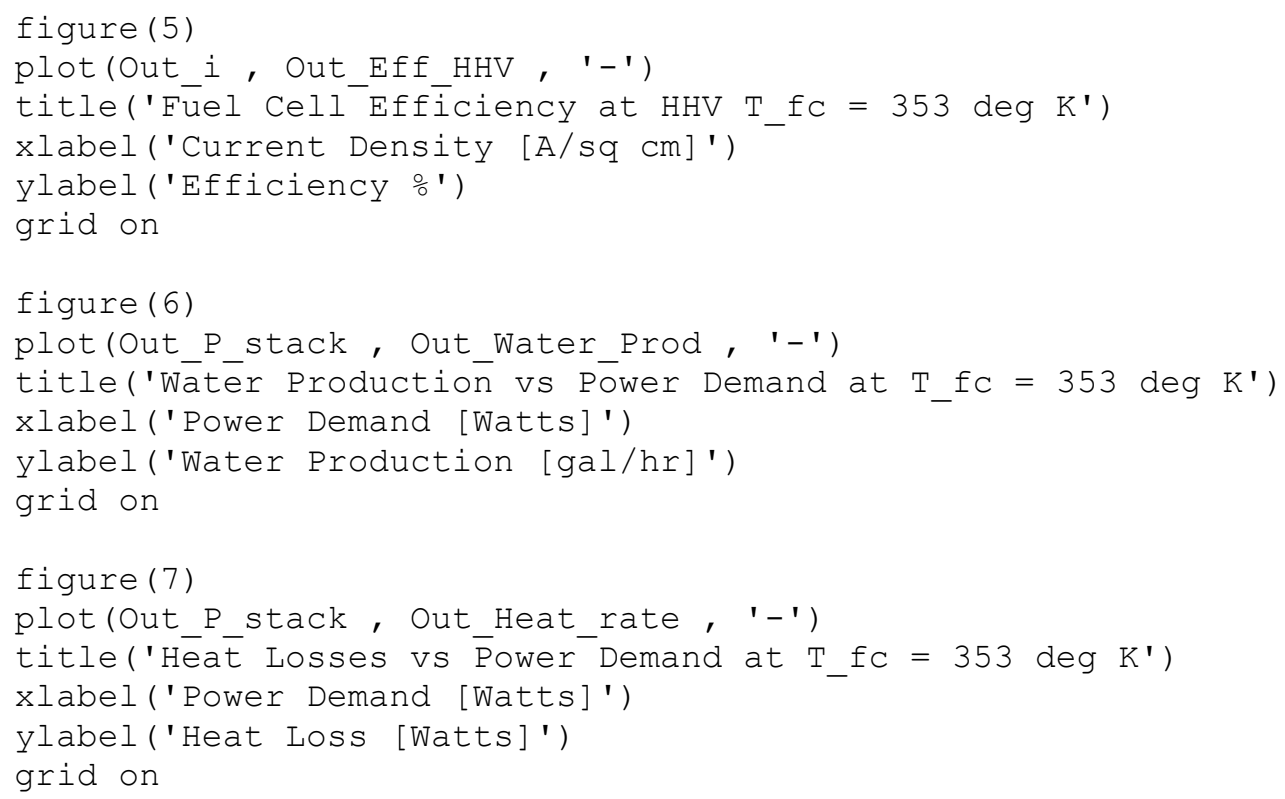


The 50-kW PEM fuel cell MATLAB model is run, and several characteristic curves are obtained and shown below. The output DC voltage (volts) of one stack versus current density $(\mathrm{A} / \mathrm{sq} \mathrm{cm})$ is shown in Fig. A1. Operating at a current density of $1 \mathrm{~A} / \mathrm{sq} \mathrm{cm}$ (total $1000 \mathrm{~A}$ ) will result in about 0.55 volts per stack, which produces a total of 55 volts for all stacks.

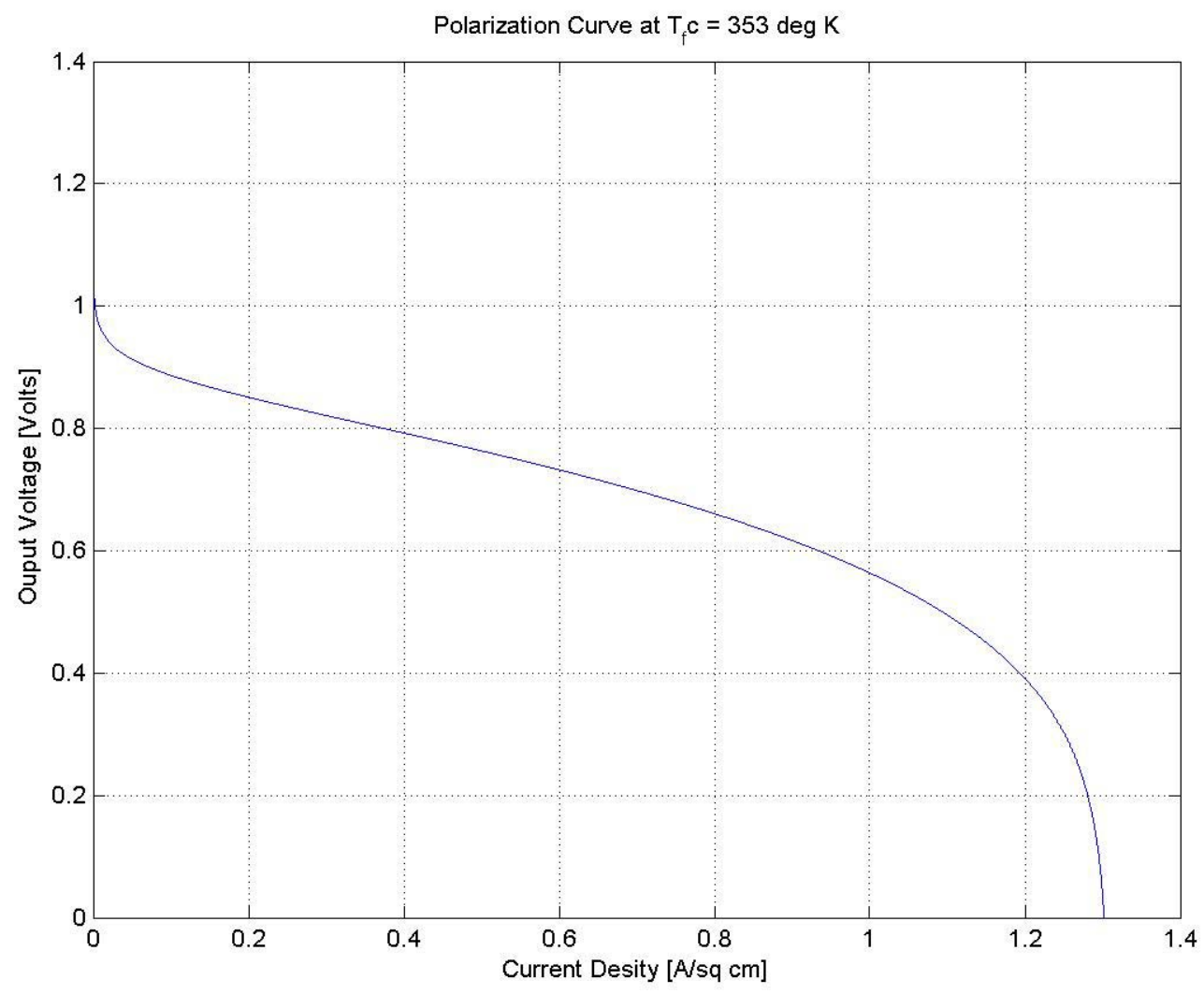

Fig. A1 Output Voltage vs. Current Density. 
The output power (watts) of all stacks versus current density $(\mathrm{A} / \mathrm{sq} \mathrm{cm})$ is shown in Fig. A2. Operating at a current density of $1 \mathrm{~A} / \mathrm{sq} \mathrm{cm}$ (total $1000 \mathrm{~A}$ ) will result in a total of about $55 \mathrm{~kW}$ for all stacks.

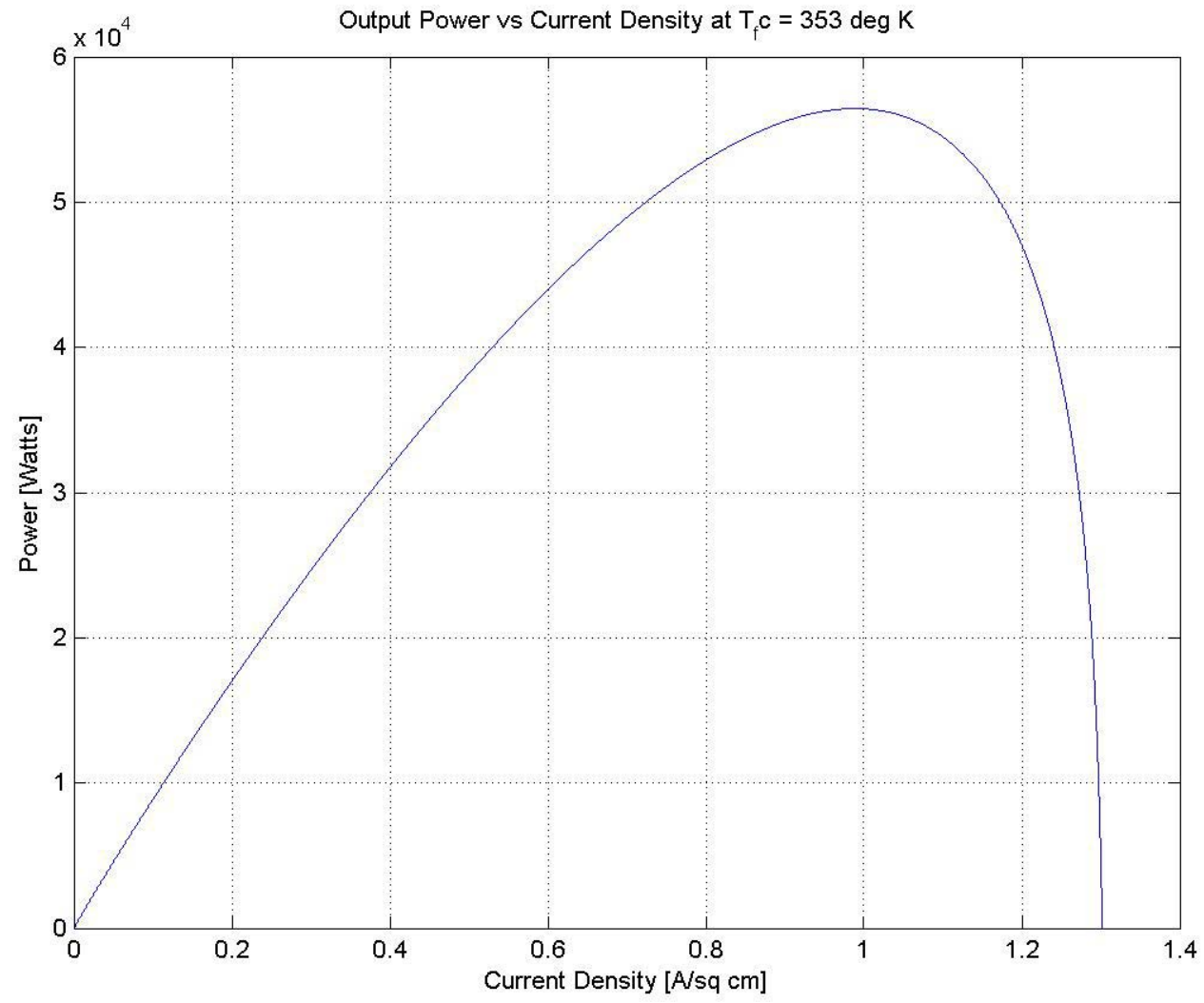

Fig. A2 Output Power vs. Current Density 
The hydrogen consumption $(\mathrm{mol} / \mathrm{sec})$ of the fuel cell versus power demand (watts) is shown in Fig. A3. Operating at a power demand of $55 \mathrm{~kW}$ will result in a hydrogen consumption of about $0.5 \mathrm{~mol} / \mathrm{sec}$.

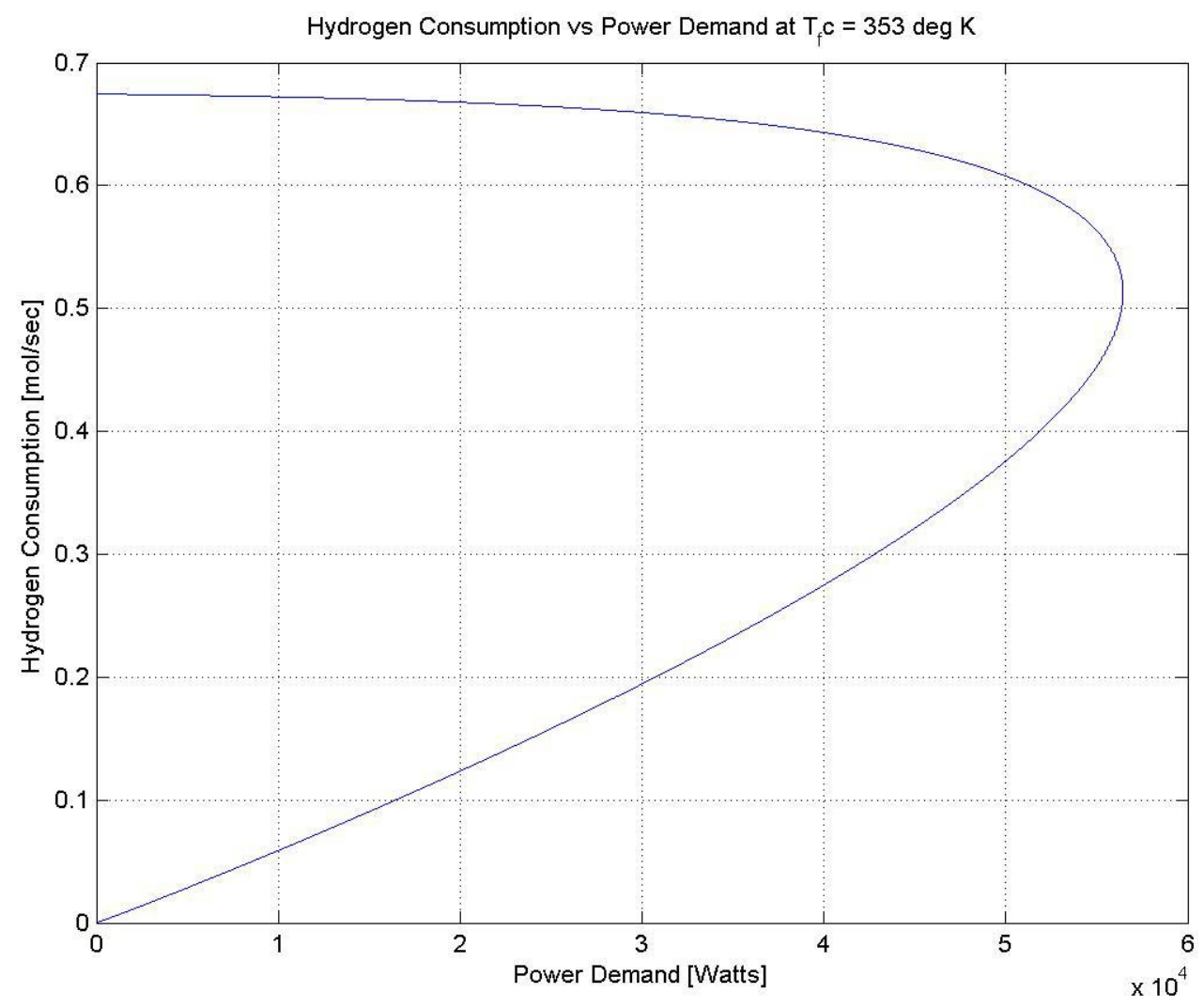

Fig. A3 Hydrogen Consumption vs. Power Demand 
The methane consumption ( $\mathrm{mol} / \mathrm{sec}$ ) of the fuel cell versus power demand (watts) is shown in Fig. A4. Operating at a power demand of $55 \mathrm{~kW}$ will result in a methane consumption of about $0.25 \mathrm{~mol} / \mathrm{sec}$.

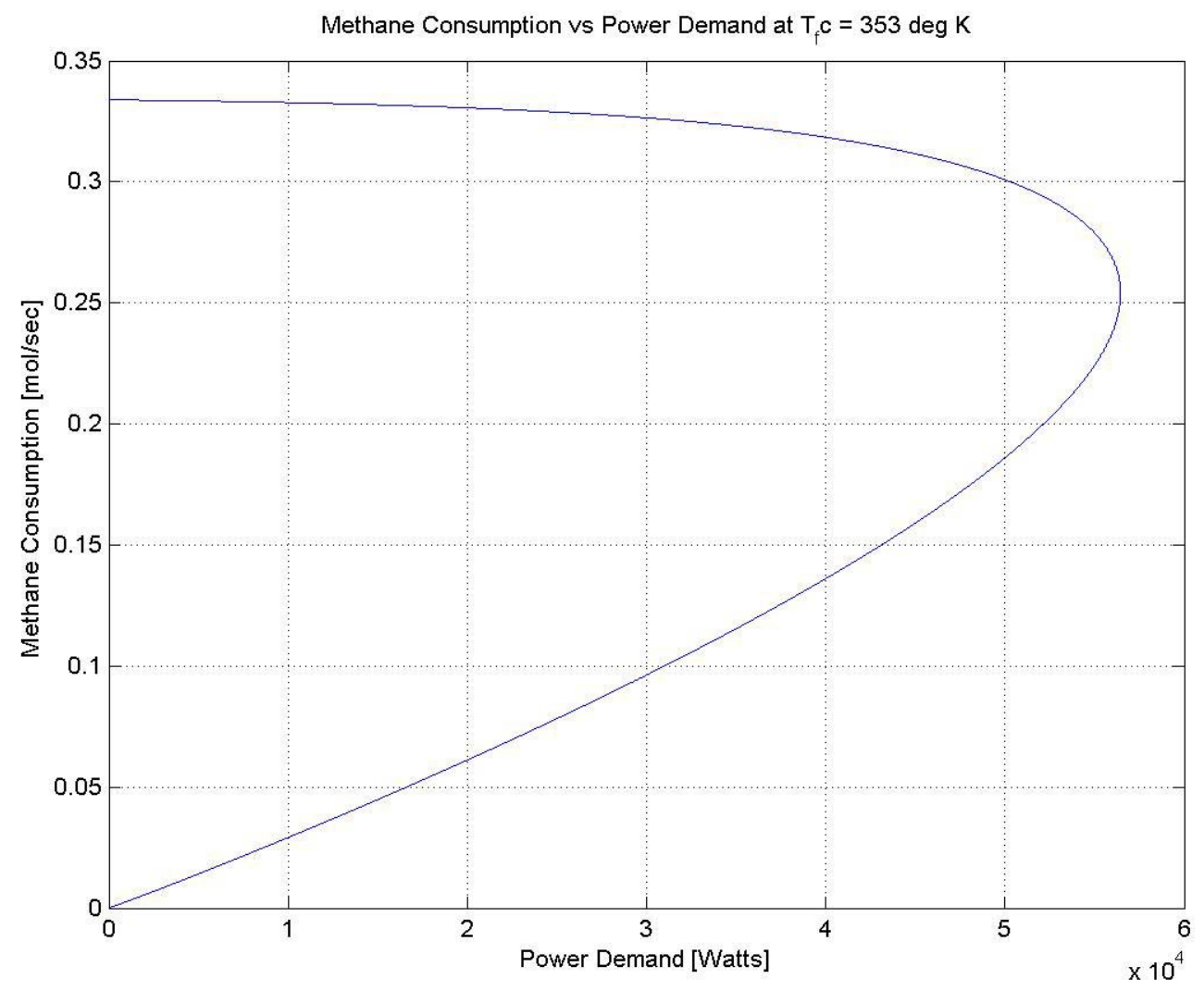

Fig. A4 Methane Consumption vs. Power Demand 
The fuel cell efficiency versus current density $(\mathrm{A} / \mathrm{sq} \mathrm{cm})$ is shown in Fig. A5. Operating at a current density of $1 \mathrm{~A} / \mathrm{sq} \mathrm{cm}$ (total $1000 \mathrm{~A}$ ) will result in an efficiency of about $30 \%$.

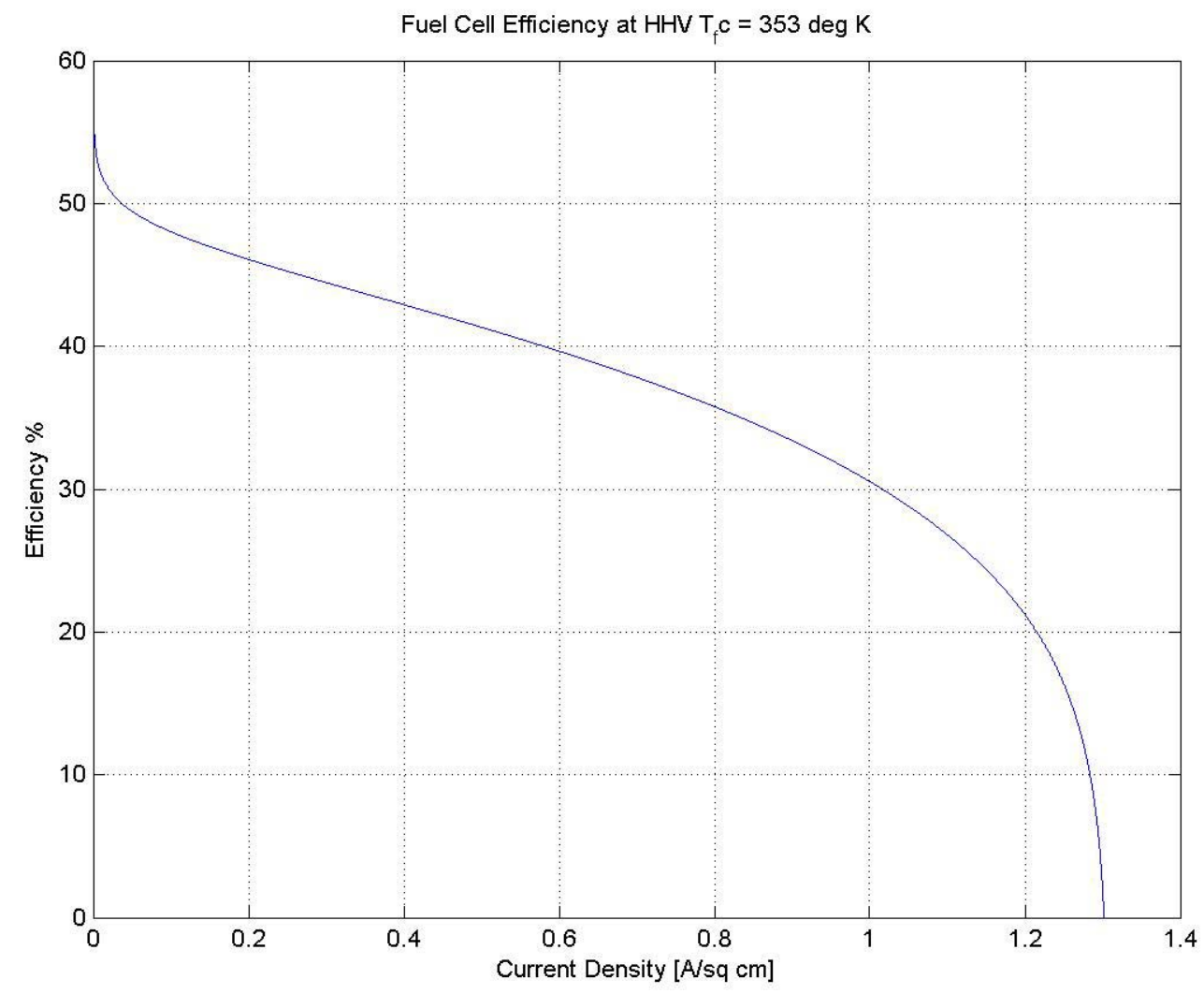

Fig. A5 Fuel Cell Efficiency vs. Current Density 
The water production ( $\mathrm{gal} / \mathrm{hr}$ ) of the fuel cell versus power demand (watts) is shown in Fig. A6. Operating at a power demand of $55 \mathrm{~kW}$ will result in a water production of about $7 \mathrm{gal} / \mathrm{hr}$.

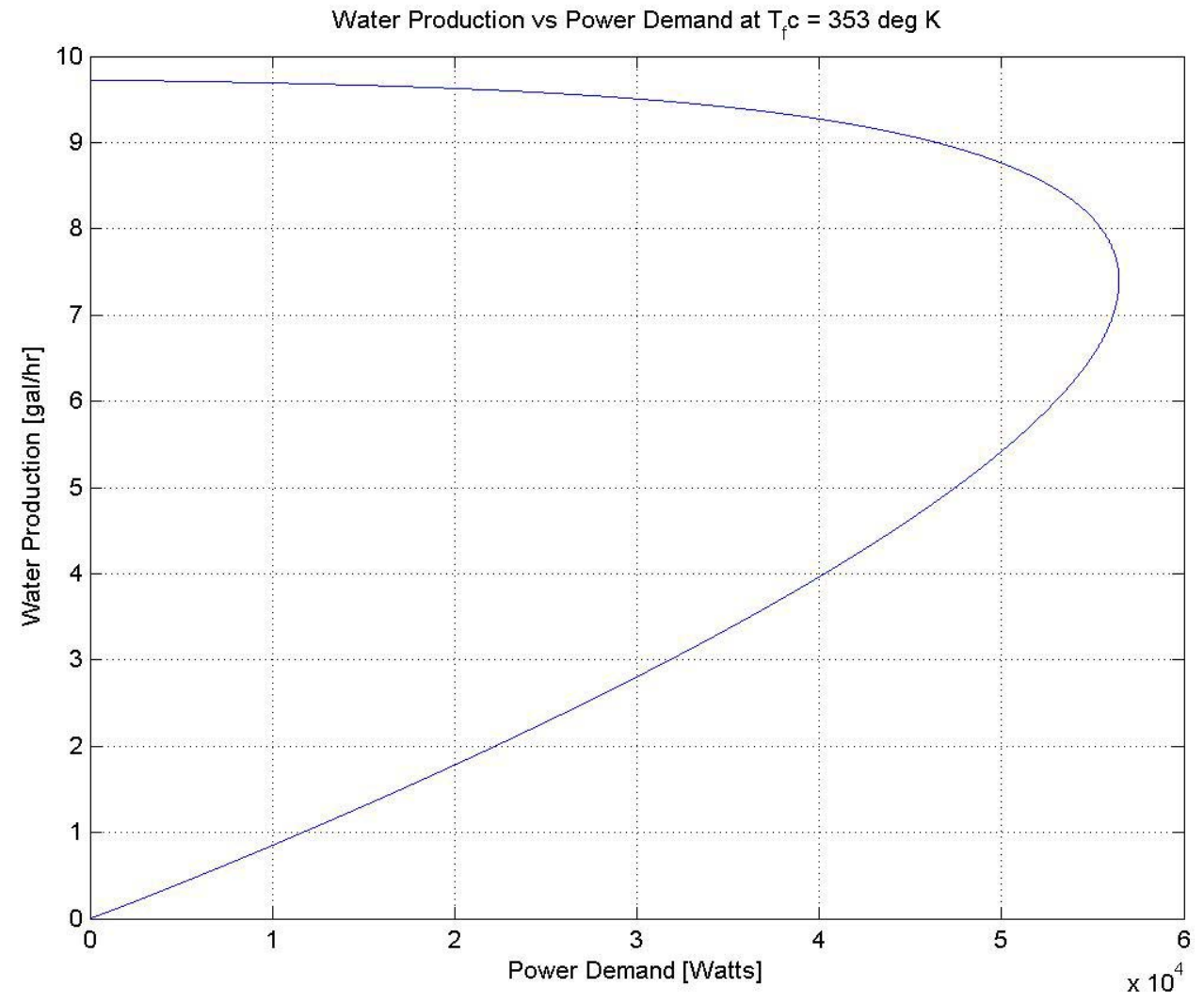

Fig. A6 Water Production vs. Power Demand 
The heat loss (watts) of the fuel cell versus power demand (watts) is shown in Fig. A7. Operating at a power demand of $55 \mathrm{~kW}$ will result in a heat loss of about 0.08 watts.

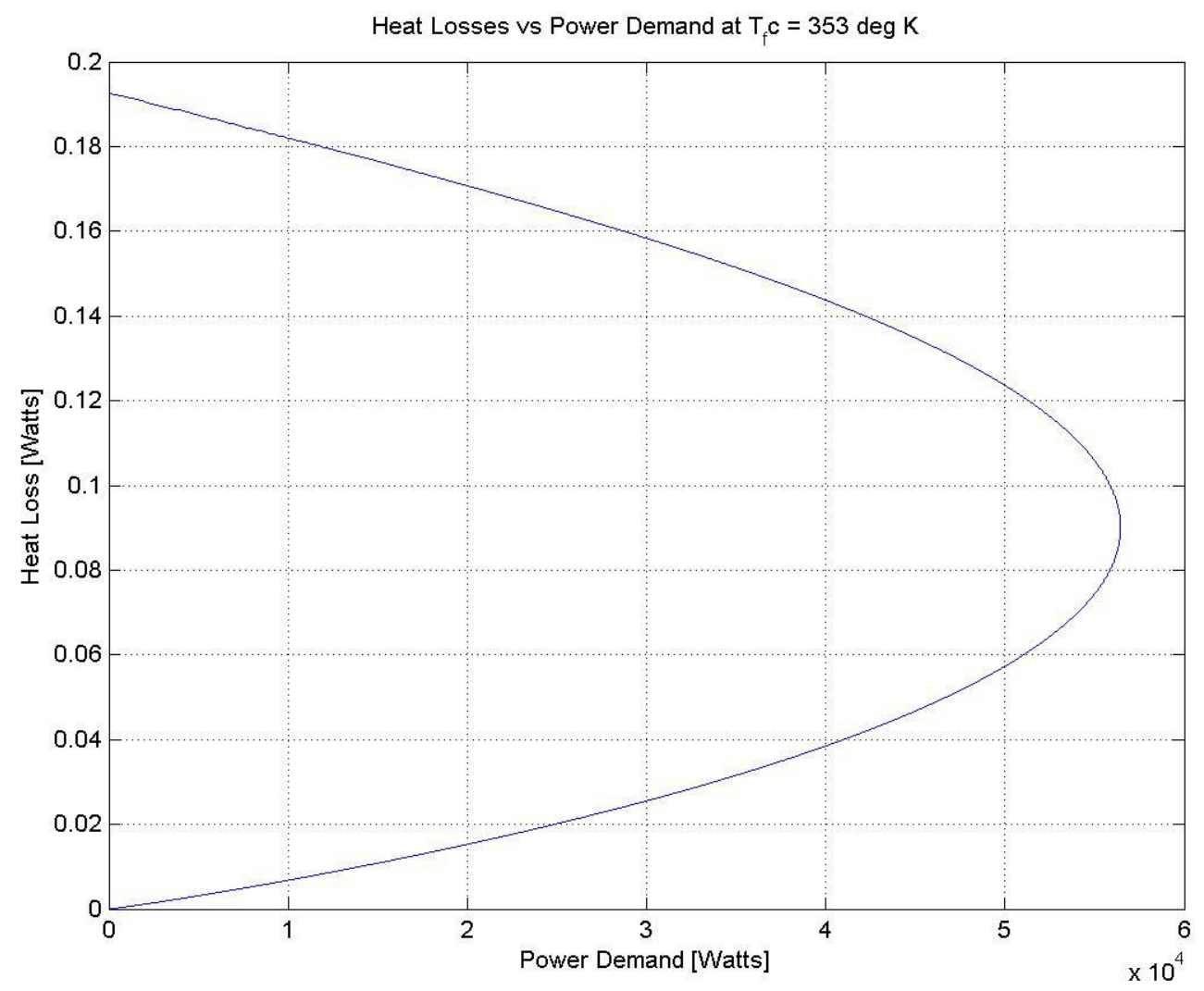

Fig. A7 Heat Losses vs. Power Demand 


\section{APPENDIX B}

\section{TRANSIENT MODEL AND SIMULATION}


The following is a listing of a MATLAB transient model of the 50-kW PEM fuel cell including the methanol reformer, the PEM stack and the power conditioning unit.

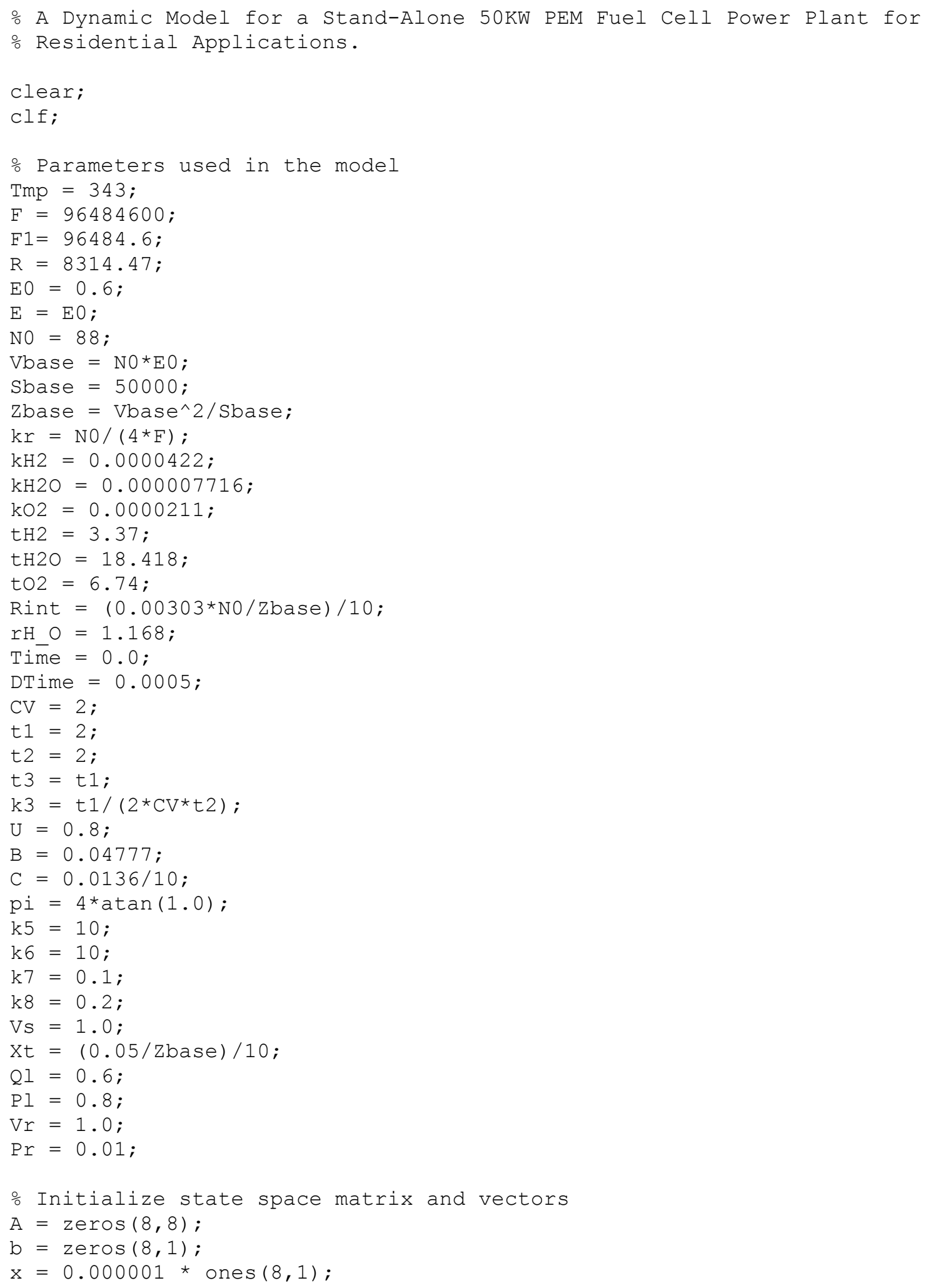




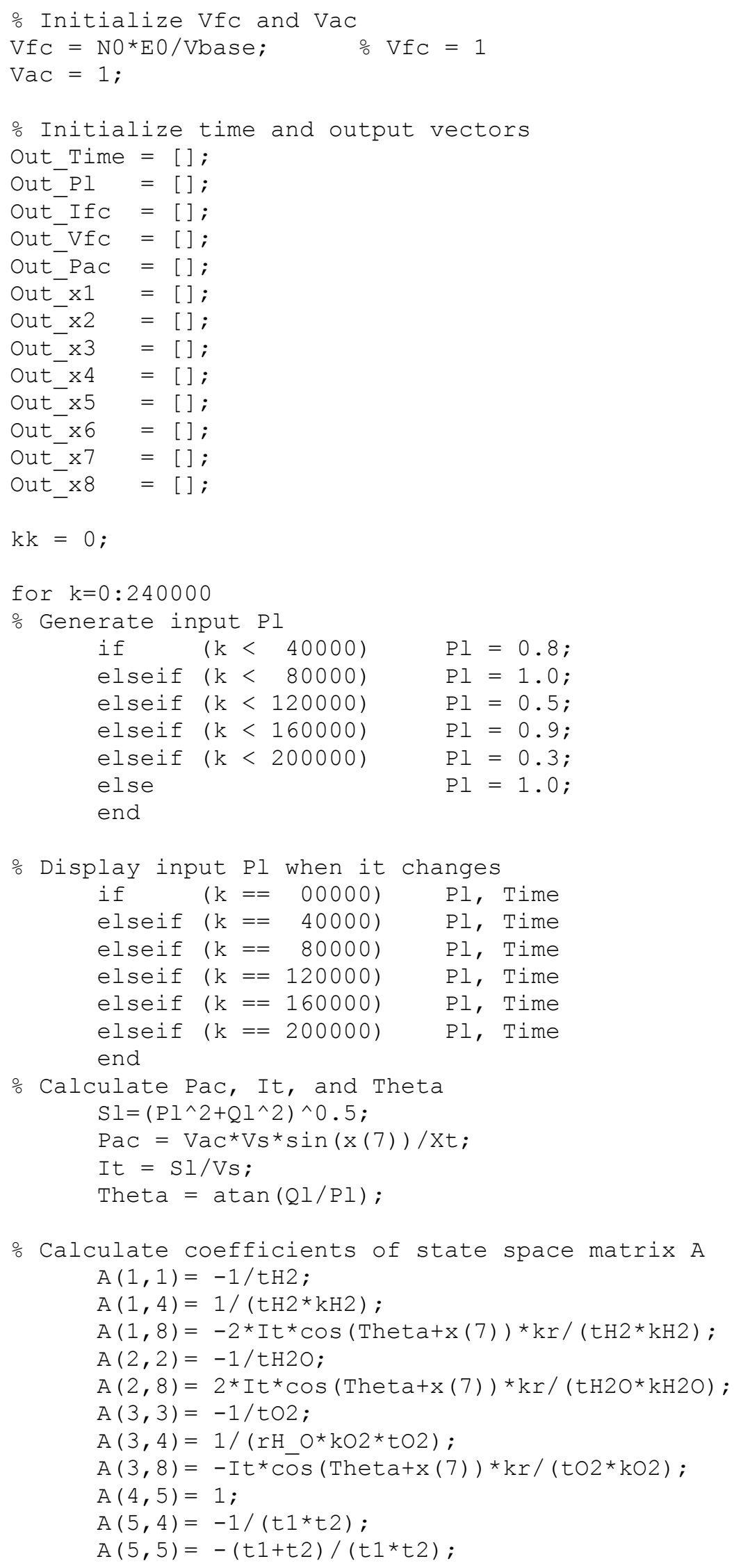




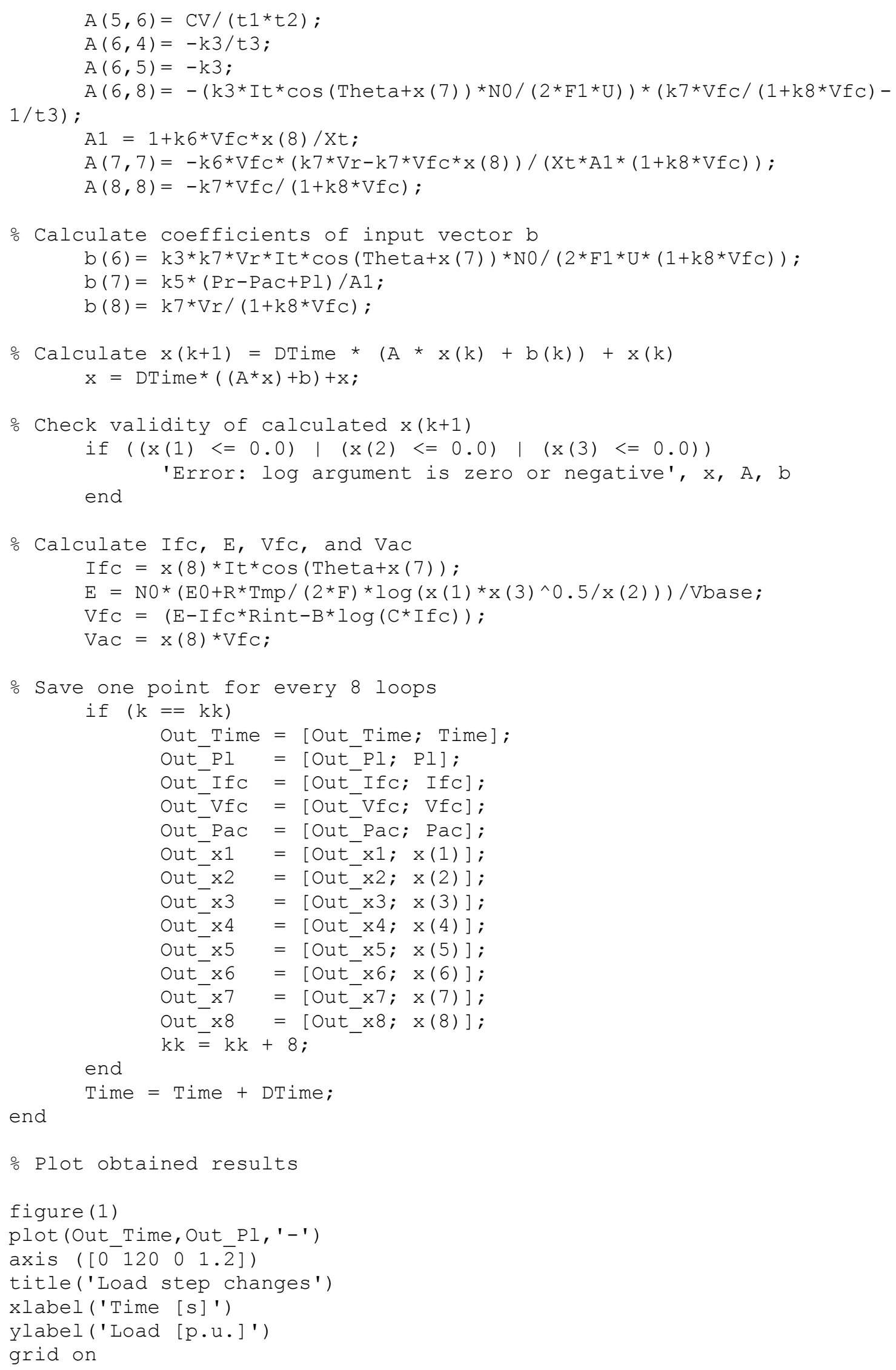




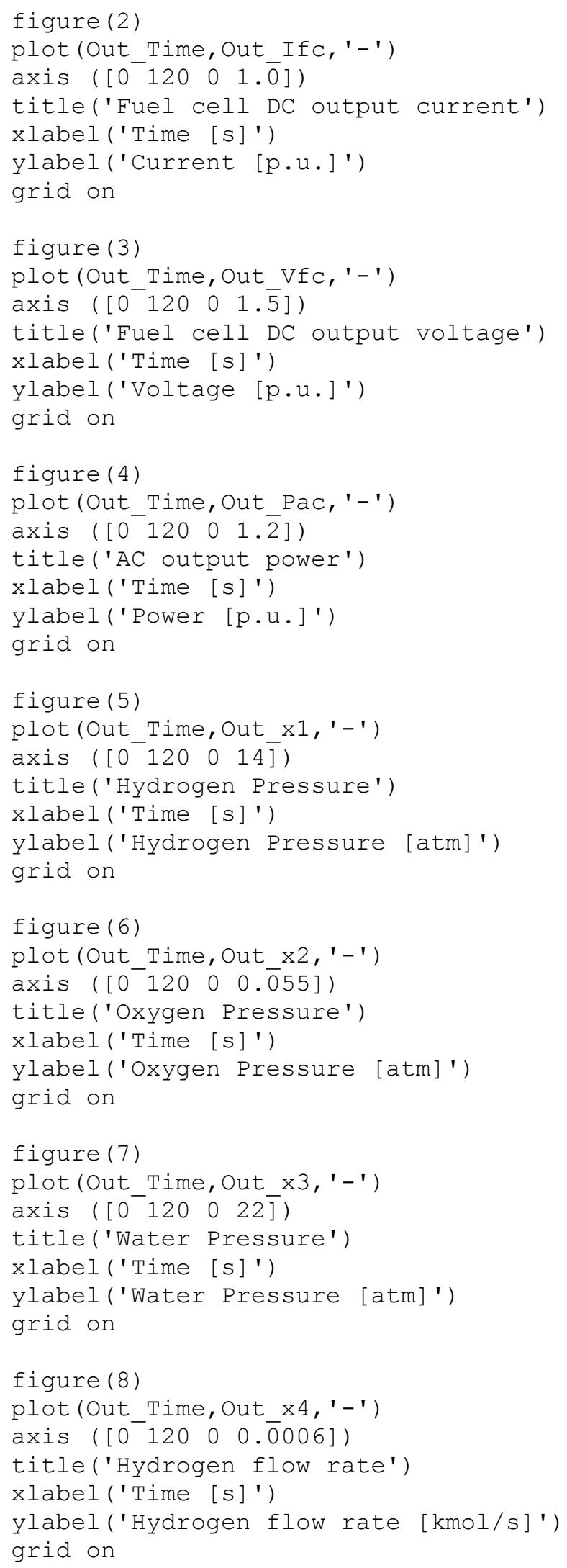




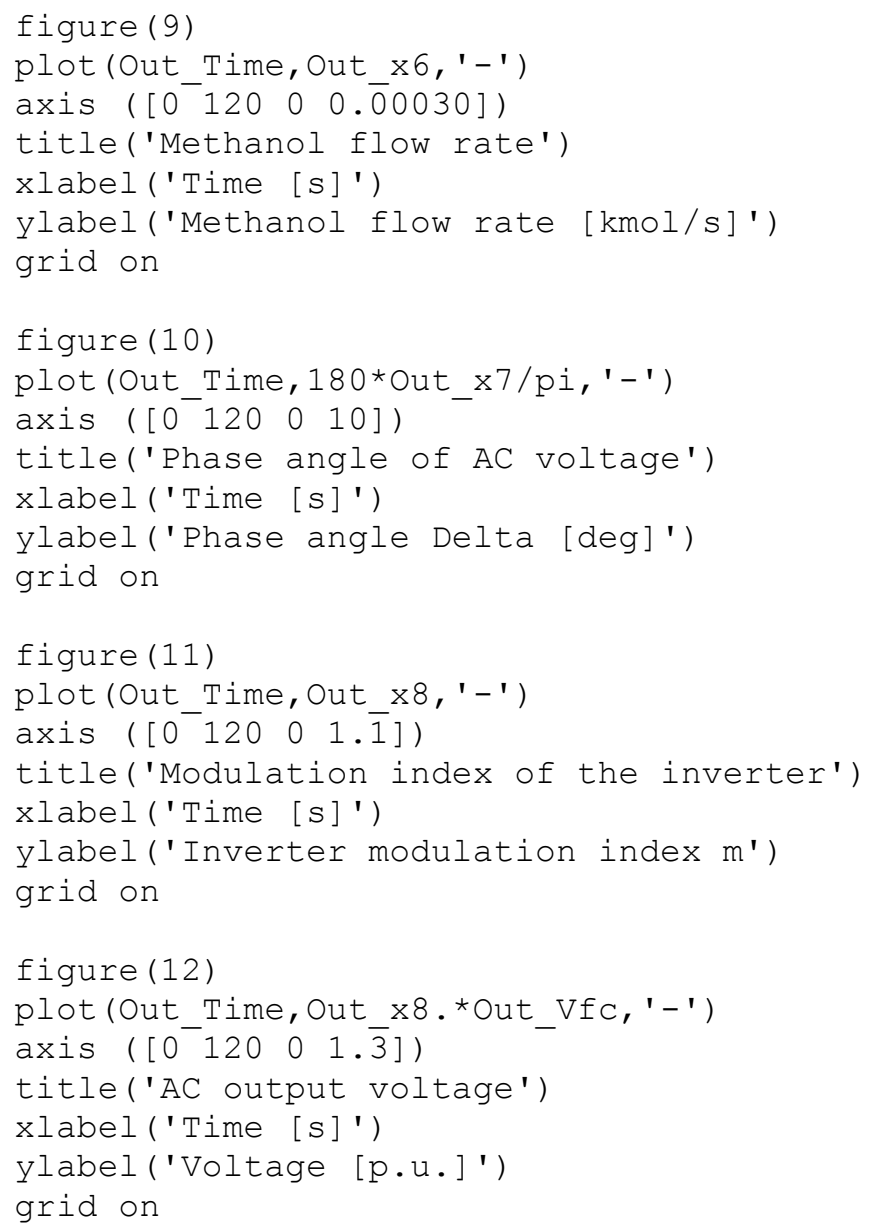


The 50-kW PEM fuel cell including the methanol reformer, the PEM stack and the power conditioning unit MATLAB model is run, and subjected to step changes in a residential load connected to it. The input load step changes (per unit, p.u.) versus time (sec) are shown in Fig. B1. The transient responses of several model quantities are shown in subsequent figures. Note that responses during the first $18 \mathrm{sec}$ should be ignored since the model starts with zero initial conditions. In addition, the results show the fast response capabilities of the PEM FCPP in following changes in the load.

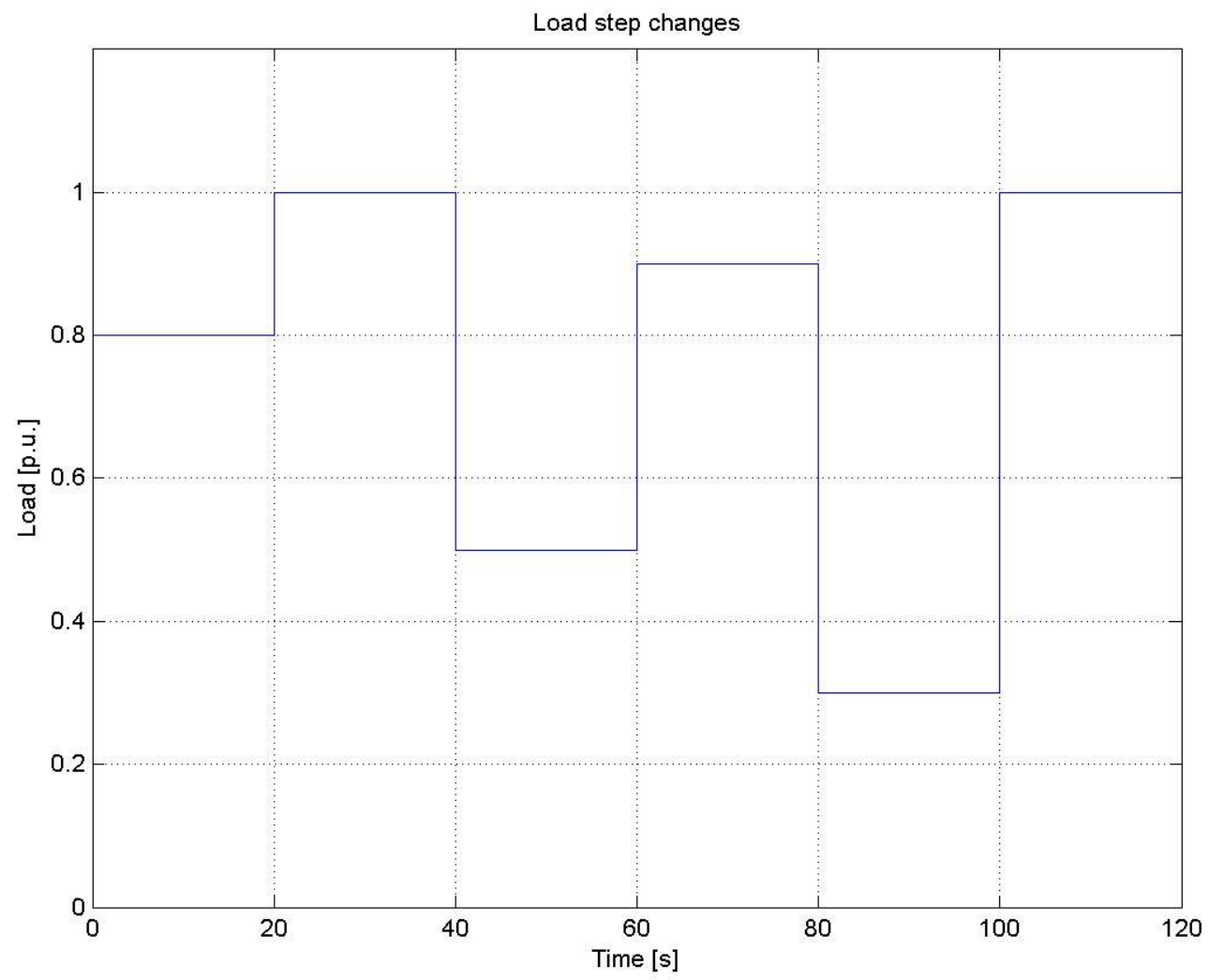

Fig. B1 Input Load Step Changes vs. Time 
The output DC current of the fuel cell (p.u.) versus time (sec) is shown in Fig. B2.

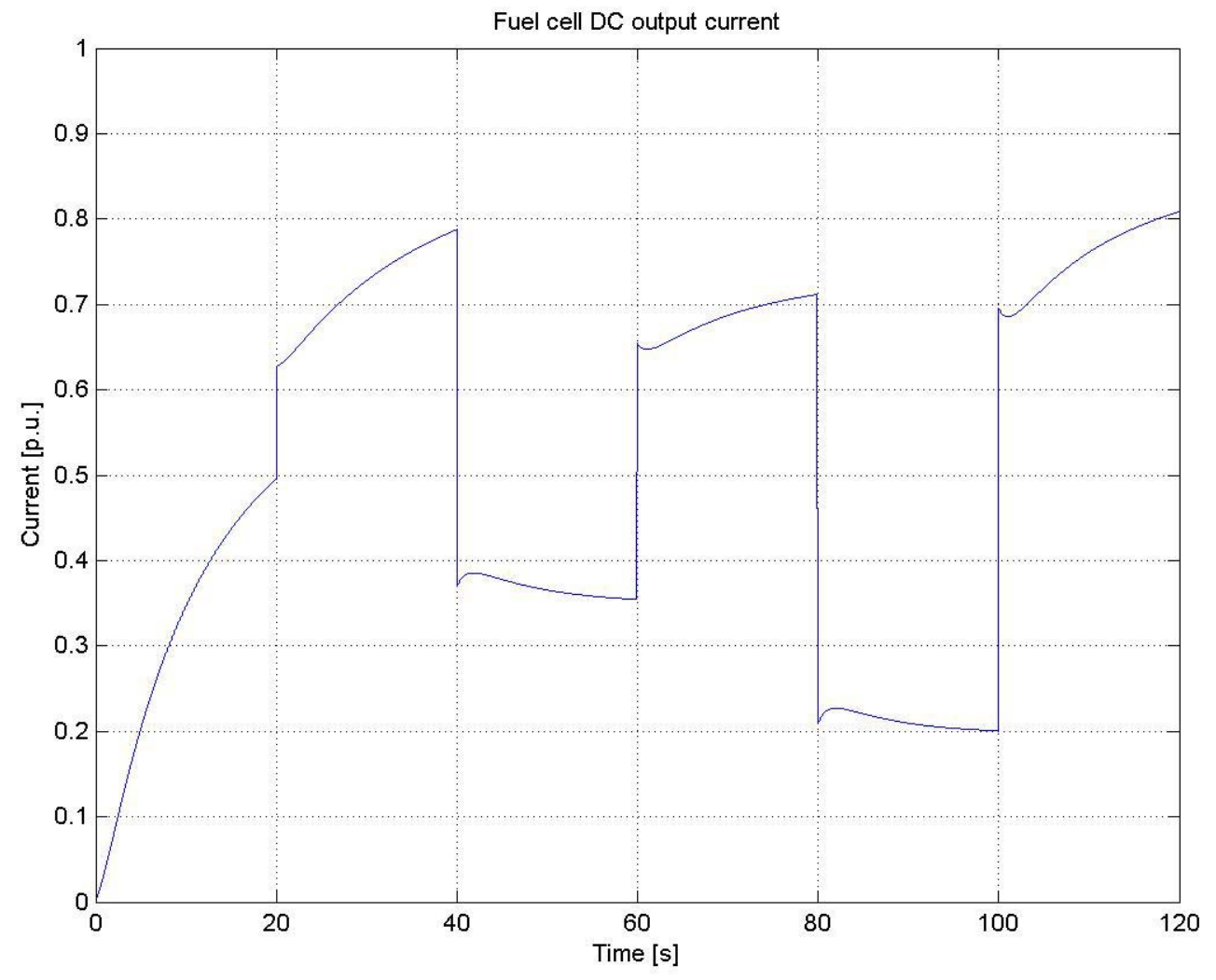

Fig. B2 Fuel Cell DC Output Current vs. Time 
The output DC voltage of the fuel cell (p.u.) versus time (sec) is shown in Fig. B3.

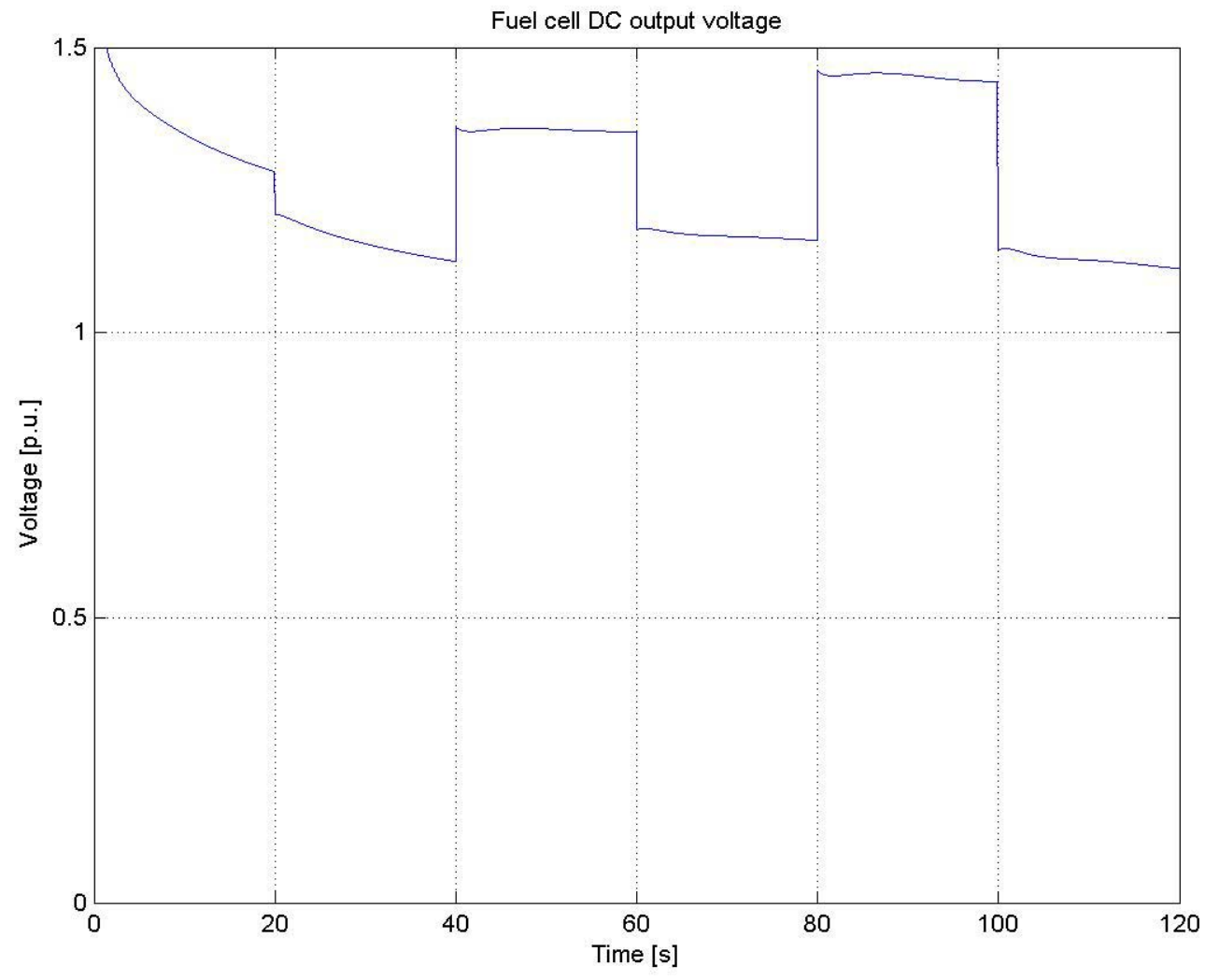

Fig. B3 Fuel Cell DC Output Voltage vs. Time 
The output AC power of the fuel cell (p.u.) versus time (sec) is shown in Fig. B4.

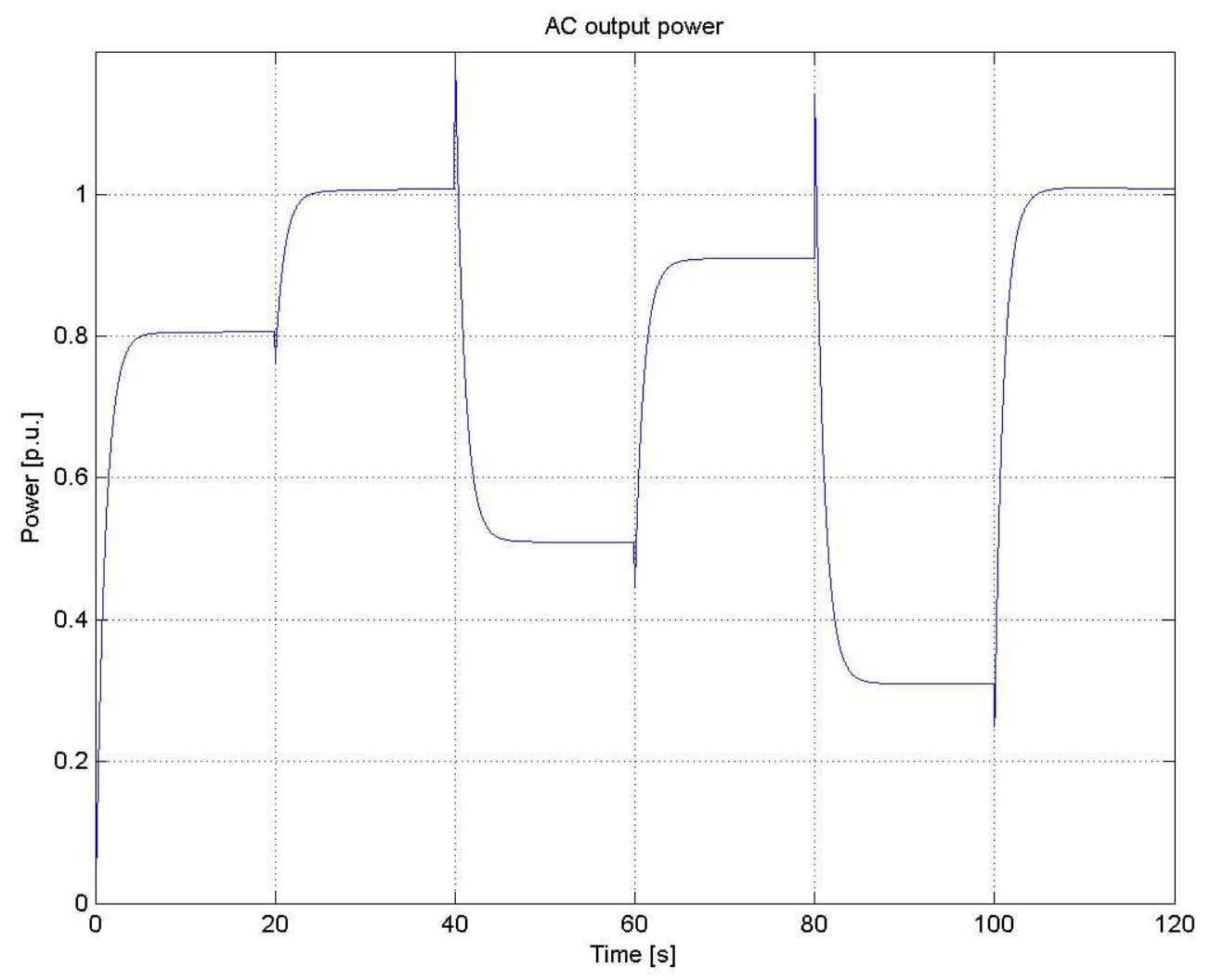

Fig. B4 AC Output Power vs. Time 
The hydrogen pressure (atm) versus time (sec) is shown in Fig. B5.

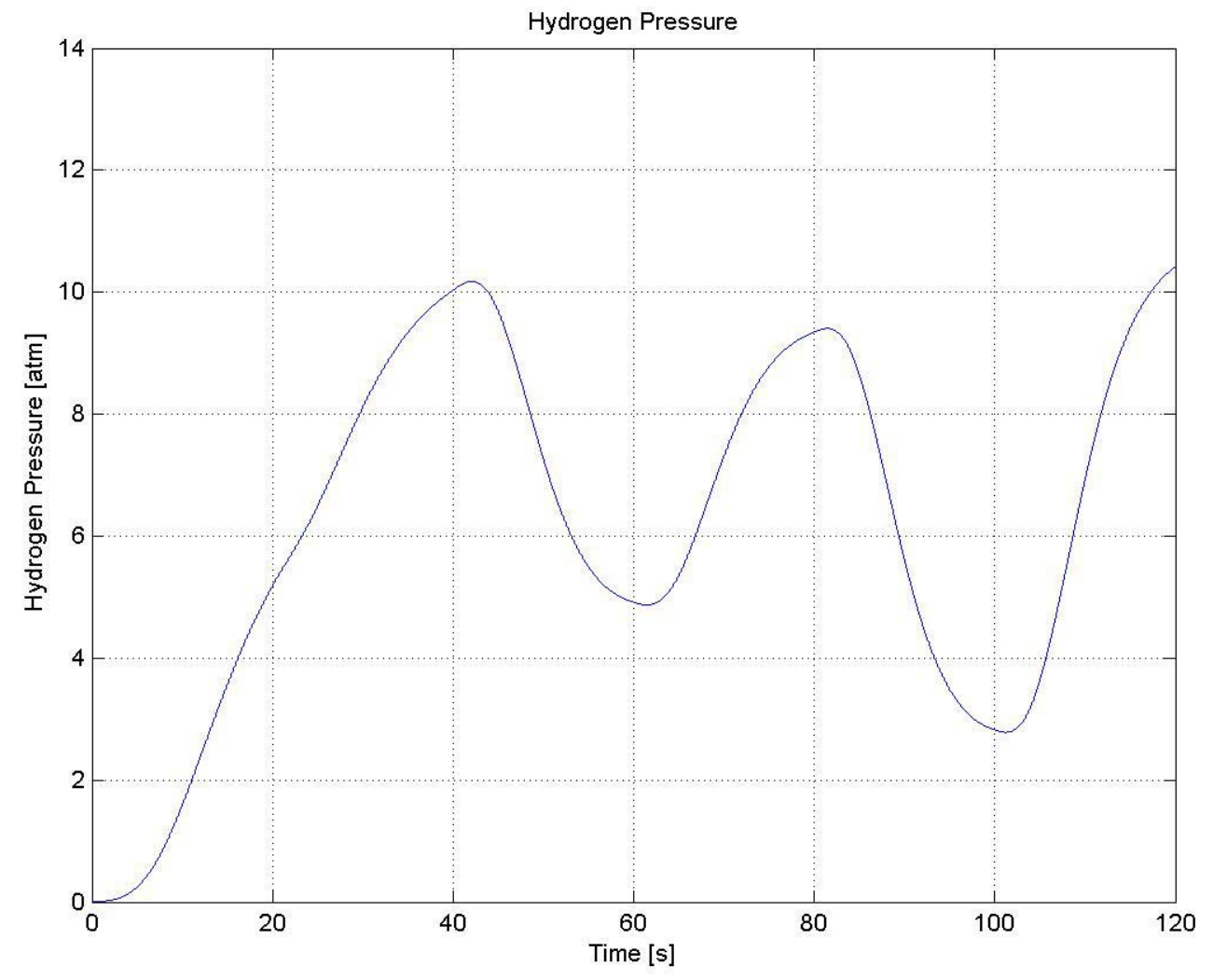

Fig. B5 Hydrogen Pressure vs. Time 
The oxygen pressure (atm) versus time ( $\mathrm{sec}$ ) is shown in Fig. B6.

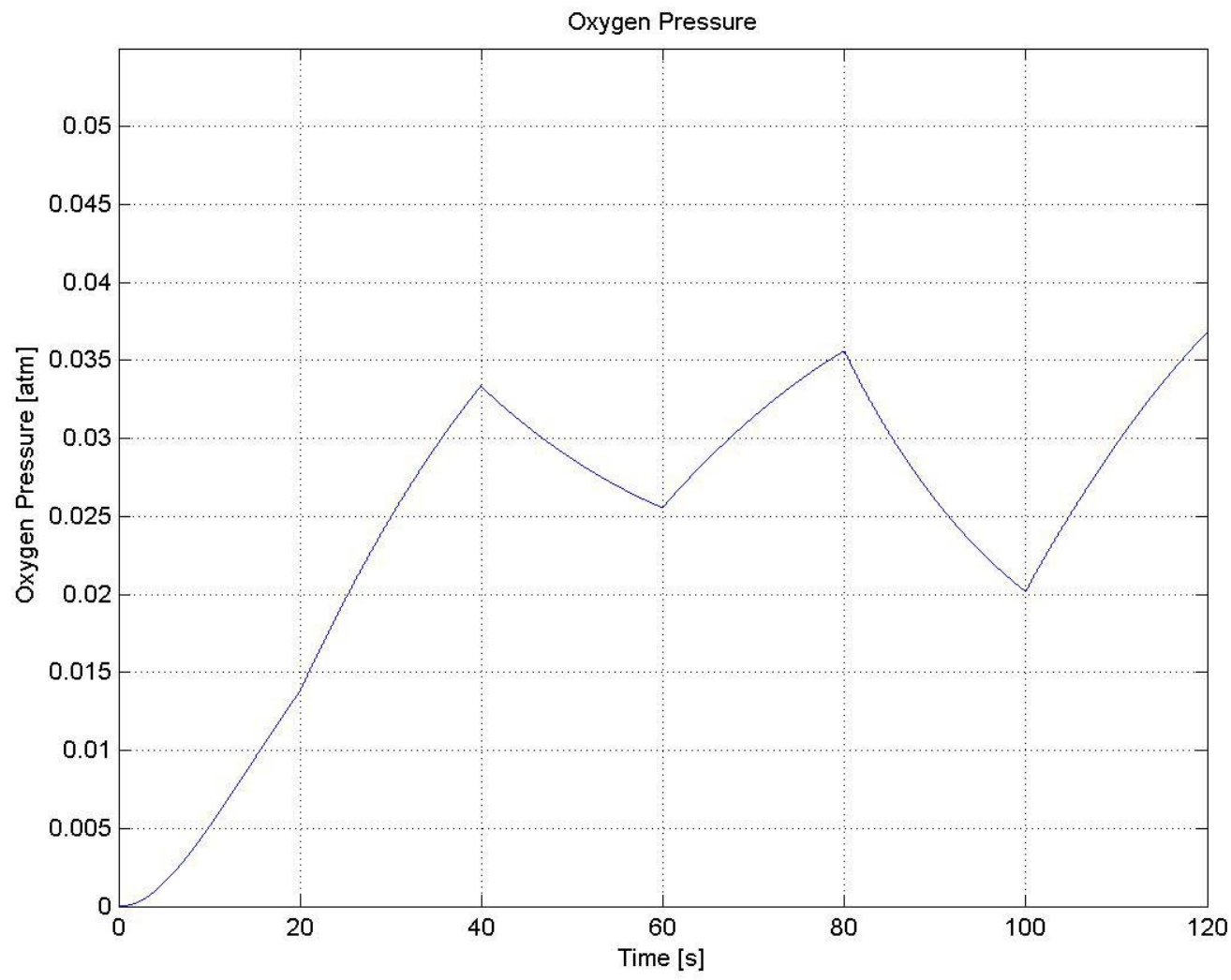

Fig. B6 Oxygen Pressure vs. Time 
The water pressure (atm) versus time (sec) is shown in Fig. B7.

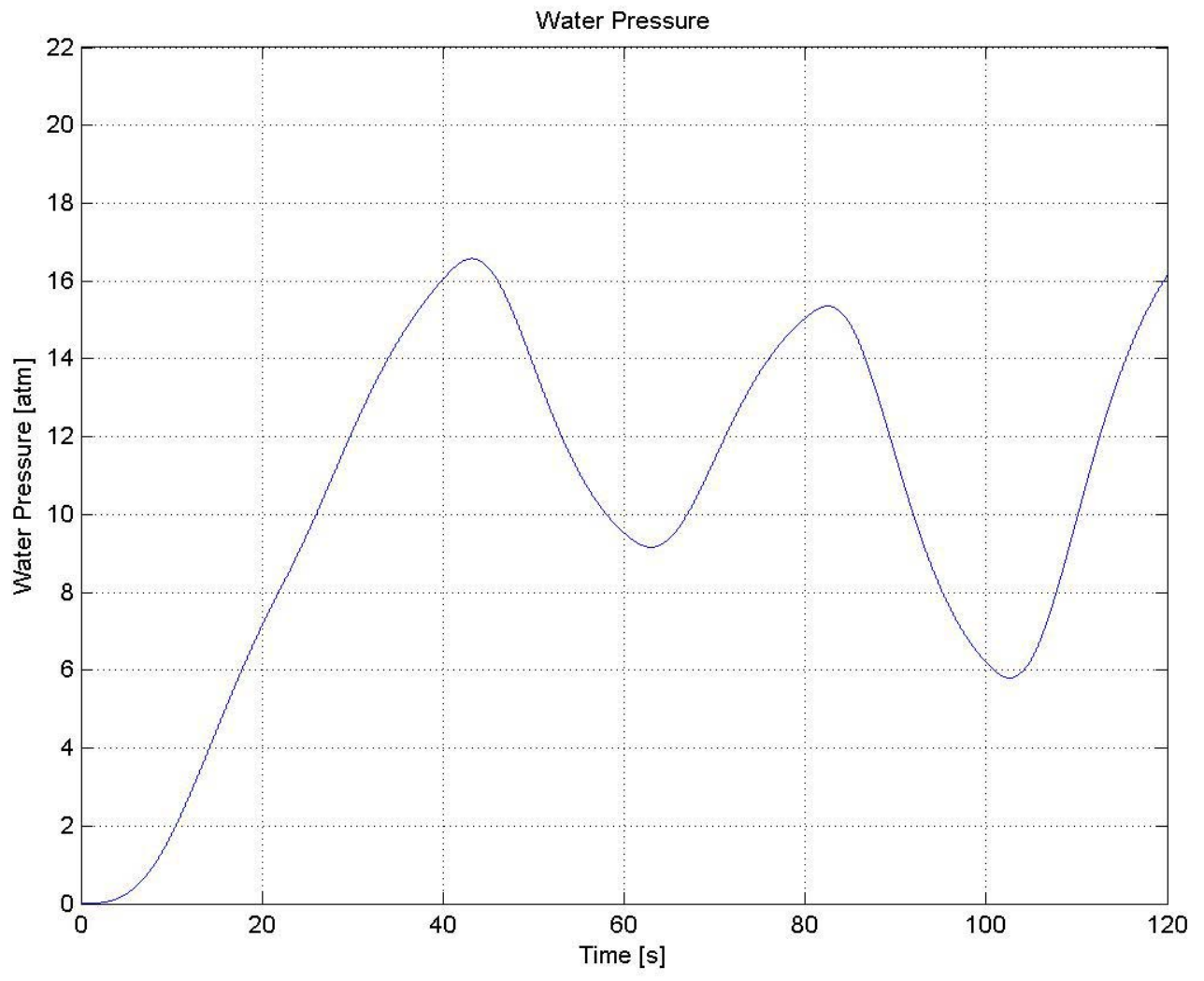

Fig. B7 Water Pressure vs. Time 
The hydrogen flow rate $(\mathrm{kmol} / \mathrm{s})$ versus time $(\mathrm{sec})$ is shown in Fig. B8.

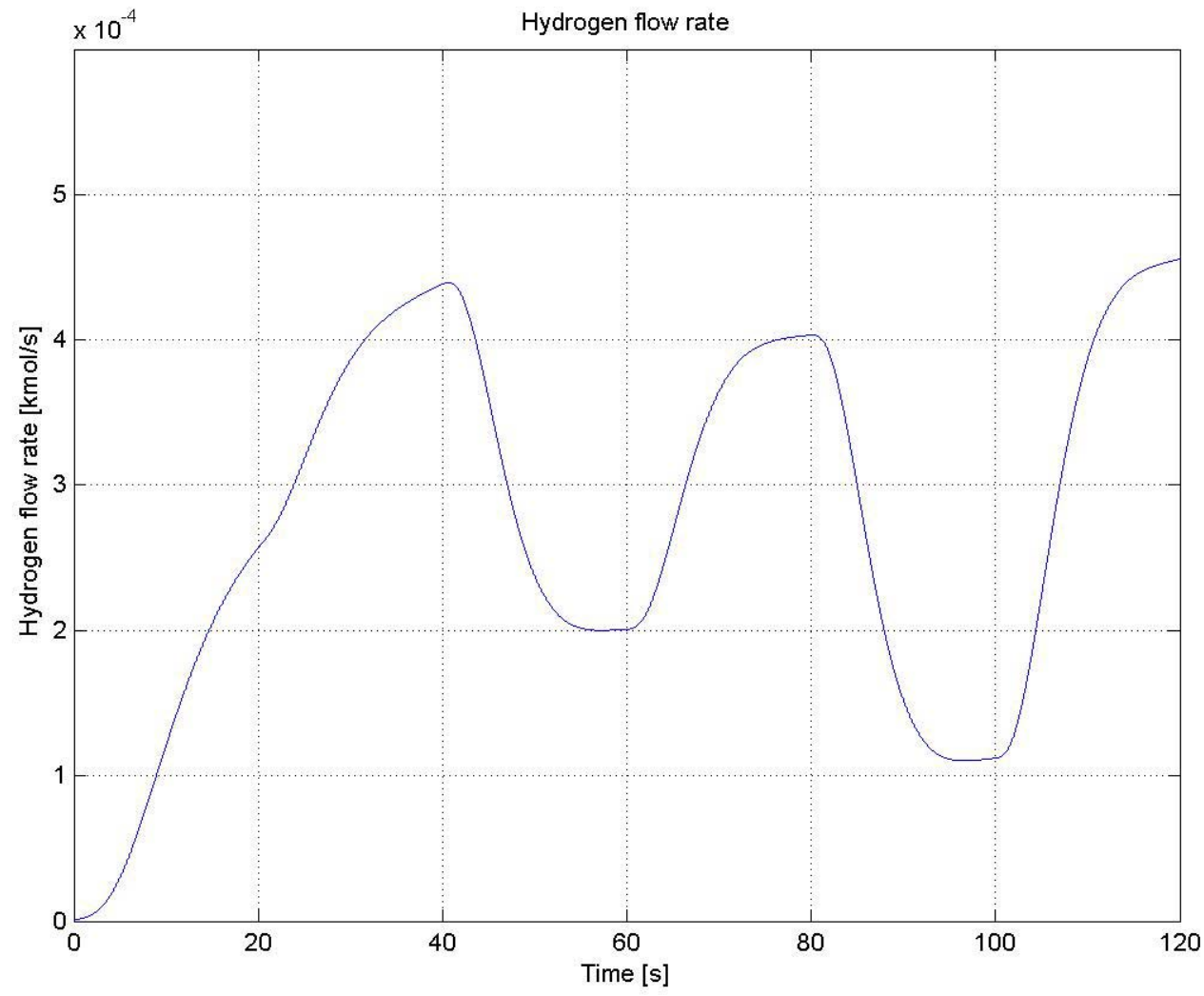

Fig. B8 Hydrogen Flow Rate vs. Time 
The methanol flow rate (kmol/s) versus time (sec) is shown in Fig. B9.

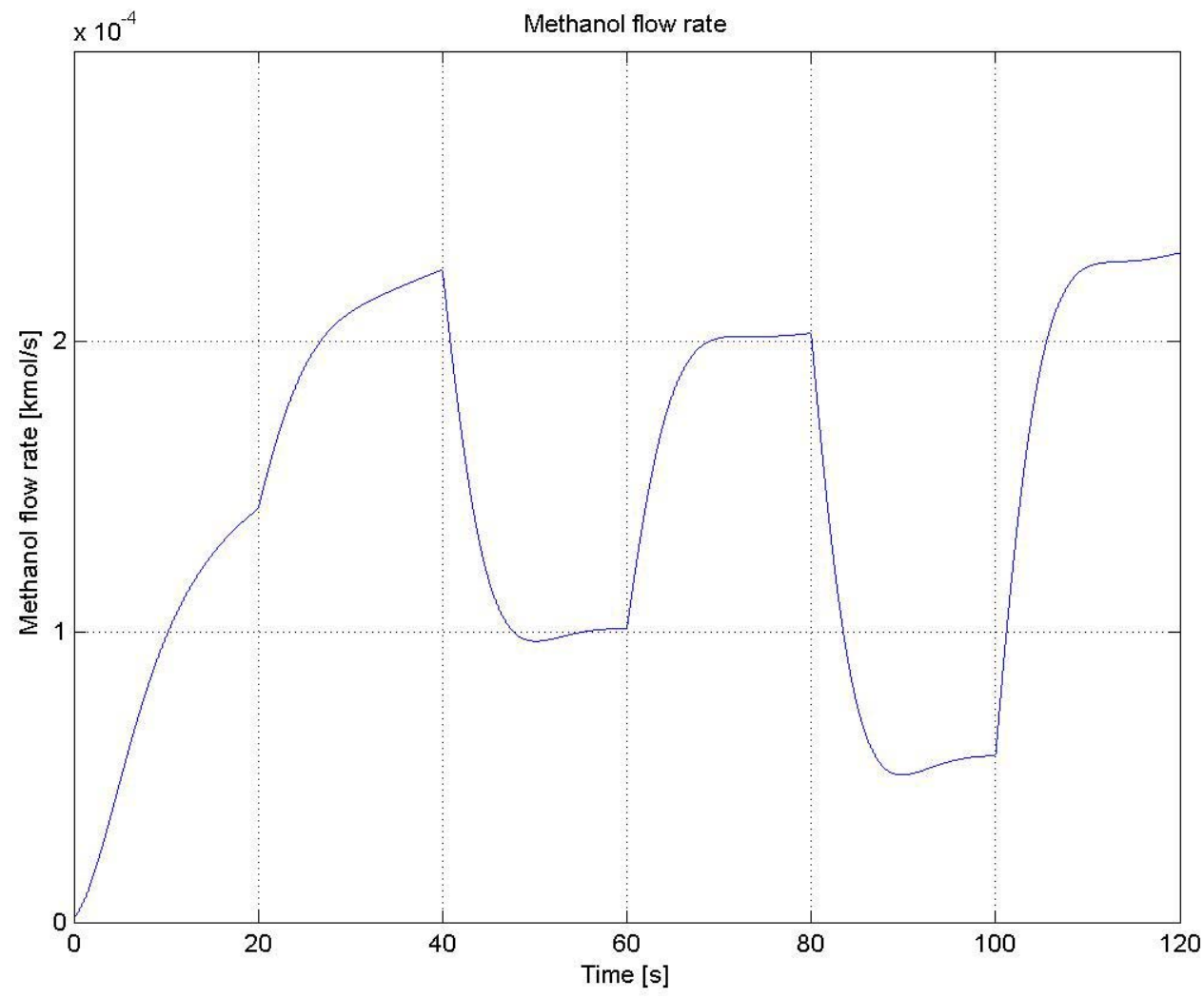

Fig. B9 Methanol Flow Rate vs. Time 
The phase angle of AC voltage (deg) versus time (sec) is shown in Fig. B10.

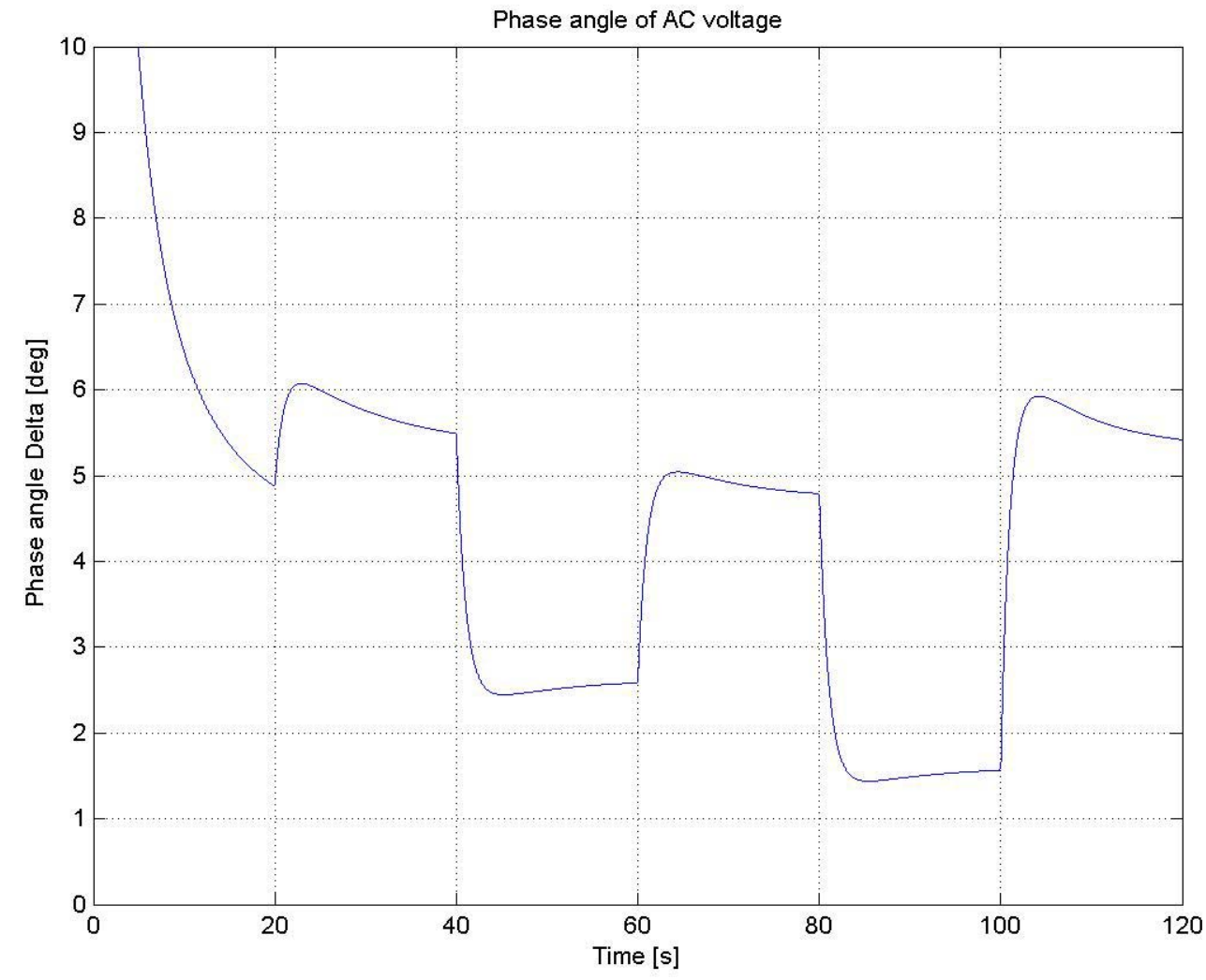

Fig. B10 Phase Angle of AC Voltage vs. Time 
The modulation index of the inverter in the power conditioning unit versus time (sec) is shown in Fig. B11.

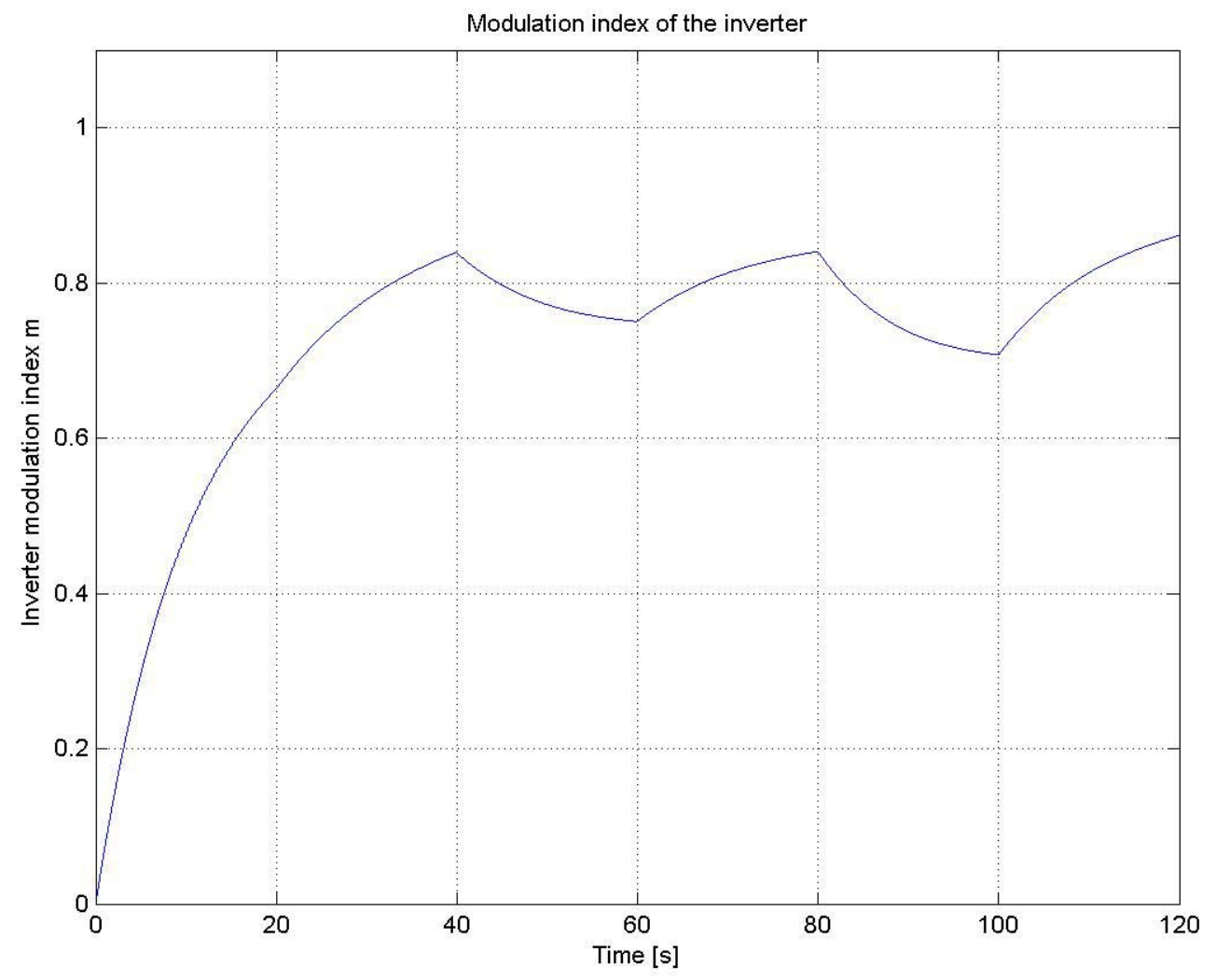

Fig. B11 Modulation Index of the Inverter vs. Time 
The output AC voltage (p.u.) versus time (sec) is shown in Fig. B12.

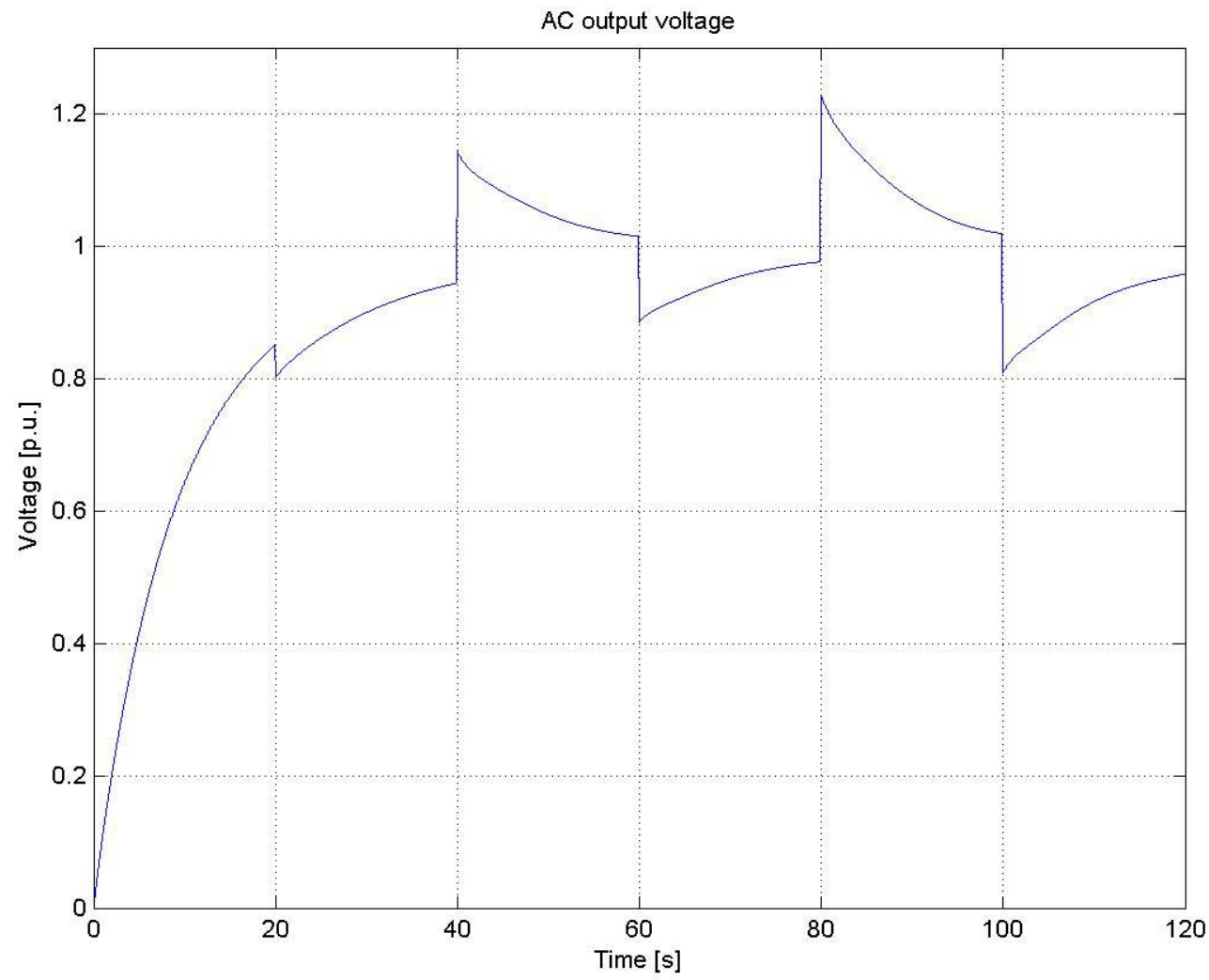

Fig. B12 AC Output Voltage vs. Time 